Institute for Materials Science and Engineering

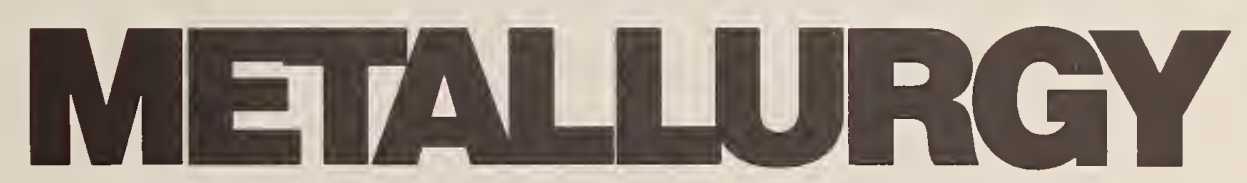

NBSIR 85-3191

U.S. Department of Commerce National Bureau of Standards

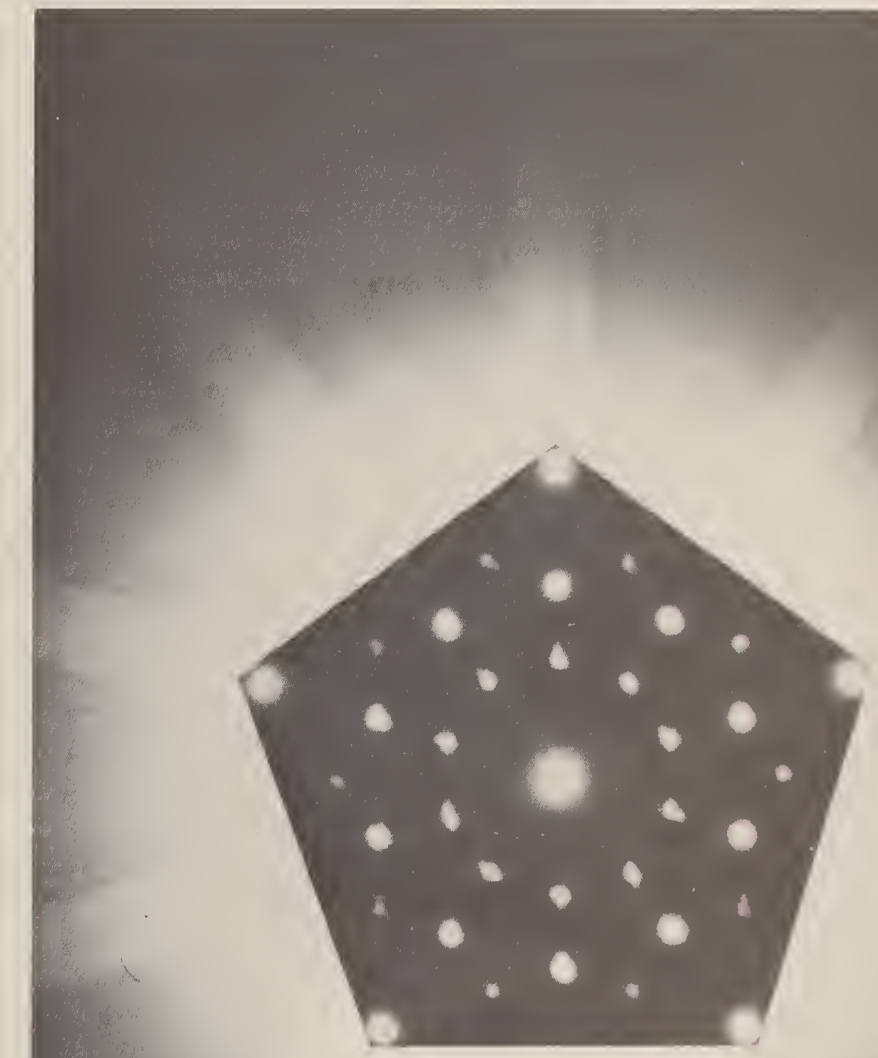

$-Q C$

100

.456

$85-3191$ 
Superimposed selected area diffraction and convergent beam diffraction patterns of aluminum-maganese icosahedral phase revealing true 5 -fold symmetry

Microscopy by R. J. Schaefer and L. Bendersky 


\section{Institute for Materials Science and Engineering}

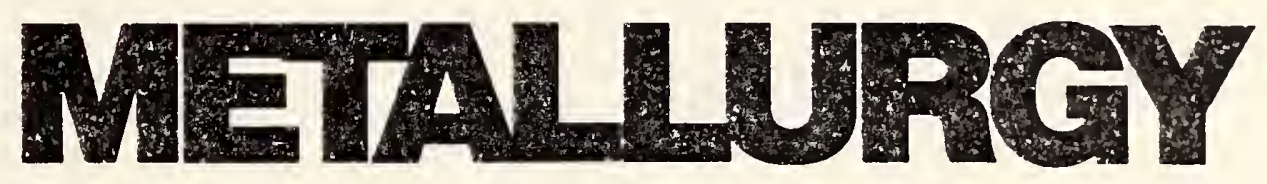

E. N. Pugh, Chief

J. G. Early, Deputy

NBSIR 85-3191

U.S. Department of Commerce

National Bureau of Standards

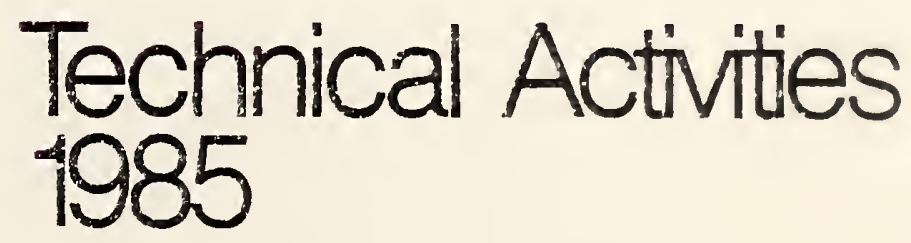




\section{CHIEF}

E. Neville Pugh

Phone: (301) 921-2811

\section{DEPUTY CHIEF}

James G. Early (Acting)

Phone: (301) 921-2811

\section{GROUP LEADERS}

Structure Characterization

Masao Kuriyama

Phone: (301) 921-2986

Metallurgical Processing

John R. Manning

Phone: (301) 921-3354

Wear and Mechanical Properties

Arthur W. Ruff

Phone: (301) 921-2966

Chemical Metallurgy

James G. Early (Acting)

Phone: (301) 921-2982

Corrosion

U. Bertocci (Acting)

Phone: (301) 921-2094

Electrodeposition

David S. Lashmore

Phone: (301) 921-2958

Nondestructive Characterization

Haydn N. G. Wadley

Phone: (301) 921-2956 
This report summarizes the FY 1985 activities of the Metallurgy Division of the National Bureau of Standards. The research centers upon the structure-processing-properties relations of metals and alloys, and on the methods of their measurement. Task efforts comprise studies of synchrotron radiation research for materials characterization, metallurgical processing, wear and mechanical properties, chemical metallurgy, corrosion and protection of metals, electrodeposition, and nondestructive characterization.

The work herein described also includes three cooperative data programs with American professional societies and industry: the American Society for Metals (ASM) - NBS Alloy Phase Diagram Program, the National Association of Corrosion Engineers (NACE) - NBS Corrosion Data Program, and the American Iron and Steel Institute (AISI) NBS Steel Sensor Program.

The new Institute for Materials Science and Engineering beam lines at the National Synchrotron Light Source were commissioned this year and the first synchrotron radiation experiment successfully completed. The feasibility of the new piezoelectric sensor developed under the AISI-NBS Steel Sensor Program for detection of porosity in steel was demonstrated. This new technology was turned over to Argonne National Laboratory for development of a field system.

The scientific publications, invited talks, committee participation, and other professional interactions of the 91 full-time and part-time permanent members of the Metallurgy Division and its 33 guest researchers are identified. 

TABLE OF CONTENTS

PAGE

OVERVIEW • • • • • • • • • • • • • • • • • • • • • • 1

METALLURGY DIVISION

ORGANIZATIONAL CHART . . . . . . . . . . . . . . • . 9

RESEARCH STAFF . . . . . . . . . . . . . . . 10

TECHNICAL ACTIVITIES

Structure Characterization ... . . . . . . . 15

Metallurgical Processing ............. . 23

Wear and Mechanical Properties . . . . . . . . 35

Chemical Metallurgy ............... . 45

Corrosion . . . . . . . . . . . . . . 51

Electrodeposition . . . . . . . . . . . . 61

Nondestructive Characterization . . . . . . . . . 71

Magnetic Materials . . . . . . . . . . . 85

OUTPUTS/INTERACTIONS

Recent Publications . . . . . . . . . . 86

Industrial and Academic Interactions . . . . . . . 96

Technical/Professional Committee . . . . . . . . 102

Leadership

Associated Activities . . . . . . . . . . 106

APPENDIX

Organizational Chart

National Bureau of Standards . . . . . . . . . . Al

Organizationa1 Chart

Institute for Materials Science and Engineering . . . . . . A2 

METALLURGY DIVISION (450)

E. Neville Pugh, Chief

James G. Early, Acting Deputy Chief

June Toms, Secretary

The Metallurgy Division conducts fundamental research on the structureproperties-processing relations of metals and alloys, and on the methods of their measurement. It also evaluates data, compiles data bases, and produces standard reference materials. It performs these activities for the benefit of American industry, government, and universities. Within the Division the work is carried out in seven discipline or interestoriented groups.

The National Bureau of Standards/Institute for Materials Science and Engineering (NBS/IMSE) part of the National Synchrotron Light Source (NSLS) was commissioned this year. The first synchrotron radiation experiment using white radiation was conducted in March 1985. Scientists in the Structure Characterization Group completed the alignment of the monochromator system so that either white radiation or tunable monochromatic radiation is available. Initial experiments have confirmed the high resolution achievable with the small emittance source at NSLS. A significant new effort to develop a high resolution $x$-ray image camera has been started. This direct detection camera, based on a charge coupled device (CCD) area sensor, has the potential for providing both good spatial resolution and high sensitivity for NDE radiography.

Continuing studies of new phenomena produced during rapid solidification have been directed towards developing materials with improved properties or potential for improved properties not attainable by conventional means. Extensive studies of the conditions necessary for the formation of a new alloy phase, a quasicrystalline Al-Mn phase, with five-fold point group symmetry have been carried out. A second quasicrystalline phase exhibiting decagonal or ten-fold symmetry was discovered under certain solidification conditions. Recent studies of diffusion-induced grain boundary motion (DIGM) and liquid phase sintering have identified diffusion induced coherency strains as the driving force.

The initial studies using the new materials characterization technique of thermal wave microscopy detected density differences in the wear debris from sliding contact surfaces which may be related to the observed differences between reversed and unidirectional sliding. A new standard reference material, No. 1891, has been issued for corrosion studies of synthetic implant alloys. A highly reliable acoustic emission technique has been developed for inspection of large pressure vessels.

The collaborative effort with the American Society for Metals (ASM) in the ASM/NBS Alloy Phase Diagram Data Center continues to provide critically evaluated phase diagrams. During the year, thirteen titanium, seven 
aluminum, and three iron based binary systems were evaluated by NBS scientists. Dr. J. Murray of NBS is now the editor of the Bulletin of Alloy Phase Diagrams. A major new effort was initiated to digitize over 1500 binary phase diagrams for the new ASM compendium to replace the compilations of Hansen, Elliott, and Shunk. Scheduled for completion the end of 1985, this enlarged data base will contain consistent pure element properties, nomenclature, diagram style, and format.

Mechanistic studies of corrosion processes continue to focus on environmentally induced cracking (both stress corrosion cracking and hydrogen embrittlement) and pitting. A new, computerized, portable corrosion measuring system was placed in field testing by measuring the corrosion of bridge decks and steel pilings. A new program was initiated for the Nuclear Regulatory Commission (NRC) in support of NRC's program to identify a permanent solution to the problem of nuclear waste disposal.

The NACE-NBS Corrosion Data Center expanded its efforts in the three pilot projects on kinetic data for atmospheric corrosion, localized corrosion, and uniform corrosion. Modifications to the graphics software has increased the flexibility of the data display to include greater accessibility and data manipulation. Techniques such as windowing, autoscaling, and statistical analysis are now available. A very successful Corrosion Data Workshop was organized with strong industry participation to address the corrosion data needs of users. Using the fund raising technique of the ASM-NBS Alloy Phase Diagram Data Center as a model, efforts have been initiated through the Secretary of Commerce to enlist the participation of the chief executive officer or similar top management of a major corporation to lead the private sector fund raising for the Corrosion Data Center.

Production of Standard Reference Materials by the Electrodeposition Group continues to provide important support to the industrial sector. Corrosion step-test standards for evaluating electroplated parts are now available to the automotive industry. A recently developed mathematical model of the alloy deposition process predicts the composition of multi-component deposition by either pulsed or direct current. Composition modulated alloys (CMA) with layer spacings as low as $1 \mathrm{~nm}$ have been provided by electrodeposition. An automated microhardness system has been developed that provides hardness data as well as information on other aspects of deformation.

The collaborative program with the American Iron and Steel Institute (AISI) to develop sensors for the steel industry has led to the successful demonstration of an ultrasonic sensor for detecting porosity in hot steel ingots. A prototype system is currently undergoing field trials. A new program has been initiated in the Nondestructive Characterization Group to develop NDE techniques for characterizing fiber/matrix interfaces in metal matrix composites. Continued efforts to develop noncontacting measurement techniques has concentrated on laser/EMAT systems which have been successfully demonstrated on steel at $750^{\circ} \mathrm{C}$. 
A new activity in magnetic materials was started in the Metallurgy Division this year under the leadership of Dr. L. H. Bennett. Focus is on the properties of both soft and hard magnetic materials. of particular concern for soft materials are magnetic thin films, especially compositionally modulated alloys where proximity effects and local anisotropies will dominate. For hard magnets, concern has centered on the relationship between the real space atomic topology and the occurrence of local site magnetic moments. A new laboratory for the measurement of ac magnetic susceptibility was established. This technique provides information not generally available from dc measurements. Attention is currently being addressed to obtaining coil designs useful to the measurement of magnetic thin films.

The Division was staffed in 1985 by 91 ful1-time and part-time permanent people. In addition, there were 33 guest researchers and research associates in residence during the past year who collaborated with Division scientists on various studies. 
The activities of the Division are formally identified in eight tasks which largely parallel the objectives of the seven groups. These tasks are listed below. The major accomplishments associated with each of these tasks, and a fuller description of task-related activities follow.

Task 26105--SYNCHROTRON RADIATION RESEARCH FOR MATERIAL SCIENCE. Relates to joint NBS/Naval Research Laboratory $x$-ray instrumentation complex at the National Synchrotron Light Source, and its use to perform microstructural characterization.

Task 15442--STRUCTURE CHARACTERIZATION. Addresses activities in the application of synchrotron radiation to materials science, with particular emphasis in microstructural details for evaluation of materials quality processing, and new materials design. Also addresses the activities on analytical electron microscopy to complement the evaluation performed by radiation.

Task 15443--METALLURGICAL PROCESSING. Contains most of the Division's competence in rapid solidification, surface modification, interface stability and measurement, and the Diffusion in Metals Data Center.

Task 15444--WEAR AND MECHANICAL PROPERTIES. Focused on measurement methods, understanding, and predictive methodology of tribology. It also includes research on synthetic metal implants.

Task 15445--CHFMICAL METALLURGY. Contains all activities related to the ASM/NBS Alloy Phase Diagrams Program including data/bibliographic base compilations, graphics, phase system evaluations, and modelling, and the publication of the Bulletin of Alloy Phase Diagrams.

Task 15446--CORROSION AND PROTECTION OF METALS. Relates to major focused effort on study of corrosion in metals, including predictive models and measurement methods. Now contains all activities related to NACE/NBS Cooperative Program for Corrosion Data.

Task 15447--ELECTRODEPOSITION (ELECTROCHEMICAL PROCESSING). Covers all Division activities in electrodeposition, and its processing/structure/ properties relations. Also covers electrodeposited Standard Reference Materials for hardness, thickness, and crack dye-penetrant.

Task 15448--NONDESTRUCTIVE CHARACTERIZATION. Addresses activities in nondestructive evaluation and processing control. Includes work on acoustic sensing, including that related to the new cooperative American Iron and Steel Institute (AISI) program. 
Task 15442--ADVANCED MICROSTRUCTURE CHARACTERIZATION.

Task 26105--SYNCHROTRON RADIATION RESEARCH FOR MATERIAL SCIENCE.

- The IMSE synchrotron radiation beam lines were commissioned on March 5, 1985 and "stand-alone" status established on May 11, 1985.

- First synchrotron radiation experiment, using white radiation beam, was carried off at NBS/IMSE X-23A beamline of NSLS on March 5-7, 1985, to establish the selected area diffraction/ microradiograph technique in real time.

- Monochromatic real time topographic capability was established on May 9-22, 1985. An assessment of the crystal perfection of the electro-optical materials was made.

- The experimental confirmation of the $\mathrm{x}$-ray Raman EXAFS of low $\mathrm{Z}$ elements was carried out using hard radiation.

- An atomic scale model for rapidly cooled Al-Mn alloys with icosahedral symmetry based on internal modulations was proposed.

- Dental microradiographic techniqiues were used to reveal detailed structural features in teeth.

Task 15443--METALLURGICAL PROCESSING.

- A new alloy phase that shows 5-fold icosahedral symmetry both in its electron diffraction pattern and growth morphology was discovered as a result of a cooperative program on rapid solidification between NBS and The Johns Hopkins University. This icosahedral Al-Mn phase belongs to a new class of materials that are neither crystalline, since crystallography does not allow periodic crystal lattices with 5-fold symmetry, nor amorphous.

- Quasicrystals have been produced in the NBS Metals Processing Laboratory by all three major rapid solidification techniques, melt-spinning, surface melting with subsequent rapid re-freezing, and atomization, and have been found in a number of different alloy systems.

- The effect of container side walls on the convection produced during directional solidification was analyzed. It has been assumed that side walls will reduce convection because of forces between the side walls and the flowing fluid. It was found that there are regimes where the presence of side walls will instead increase alloy convectional instabilities. 
- A driving force arising from the effect of diffusion-induced coherency strains has been identified as responsible both for diffusion-induced grain boundary migration and for liquid film migration that occurs during liquid phase sintering. This result has significant implications for surface alloying to produce protective coatings and for diffusional interactions at interfaces in composite materials.

- Coarsening of the microstructure in rapidly solidified Al-8 wt\% Fe powder was measured. The rate of coarsening depended strongly on the original powder microstructure, which in turn depended on the original powder particle size. The slowest, most desirable coarsening regimes were found in alloy samples having the smallest original particle diameters.

Task 15444--WEAR AND MECHANICAL PROPERTIES.

- Application of the new technique of thermal wave microscopy (TWM) to the study of wear debris accumulations on sliding contact surfaces was accomplished. TWM of wear tracks on an oxidized Cu$15 \mathrm{wt} . \% \mathrm{Zn}$ alloy showed evidence for periodic density differences in debris compacts. The presence of such compacts may help explain the differences in the frictional running-in behavior between reversed sliding and unidirectional sliding.

- Standard reference material 1891 , a Co-Cr-Mo material for use with ASTM F 746, was completed and is now available for monitoring the corrosion behavior of that alloy and similar synthetic implant alloys. Corrosion and fatigue data from porous metal coated surgical implant metals show effects of porous coating production on material properties and indicate microstructural changes to be avoided during processing steps on such alloys.

- Design and test criteria based on fracture mechanics analysis were developed to establish the basis for constructing seamless pressure vessels from significantly higher strength steels while maintaining the same level of safety. A technique has been developed for the use of acoustic emission to periodically inspect large pressure vessels.

- A method has been developed for the quantitative measurement of the severity of galling wear damage. The method employs topographic parameters obtained from data acquired by means of an automated profilometer system developed at NBS. The system permits quantitative assessment of the amount of galling damage, and the results can then be compared with others using different test methods or involving other alloys. 
Task 15445--CHEMICAL METALLURGY.

- Graphics programs to provide publication quality diagrams for the Bulletin of Alloy Phase Diagrams and provide input program for the phase diagrams database were made fully operational.

- An inter-phase diagram database has been set up to allow for efficient searching of the metallurgical important information embedded in a phase diagram. This subset is extracted by a newly written program which performs a topological analysis of the curves in the phase diagram.

- Graphing algorithms to allow isotherms or isopleth representation of ternary phase diagrams have been developed. Algorithms which allow real time translation and rotation of diagrams on the $(b / w)$ Evans and Sutherland terminal are now available.

- Theoretical and experimental results in the area of magnetic particle inspection led to the incorporation into a new military standard of a new method for using Hall-effect probes to determine proper magnetization levels for effective inspection.

Task 15446--CORROSION AND PROTECTION OF METALS.

- Substantial progress has been made towards understanding the discontinuous nature of cleavage crack propagation in ductile fcc alloys undergoing transgranular stress corrosion cracking.

- Modeling of the chemistry and electrochemistry inside transgranular cracks has been extended to CuAu alloys in chloride solutions. The results confirm that hydrogen embrittlement can be excluded as a cause of brittle fracture.

- Portable computer systems have been developed to measure corrosion rates in the field and are being used to monitor the corrosion of steel reinforcing bars in concrete bridge decks and underground steel pilings.

- A Corrosion Data Workshop, organized jointly with the National Association of Corrosion Engineers (NACE), was attended by approximately fifty corrosion specialists from industry, government, and academe; the Proceedings will be used to help direct the future activities of the NACE-NBS Corrosion Data Program.

- Analysis of the statistical properties of the random fluctuations of the passive current during pit initiation has shown that the process cannot be modeled by renewal processes or homogeneous Markov chains, but more complicated stochastic models have to be employed. 
- The first stage of a mathematical model of the alloy deposition process taking into account diffusion migration and convection was completed. The model is capable of predicting composition of alloys of up to 15 components using pulsed or direct current. The model was tested for the electrodeposition of $\mathrm{Sn}-\mathrm{Pb}$ (solder). Future work will focus on the effects of the substrate on exchange current and on nucleation and growth.

- Electrodeposition from a single electrolyte produced composition modulated alloys of copper--nickel and nickel-palladium with layer spacings as 1 ow as $1 \mathrm{~nm}$. Comparison made between potentiostatic and galvanostatic deposition indicated that potentiostatic deposition provided significantly sharper interfaces.

- Development and production of 150 corrosion step-test Standard Reference Materials samples were completed and have now been made available to the automotive industry.

- An automated microhardness system was developed and was shown to be capable, not only of measuring microhardness but also of yielding information on modulus and ultimate tensile strength.

Task 15448--NONDESTRUCTIVE CHARACTERIZATION.

- Research on an ultrasonic sensor for detecting gross porosity/pipe in hot steel ingots has been completed, and a prototype system incorporating the NBS approach is undergoing trials at the Argonne National Laboratory.

- Improved tomographic algorithms for reconstructing internal temperature distrihutions have been developed and successfully experimentally evaluated on austenitic stainless steel samples at temperatures up to $750^{\circ} \mathrm{C}$.

- Noncontact laser/EMAT measurement methodologies for high temperature ultrasonic sensors have been developed and successfully tested on steel up to $750^{\circ} \mathrm{C}$.

- The eddy current inverse problem of determining the depth profile of the electrical conductivity has been implemented and applied to laboratory models. 

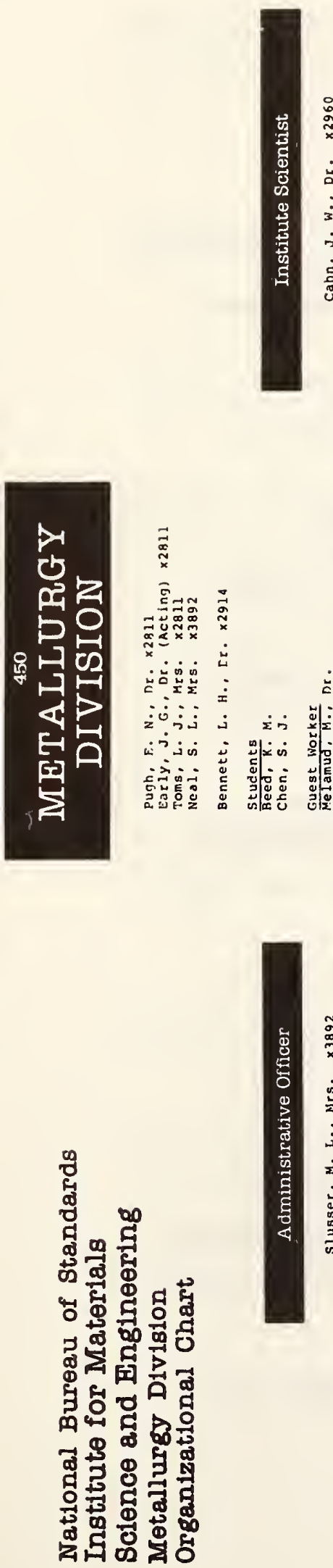

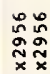

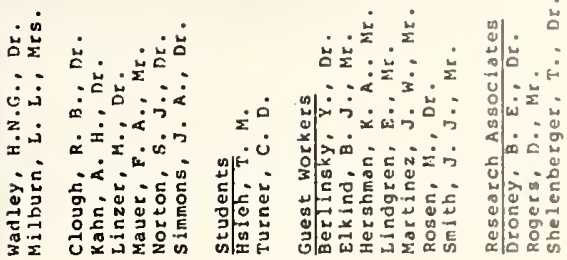


Beauchamp, Carlos R.

Bertocci, Ugo

Biancaniello, Francis S.

Black, David R.

Blau, Peter J.

Boettinger, William J.

Brown, Henrietta J.

Burdette, Harold E.

Clough, Roger B.

Coriell, Sam R.

Dobbyn, Ronald C.
- Computer simulation of electrodeposition processes

- Electrochemical measurements of kinetic parameters

$\odot$ Corrosion measurements of electrodeposited coatings

$\odot$ Electrochemical measurements

- Computer modeling

$\odot$ Passivity and pitting

- Special alloy and quasicrystal preparation

$\odot$ Melt-spinning rapid solidification

- Inert gas atomization and metal powder processing

$\odot$ Inelastic $x$-ray scattering

$\odot$ Energy dispersive $x$-ray diffraction

$\odot$ X-ray optics

- Friction and wear transitions

- Wear microstructure relations

- Microindentation and scratch hardness

$\odot$ Rapid solidification

- Alloy microstructural characterization

- Relation of alloy microstructures to processing conditions

- Coating thickness SRM development

- Simultaneous thickness electropotential (STEP) SRM development

$\odot \quad$ X-ray optics engineering

$\odot$ Crystal growth

$\odot$ Instrumentation

$\odot$ Acoustic emission

$\odot$ Mechanical properties

- Surface modification

- Modeling of solidification processes

- Interface stability

$\odot$ Convection and alloy segregation during solidification

$\odot \quad X-r a y$ dynamic imaging

- X-ray optics

- Synchrotron radiation instrumentation 
Early, James G., Jr.

Escalante, Edward

Fraker, Anna C.

Handwerker, Carol A.

Hardy, Stephen C.

Harris, Jonice S.

Interrante, Charles G.

Ives, Lewis $\mathrm{K}$.

Johnson, Christian E.

Kahan, Daniel J.

Kahn, Arnold $\mathrm{H}$.

Kaufman, Michael J.
- Powder metallurgy

- Hot isostatic pressing

$\odot$ Ferrous alloys and resource recovery

- Corrosion rate measurement for practical applications

$\odot$ Underground corrosion

- Atmospheric corrosion

- Titanium alloys

- Corrosion processes

- Transmission electron microscopy

$\odot$ Surgical implant metals

- Interface studies

- Diffusion-induced grain boundary migration

$\odot$ Liquid film migration

- Alloy coarsening

- Surface tension measurements

- Interface segregation

$\odot$ Scanning electron microscopy

- Fatigue properties measurements

$\odot$ Wear and friction properties

- Hydrogen embrittlement

- Nuclear waste disposal

- Environmental testing

$\odot$ Wear of metals

- Transmission electron microscopy

- Erosion of metals

- Ultra-black coatings

- Electroless deposition processes

- Metallic glass alloy deposition

- Microhardness SRM research

- Evaluation of binary alloy phase diagrams

- Prepare computer graphics for phase diagrams

- Eddy current modeling

- Electromagnetic theory

$\odot$ Solid state physics

- Physical Metallurgy

- Electron Microscopy

- Stress Corrosion Cracking 
Kelley, David R.

Kuriyama, Masao

Lashmore, David S.

Linzer, Melvin

Long, Gabrielle G.

Manning, John R.

Mauer, Floyd A.

McAlister, Archie $\mathrm{J}$.

Mullen, Jasper L.

Murray Joanne L.

Norton, Stephen J.
- Microhardness SRM development

$\odot$ Dye penetrant SRM development

$\odot$ Precious metal electrodeposition

$\odot$ Scattering physics

- Solid state physics

- Crystallography

- Electrochemical mechanisms of coating processes

- Pulsed alloy deposition

- Composition modulated alloy deposition

- Properties and structure of electrodeposited coatings

- Ultrasonic imaging

- Acoustic emission

$\odot$ Ultrasonic scattering

- X-ray scattering physics

- X-ray absorption spectroscopy

$\odot$ Disordered materials

- Metallurgical processing

- Diffusion kinetics

$\odot$ Interface migration

- Ultrasonic tomography

$\odot$ X-ray diffraction

- Ultrasound-microstructure relations

- Differential thermal analysis

- Equilibrium phase diagrams

- Enthalpy and kinetics of metastable phase transformations

- Evaluation of binary and higher order phase diagram data

- Development of automated hardness testing

$\odot$ Electrochemical measurements for determining metal corrosion

- Analytical spectroscopy

- Thermodynamic modeling of alloy phase diagrams

- Data evaluation for $\mathrm{Ti}$ and Al-based alloy systems

- Editor, Bulletin of Alloy Phase Diagrams and Constitution of Binary Alloys

- Computer database development for alloy phase diagrams

- Ultrasonic imaging

$\odot$ Inverse modeling

$\odot$ Dimensional resonance tomography 
Olson, Craig D.

Parker, Robert L.

Polvani, Robert S.

Pugh, E. Neville

Ridder, Stephen D.

Ruff, Arthur W.

Schaefer, Robert $\mathrm{J}$.

Shull, Robert D.

Simmons, John A.

Smith, John H.

Spal, Richard D.

Stockton, Charlotte $K$.
๑ Scanning electron microscopy

- X-ray microanalysis

$\odot$ Thermal wave microscopy

- Ultrasonic detection of solid/liquid interface, interface kinetics

- Applications to alloys, continuous casting, metallography, solidification

- Mechanical behavior

$\odot$ High temperature strengthening mechanisms

- Microindentation measurements

$\odot$ Dimensional instability behavior

- Mechanistic studies of SCC

- Electrochemistry of localized environments

$\odot$ Physical metallurgy

- Microparticle rapid solidification

- Solidification dynamics

$\odot$ Inert gas atomization

- Wear and friction

- Microstructure effects

- Mechanical behavior

$\odot$ Microscopy

- Quasicrystals

- Electron beam rapid solidification

$\odot$ Convection and interface effects during solidification

X-ray and neutron diffraction

$\odot$ Physical metallurgy

$\odot$ Environmentally induced cracking

- Electron microscopy

$\odot$ Dislocation theory

- Acoustic emission

$\odot$ Inverse modeling

$\odot$ Mechanical properties of materials

- Fracture of materials

$\odot$ Structural integrity analysis

$\odot \quad X$-ray imaging

$\odot$ X-ray optics

$\odot$ Instrumentation

- Rapid solidification

- Alloy characterization

- Quasicrystals 
Swartzendruber, Lydon J.

Ugiansky, Gilbert M.

Van Orden, Ann C.

Voorhees, Peter W.

Wadley, Haydn N. G.
- Magnetic methods, NDE

- Gamma-ray resonance spectroscopy

- Iron binary phase diagrams

- Corrosion data evaluation and dissemination

- Computer database management

- Slow strain rate testing

- Corrosion data collection and evaluation

- Marine corrosion

- Localized corrosion

- Coarsening phenomena

- Elastic effects during pahse transformations

- Anisotropic interface effects

- Dislocations and fracture

- Acoustic emission

- Ultrasonics 
ADVANCED MICROSTRUCTURE CHARACTERIZATION

Task 15442

SYNCHROTRON RADIATION RESEARCH FOR MATERIALS SCIENCE

Task 26101

Important new materials in industry are produced by far more sophisticated control and processing methods than heretofore utilized. Coupled with increased national emphasis on quality control and automation for increased productivity, these advanced materials require a new, wide range of atomistic structural determination techniques and microstructural characterization methods as well as new techniques to utilize well-controlled solid-state engineering. The objectives of Task 15442 and Task 26101 are to address this challenge through the development of measurement methods and standards for the advanced quantitative characterization of metallurgical microstructures and other high-tech materials. Methods in these tasks are primarily centered around the use of synchrotron radiation and $x$-ray scattering principles. The research coverage is, therefore, quite wide, ranging from the atomic structural determination of disordered materials and films, through studies of solidification processes, nondestructive evaluations of flaws and strains in materials, microstructural characterization of films and high-tech materials, to a study of the structural features of human teeth.

These tasks are related directly to the synchrotron radiation program in the Institute for Materials Science and Engineering (IMSE), which was initiated in FY80. The Office of Nondestructive Evaluation in IMSE has contributed to the support of this effort, in particular, in the areas of data processing and image detector development for real time observations. This IMSE synchrotron radiation program is the materials science part of the joint effort between the Naval Research Laboratory (NRL) and the National Bureau of Standards (NBS) to establish a synchrotron radiation facility for NBS and NRL scientists at the National Synchrotron Light Source (NSLS), Brookhaven. In FY85, scientists from the Structure Characterization Group have been working on a regular basis at NSLS to commission the IMSE synchrotron radiation beam lines.

\section{FY 85 Significant Accomplishments}

- The IMSE synchrotron radiation beam lines were commissioned on March 5, 1985 and "stand-alone" status established on May 11, 1985.

- First synchrotron radiation experiment, using white radiation beam, was carried out at NBS/IMSE X-23A beamline of NSLS on March 5-7, 1985 , to establish the selected area diffraction/microradiography technique in real time.

- Monochromatic real time topographic capability was established on May 9-22, 1985. An assessment of the crystal perfection of electro-opt1cal materials was made.

- The experimental confirmation of the $x$-ray Raman EXAFS of low $Z$ elements was carried out using hard radiation. 

symmetry based on internal modulations was proposed. structural features in teeth.

Commission of the NBS/IMSE X-23A BEAM Lines at NSLS

Subtask 1 of Task 15442 and

Subtask 1 of Task 26101

R. C. Dobbyn, D. R. Black, R. D. Spa1, H. E. Burdette, G. G. Long and M. Kuriyama

On March 5, 6 and 7, 1985, NSLS operated the x-ray storage ring at 2.045 Gev with a current starting at $9 \mathrm{~mA}$ down to $4 \mathrm{~mA}$. This low current beam is called an "alignment beam" for the alignment of experimental stations and instruments for individual Participating Research Teams (PRTs). After the beam transport pipes and experimental stations were aligned for the NBS/IMSE beam lines (NBSX-23A), scientists in the Structure Characterization Group took advantage of the availability of this beam to perform an experiment using white radiation.

The purpose of this experiment was to establish the real time selected area diffraction technique for multigrain materials combined with microradiography. An imaging detector was positioned to view a radiographic image of an A1-5 wt.\% Sn multigrained sample $1.5 \mathrm{~mm}$ thick, while Laue spots from the sample were observed by the same detector. With a $6 \mathrm{~mm}$ aperture, multigrains were observed in the radiographic image (non diffracted forward direction image), and many Laue spots appeared associated with these differently oriented grains. Inserting a pinhole apperture ( $\sim 1 \mathrm{~mm}$ in diameter), one grain was located in the radiographic image. Then the number of Laue spots seen on the screen was reduced to give the orientation of this grain. Mapping of the grain orientation was completed by positioning the pinhole apperture onto each visible grain. The ability to determine and follow the relative orientation of growing (or shrinking) adjacent grains and the change in their grain boundaries is valuable in various materials science problems, such as liquid-phase sintering, grain boundary migration, grain coarsening and recrystallization. In spite of the weak synchrotron radiation beam in this running period, the experiment was successful to prove the potential value of this technique.

During the period of May 9 to May 22, NSLS provided, for the first time, usuable synchrotron radiation beams (almost 13 hours per day) for experimenters. Scientists in the Structure Charcterizatrion Group utilized this opportunity to complete the set-up and alignment of a monochromator system and the topography station. Either white radiation or tunable monochromatic radation is provided in this station. Debugging and refinement of this beam line continues, but various experiments can now be carried out. 
In this beam running period, the characteristics of the NSLS synchrotron radiation beam were measured. This provides valuable information, particularly on the source size, for the planning of experiments in the regular running periods. Also, a routine monochromatic radiation topography capability has been commissioned. Synchrotron radiation was produced at about $60 \mathrm{~mA}, 2.4 \mathrm{Gev}$ and a fill (uninterrupted duration of available beam) normally lasted 3 to 4 hours, with 3 to 4 fills a day. Monochromatic radiation topography was employed to study the microstructure of advanced electro-optic single crystals, in collaboration with a scientist in the ceramics division. The structural perfection of lithium niobate crystals was investigated as a function of growth direction and selected processing parameters. Since some samples of very high quality were evaluated, it now becomes possible to measure the quantitative effects of processing technology. Filamentary microstructures of the size $1 \mu \mathrm{m}$ or longer were observed among the high quality samples grown from the congruent melt. Research is being carried out on these filamentary microstructures in samples processed by an improved stoichiometric optimization technique.

Experiments on bismuth silicate single crystals yielded extraordinary topographs (figure 1) showing evidence of very unusual "moire" type patterns. These crystals did not show any evidence of imperfection under an optical microscope or under infrared microscopy. However, the topographs clearly show dislocations, regular grain boundaries, almost coherent coexistence of two domains, in addition to the imperfect surface treatment. Although these data are still being analyzed, they are early evidence of the high resolution results that can be achieved with the small emittance source at NSLS.

Inelastic X-Ray Raman EXAFS of Low Z Elements in Materials using Hard Radiation

Subtask 2 of Task 15442

R. D. Black, G. G. Long and M. Kuriyama

The detection of atoms of low atomic number, such as carbon, phosphorus, sulfur and etc., in materials is required to determine the overall properties of the materials. The mere identification of these species, norma1ly obtained by Auger spectroscopy, is not sufficient to determine their precise role within the materials. The chemical and electronic states of these atoms in their environment must be determined. For this purpose, Extend X-Ray Absorption Fine Structure (EXAFS) measurements tuned to these elements are desirable. However, the wave length of radiation that excites their $\mathrm{K}$-shell electrons is quite long. For such soft radiation, ultra high vacuum systems are required to deliver radiation and collect data. Normally, these clean beam lines do not permit "dirty" real materials in the systems.

When hard radiation is scattered by a sample, it experiences inelastic scattering as well as elastic (coherent) scattering. This is known, in general, as Compton scattering; it consists of the scattering due to "free" electrons (traditional Compton scattering) and the scattering due to bound 
electrons, such as $\mathrm{K}$ and $\mathrm{L}$ shell electrons. The latter is called $\mathrm{x}$-ray Raman scattering [1], [2]. The scattered radiation suffers energy losses corresponding to the $\mathrm{K}$-shell or $\mathrm{L}$ shell excitation. In theory, the differential cross section of the scattered radiation (as a function of energy) is proportional to the absorption cross section [3], [4]. Thus, the measurement of the energy spectrum of scattered radiation yields the same information as absorption spectroscopy, namely EXAFS. For low Z elements, this principle is used to obtain their EXAFS data without using soft radiation, thus avoiding complex experimental problems associated with soft $x$-ray absorption spectroscopy. Since the harder $x$-ray photons penetrate much deeper into the sample, bulk properties of low $\mathrm{Z}$ atoms in materials can be measured, and sample preparation is much less critical.

Several experiments were performed using amorphous boron, amorphous carbon, graphite, diamond and a lithium crystal to confirm the existence of EXAFS in $x$-ray Raman scattering. The energy loss spectra were obtained with a double flat crystal spectrometer using two Ge (111) crystals and a proportional counter. The smallest step size available corresponded to a resolution of $0.2 \mathrm{ev} /$ channel (step), but typically experiments were performed at 1.2 ev/channel. The incident energies of photons were $6.40 \mathrm{kev}$ and $8.04 \mathrm{kev}$, respectively for lithium and for boron and carbon. Data for boron and carbon, with $\mathrm{K}$ edges at $183 \mathrm{ev}$ and $277 \mathrm{ev}$, respectively, were accumulated by the spectrometer at $1.71 \mathrm{ev} /$ channel, and the spectra of lithium whose $\mathrm{K}$ edge is at $54 \mathrm{ev}$ were taken at $1.1 \mathrm{ev} /$ channel. All of these spectra clearly indicated the presence of the $x$-ray Raman scattering. Experiments are being performed to extract the EXAFS portion of $x$-ray Raman scattering spectra with better statistics.

[1] T. Suzuki, J. Phys. Soc. Jpn 221139 (1967).

[2] N. G. Alexandropoulos and G. G. Cohen, Phys. Rev. 187455 (1969).

[3] Y. Mizuno and Y. Ohmura, J. Phys. Soc. Jpn 22445 (1967).

[4] M. Kuriyama, Acta Crysta11. A 27634 (1971).

Atomic Structure of Rapidly Cooled Alloys with Icosahedral Symmetry Subtask 3 of Task 15442

M. Kuriyama, G. G. Long and L. Bendersky

As part of the atomic structural research in this task, this work was undertaken to explore the unique opportunity offered by the fabrication of an icosahedral phase alloy. A recent report [1] of the existence of an icosahedral phase with long-range orientational order and icosahedral point group symmetry has stimulated the suggestion [2] that crystallography should be generalized to include nonperiodic structures which retain simple point group symmetries (i.e., which have long range correlations). Other proposals are that the astonishing electron diffraction patterns are due to either the existence of a real three-dimensional modulated crystal [3], or alternatively an ordered-glassy incommensurate structure [4]. [For detailed information on the significance of this material, see Task 15443]. The objective of this work was to determine whether the diffraction data are consistent with a fundamental aperiodicity, or if the material is more 
correctly described as a new type of real crystal.

The experimental data consisted of a set of five diffraction patterns taken from a single sample: a twofold pattern, a fivefold pattern, a threefold pattern and two apparent mirror patterns. The present analysis originated from the assumption that the new phase can be described as an imperfect crystal in which lattice translations do not necessarily hold. This starting point should not bias the interpretation of the data because the mathematics of icosahedral symmetry, or any other symmetry or periodicity, is not invoked.

The result of the analysis [5] is the identification of two sets of modulations in momentum space, each of which has six independent modulation vectors. The sets of modulations are found to have the same icosahedral angles $\left(63.4^{\circ}\right.$ and $\left.116.6^{\circ}\right)$ and their magnitude are approximately in the ratio of $\tau^{3}: 1$, where $\tau$ is the Golden section. After conversion to real space, one of the sets is considered to represent "correlation distances" rather than being referred to as ordinary modulations. Using these, an atomic arrangement was found which lead to the identification of a unit cell for a reference cubic lattice. The two rhombohedra (pointed and flat) commonly used in nonperiodic icosahedral models were derived, where these rhombohedra are decorated by atomic sites on each face as well as at each vertex. The unit cell for the reference lattice is called "icosahedral cubic," since the properties of the icosahedral point-group are accomodated in this unit cell. The unit cell is constructed from four flat and four pointed rhombohedra with the lattice parameter $a=0.738 \mathrm{~nm}$.

Despite the conformance of the derived unit cell to icosahedral point-group symmetry, one would not expect a cubic cell to produce the observed patterns. Since each diffraction spot was indexed by six vectors, unlike ordinary diffraction patterns, and only three vectors define the unit cell, three more vectors in real space are required to explain the appearance of the point-group symmetry patterns. The explanation of these patterns lies in the fact that, from the icosahedral cubic unit cell of the reference lattice, additional icosahedral atomic positions are found to lead to a different length scale whose ratio to the unit cell is $\tau$. It is recognized that the length of the original unit cell is comprised of the new length scale cube and another smaller cube. The occupancy of the atomic sites depends on the sequences of these cubes, thus creating local deviations from periodicity everywhere in the material. These deviations appear in the diffraction patterns as internal modulations, whose modulation wave length is smaller than the unit cell length of the reference lattice.

The key is to identify the internal modulations as the external (in regular sense) modulations through Umklapp processes. It is remarkable that the mathematical relationship, $\tau \mathrm{N}_{-}(-1)^{\mathrm{N}} \tau^{-\mathrm{N}}=\mathrm{L}$, with an integer $\mathrm{N}$ and a Lucas number L, holds, and thus Umklapp processes (relating to L) always exist. One of these modulation periodicities, $N=3$, agrees well with the second set of observed modulations. It is significant that the atomic scale models constructed via experimental analysis lead to periodic (modulated) structures rather than aperiodic ones. However, successively larger periodic arrays 
are required to complete the description of the atomic occupancy. This suggests that the true structure is at the limit of the periodic approximations. The structure of this material consists of the three dimensionally modulated puckered layers whose modulated frequency is not monochromatic and which resembles in nature that of almost periodic functions.

[1] D. Shechtman, I. Blech, D. Gratias and J. W. Cahn, Phys. Rev . Lett. 531951 (1984).

[2] D. Levine and P. J. Steinhardt, Phys. Rev. Lett. 53, 2477 (1984).

[3] P. Bak, Phys. Rev. Lett. 541517 (1985).

[4] D. R. Nelson and S. Sachdev, Phys. Rev. B 32689 (1985).

[5] M. Kuriyama, G. G. Long and L. Bendersky, Phys. Rev. Lett. 55849 (1985).

Design of an X-ray Camera Using a CCD Sensor

Subtask 4 of Task 15442 and

Subtask 2 of Task 26101

R. Spal and M. Kuriyama

It is extremely important to develop an image camera with high spatial resolution for $x$-ray wave length regions. This camera would make NDE radiography and synchrotron radiation topography as easily accessible as SEM. Due to the lack of true lenses, $x$-ray images with fine microstructural details must be recorded on special high resolution photographic plates that were originally developed for recording of tracks of cosmic rays or high energy particles. This is a slow and tedious process, and cannot be used in real time. Recently many improvements in image detectors for real time observation of microstructural changes have been made. However, most of these are on indirect detection devices. X-ray camera are classified as either direct or indirect detection devices.

A direct detection camera detects the electric charge produced when $x$-rays strike a photoconductor, while an indirect detection camera detects the visible light rays produced when x-rays strike a phosphor. The latter detection scheme is called indirect since the visible light rays must still strike a photoconductor to produce an electric charge. This scheme has the disadvantage that the spatial resolution is controlled by the phosphor thickness, and the sensitivity is controlled by the efficiency of converting $x$-rays to visible light rays (typically about 10 percent). While the sensitivity can be improved by inserting an image intensifier after the phosphor, this further degrades the spatial resolution. By comparison, direct detection camera based on the $\mathrm{x}$-ray vidicon tube have superior spatial resolution but inferior sensitivity. A direct detection camera based on a charge coupled device (CCD) area sensor should have spatial resolution comparable to the $x$-ray vidicon, but much better sensitivity. The resolution is controlled by the CCD photosite size, which is currently as small as 15 by 15 microns for one commercial area sensor. The sensitivity is controlled mainly by the photosite dark current. Since the sensor is small, it is practical to cool it to reduce the dark current enough to detect single x-ray photons. These advantages of spatial 
resolution, sensitivity, and size promise to make the device useful for NDE radiography and synchrotron radiation topography.

A CCD image sensor which is being developed in this group has a rectangular array of square pixels with 490 rows and 328 columns. The pixel dimension, and the center to center distance between pixels, is $24.4 \mathrm{~km}$. Half of the rows are used for image integration, and the rest for image storage. The integration period may vary from $1 / 60 \mathrm{sec}$ to about 10 minutes. At the end of the integration period, the charge accumulated in the image integration region is rapidly transferred to the image storage region. During the next integration period, rows of charge in the storage region are shifted through the storage region into a serial register, and charge packets in the serial register are shifted through the serial register to an output amplifier. The output contains a signal component, a clock component, and a dark current component. The output is processed to remove the clock and rark current components, and is converted to a video signal. A commercial frame grabber stores the video signal, and drives a TV during the integration period. Constructions of the camera is in progress, and comprehensive tests are planned.

Collaborative Synchrotron Radiation Research: Dental Microradiography Subtask 5 of Task 15442

R. C. Dobbyn, D. R. Black and M. Kuriyama

In collaboration with scientists from American Dental Association Health Foundation Unit, a technique that is called parallel beam microradiography with $x$-ray image magnification [1], [2] has been applied successfully to the identification of structural details of carious lesions in human tooth specimens, revealing considerably more structural features of the lesion than do conventional contact radiographs [3]. While conventional microradiographs show dentinal tubules running parallel to one another, the present technique reveals a woven structure in which the tubules are indeed oriented in various directions throughout the thickness of the specimen. Also while the lines of Retzius in a lesion are seen as continuous radiolucent bands in a contact micrograph, the parallel beam microradiograph with an x-ray magnifier show that each band contains alternating radiopaque and radiolucent cross striations. In these parallel beam microradiographs taken with the $x$-ray magnifier (70X), the spatial resolution has reached less than 2 im.

[1] W. J. Boettinger, H. E. Burdette, M. Kuriyama, Rev. Sci. Instr. 50 26-30 (1979).

[2] S. Takagi, L. C. Chow, W. E. Brown, R. C. Dobbyn, and M. Kuriyama, Nuclear Instr. \& Methods 222 256-258 (1948).

[3] S. Takagi, L. C. Chow, W. E. Brown, R. C. Dobbyn, and M. Kuriyama, J. Dental Res. 64 866-869 (1985). 


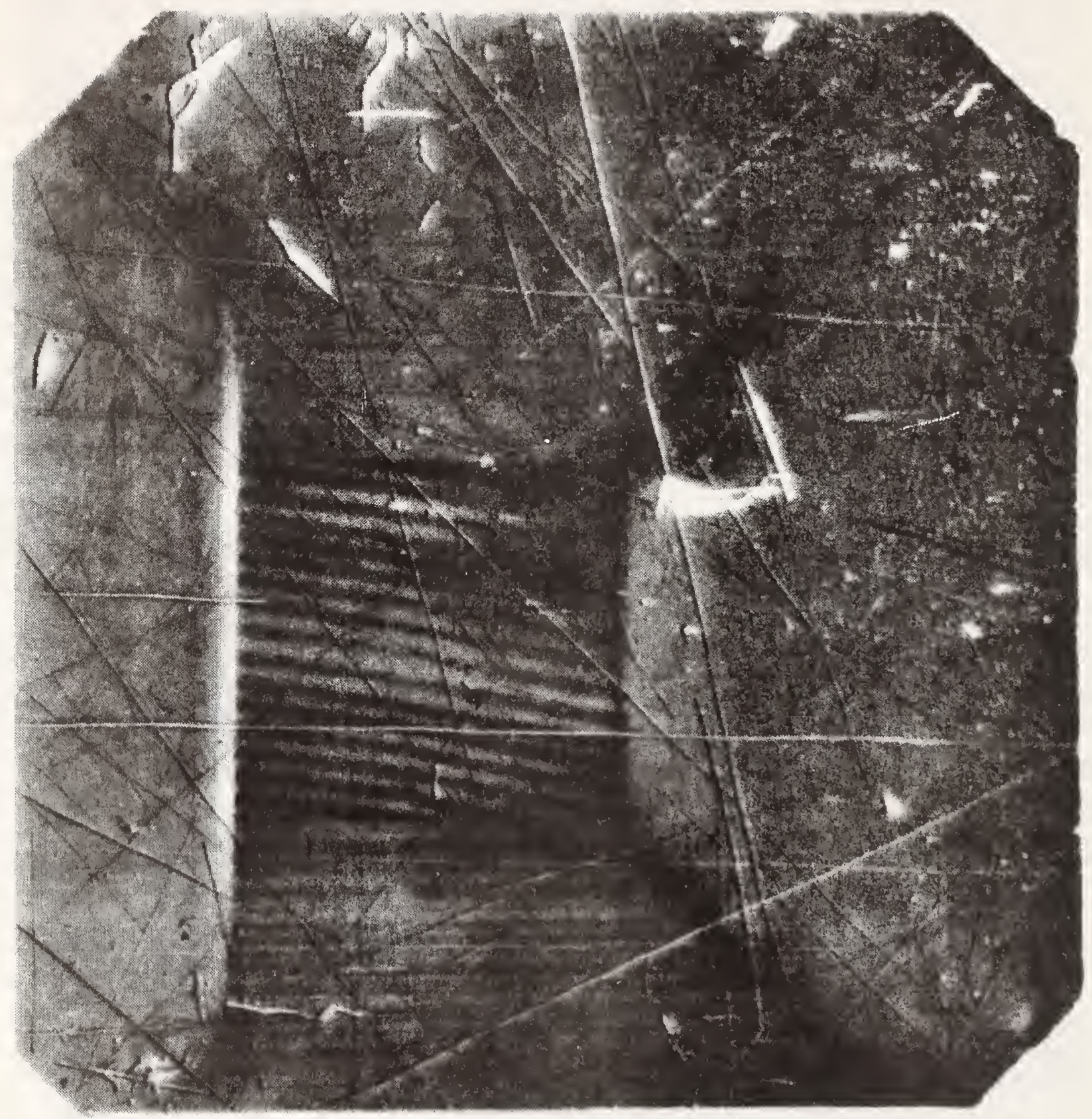

Figure 1 Synchrotron Radiation Topograph of a Bismuth Silicate Single Crystal

This topograph was taken at X-23A, NBS Materials Science Beam Lines at National Synchrotron Light Source, Brookhaven National Laboratory. Monochromatic (8 Kev) radiation was prepared by a double asymmetric Si crystal diffraction arrangement to obtain (930) diffraction in surface reflection from a supposedly perfect bismuth silicate crystal. The storage ring was operated at $35 \mathrm{~mA}, 2.4 \mathrm{Gev}$. The sample was supplied by A. R. Tanguay, Jr., University of Southern Califronia. 
METALLURGICAL PROCESSING

Task 15443

The properties of alloys depend on their processing history. The objective of this task is to develop measurements and predictive models to allow prediction of the effects that processing conditions have on alloys. Increased reliability, cost savings, and higher performance of final products can be expected from the resulting improved control of metallurgical processing. Moreover, investigations of new metallurgical phenomena, such as encountered in rapid solidification and diffusioninduced grain boundary migration, may lead to improved types of materials unobtainable by conventional means. For example, work on this task during the past year has resulted in the production and investigation of a dramatically new class of materials, called quasicrystals, which do not obey previously accepted crystallographic restrictions concerning periodicity. This work has sparked intense interest in the scientific community because of the implications it has for fundamental understanding of materials and the wide variety of new properties that might be provided.

Solidification effects, solid state transformations, diffusion, interface processes, and kinetic changes that alloys undergo during their production into final form are central areas of investigation in this task. These processes determine the microstructures and compositional distributions in alloy parts and products, which in turn decide the alloy properties and performance in use. Advanced processing techniques, such as rapid solidification, and development of improved methods for control of conventional techniques, such as continuous casting of steel and directional solidification processes, both are important parts of the solidification studies. In the solid state processing area, new activities on powder metallurgy, alloy coarsening, and the effect of diffusion-induced stresses at grain boundaries and other interfaces have been initiated. Applications of this work include improving the strength of structural alloys, modification of surface properties for corrosion and wear resistance, and optimizing fiber-matrix bonding in metal matrix composites.

Strong interactions have been established with industry, universities, and other government agencies. Visiting scientists from industry and universities come to NBS to participate in preparation of rapidly solidified alloys for exploratory research and to collaborate with NBS scientists. Major studies in this task on quasicrystals and rapid solidification are funded by the Defense Advanced Research Projects Agency. Powder processing work on rapidly solidified $\mathrm{Al}-\mathrm{Fe}$ is supported by the Naval Air Development Center and studies of stress effects on coarsening in rapidly solidified alloys by the Office of Naval Research. Measurements and modeling of convection during directional solidification are being sponsored by the National Aeronautics and Space Administration. Diffusion-induced grain boundary migration studies directed toward surface alloying were supported during the past year by the Army Research office. Interface studies for application to metal matrix composites are being funded by the office of Naval Research. 
- A new alloy phase that shows 5-fold icosahedral symmetry both in its electron diffraction pattern and in its growth morphology was discovered as a result of a cooperative program on rapid solidification between NBS and The Johns Hopkins University. This icosahedral Al-Mn phase belongs to a new class of materials that are neither crystalline, since crystallography does not allow periodic crystal lattices with 5-fold symmetry, nor amorphous. These new materials, called quasicrystals, have major implications for scientific understanding of alloy theory and for producing unusual alloy properties and performance.

- The conditions under which quasicrystals can be produced were systematically investigated. These materials now have been produced in the NBS Metals Processing Laboratory by all three major rapid solidification techniques, melt-spinning, surface melting with subsequent rapid re-freezing, and atomization, and have been found in a number of different alloy systems. Importantly, a second quasicrystalline phase showing decagonal symmetry was discovered at higher Mn concentrations. Moreover, it was found that addition of Si to Al-Mn suppressed competing phases, such as the decagonal phase, and for the first time allowed the formation of single phase icosahedral material.

- The effect of container side walls on the convection produced during directional solidification was analyzed. Usually it has been assumed that side walls will reduce convection because of forces between the side walls and the flowing fluid. Surprisingly, it was found that there are regimes where the presence of side walls will instead increase alloy convectional instabilities. Thus reducing the distance between side walls will not help to eliminate convection in those regimes.

- A driving force arising from the effect of diffusion-induced coherency strains has been identified as responsible both for diffusion-induced grain boundary migration and for liquid film migration that occurs during liquid phase sintering. Convincing evidence for this conclusion was found by analyzing experiments in which the migration rates went to zero when a composition range was selected where the lattice parameter change with composition was zero. This result has significant implications for surface alloying to produce protective coatings and for diffusional interactions at interfaces in composite materials since it predicts that coherency strains can produce significant changes in alloy interface compositions.

- Coarsening of the microstructure in rapidly solidified Al-8 wt\% Fe powder was measured. The rate of coarsening depended strongly on the original powder microstructure, which in turn depended on the original powder particle size. The slowest, most desirable coarsening regimes were found in alloy samples having the smallest original particle diameters. 
Rapid Solidification

Subtask 1 of Task 15443

W. J. Boettinger, R. J. Schaefer, S. D. Ridder, S. R. Coriell, J. G. Early,

F. S. Biancaniello, and J. W. Cahn

Rapid solidification and subsequent thermomechanical consolidation provides a new approach to alloy design which can permit the talloring of microstructure to meet specific alloy property requirements. To promote the evolution of this new design strategy into a mature element of the field of metallurgy, research has been performed in three areas: (a) an exploration of new metallic metastable phases with unique structure and properties; (b) the kinetics of microstructure formation; and (c) improvements in processing techniques used for the production and consolidation of rapidly solidified alloy particulate.

Quasicrystalline Al-Mn Phases

The recent discovery by guest worker D. Shechtman from The Johns Hopkins University and scientists at the National Bureau of Standards of new types of materials, called quasicrystals, which do not obey previously accepted crystallographic restrictions concerning periodicity has opened up major new areas of investigation important for our fundamental understanding of materials. This discovery has generated great interest in the scientific community, both in the U.S. and abroad. Quasicrystal Al-Mn alloys now have been produced at NBS by all three major rapid solidification techniques, melt spinning, surface melting with rapid re-freezing, and atomization. The current quasicrystal alloys are metastable but do not transform until heated above $300^{\circ} \mathrm{C}$.

One major area of investigation currently underway is analysis of the crystallography of these new structures. Until quasicrystal alloys were found, the general wisdom had been that even rapidly solidified alloys would be either crystalline (with fully periodic structures) or amorphous. Thus, the discovery of a new phase, that diffracted electrons like a single crystal with long-range orientational order but had point group symmetry m35 (icosahedral), figure 1, which is inconsistent with lattice translations, was indeed surprising. This phase shows 5-fold symmetry both in its electron diffraction pattern and in its growth morphology. It has now been observed in a number of aluminum-transition metal alloys and over a wide composition range, from 15 to $35 \mathrm{wt} \% \mathrm{Mn}$, in rapidly solidified Al-Mn alloys.

The solidification conditions required to form quasicrystals were examined in detail. Controlled electron beam melting and resolidification experiments were conducted in the NBS Metals Processing Laboratory at scan rates between 0.1 and $200 \mathrm{~cm} / \mathrm{s}$ on compositions between 3 and $30 \mathrm{wt} \% \mathrm{Mn}$. The microstructures produced by these experiments are summarized in figure 2. At compositions of 18 or more wt\% $\mathrm{Mn}$, the equilibrium phases are replaced by quasicrystals in the more rapidly scanned melts. Two types of quasicrystals are found to grow competitively in these melts; the icosahedral phase discovered by Shechtman and a phase, labeled $T$ in the figure, which belongs to another noncrystallographic point group (decagonal). This phase, 
which is formed by higher Mn concentrations, has a single 10-fold rotation axis and has translational periodicity along this axis. However, it is non-periodic in the other two dimensions. The decagonal phase was discovered in collaboration with guest worker L. Bendersky of The Johns Hopkins University. In the electron beam melts, the decagonal phase dominated at slower velocities $(10 \mathrm{~cm} / \mathrm{sec}$ ) while the icosahedral phase dominated in the fastest scans $(200 \mathrm{~cm} / \mathrm{sec})$. The addition of $5 \mathrm{wt} \% \mathrm{Si}$ to the alloy suppresses the formation of the decagonal phase and allows the formation of single-phase icosahedral in an alloy containing $33 \mathrm{wt} \% \mathrm{Mn}$. This recently discovered ability to produce samples that are $100 \% 1$ cosahedral is important for many types of measurements.

$X$-ray diffraction studies have demonstrated that the icosahedral phase can exist with a wide range of compositions in the Al-Mn system. However, the exact arrangement of the atoms in this phase is not known, in spite of the world-wide research effort that has developed since its initial announcement. Quasicrystal phases are now being reported with additional non-crystallographic point groups (an infinite number are possible) and in other alloy systems, so it is evident that a large new class of materials has been found.

\section{Kinetics of Microstructure Formation}

Experiments have been performed on two alloy systems, $\mathrm{Al}-\mathrm{Fe}$ and $\mathrm{Ag}-\mathrm{Cu}$, to investigate critical areas where modification of solidification theory is necessary to predict the microstructure of rapidly solidified alloys.

Rapidly solidified Al-Fe base systems are considered technologically important because, among other things, fine precipitates which strengthen the alloy and do not coarsen quickly can be produced in these systems. The low equilibrium Fe solubility and the metastable extended solubility produced by rapid solidification are important in this process. Vacuum atomized powder of $\mathrm{Al}-8 \mathrm{wt} \% \mathrm{Fe}$ was examined and found to exhibit four distinct microstructures whose relative abundance changed greatly with increasing particle diameter in the size range of $5 \mathrm{\mu m}$ to $45 \mu \mathrm{m}$ : microcellular $\alpha-\mathrm{Al}$; cellular $\alpha-\mathrm{A} 1 ; \alpha-\mathrm{Al}+\mathrm{Al}_{6} \mathrm{Fe}$ eutectic; and $\mathrm{Al}_{3} \mathrm{Fe}$ primary intermetallic structure ( $f i g .3)$. The importance of initial undercooling was demonstrated in the small powder particles $(\sim 10 \mu \mathrm{m}$ or less) which exhibit a two-zone microcellular-cellular structure in individual powder particles (fig. 4). In the two-zone microstructure, there is a transition from solidification dominated by internal heat flow (recalescence) and high growth rates (microcellular) to solidification dominated by external heat flow and slower growth rates (cellular). The formation of a two-zone microstructure from an inftially cellular structure was unanticipated and indicates the importance of solute redistribution in preventing free dendritic growth. Larger particles experience little or no initial undercooling prior to solidification and do not exhibit the two-zone structure. The larger particles contain cellular, eutectic, or primary intermetallic structures that are consistent with coupled zone analysis and imposed growth rates controlled by heat extraction through the particle surface (external heat flow). 
Ag-15 wt\% Cu alloys were solidifled at controlled rates between $0.1 \mathrm{~cm} / \mathrm{s}$ and $18 \mathrm{~cm} / \mathrm{s}$ using electron beam melting and resolidification to document the change in cellular microsegregation patterns which occur with increasing growth rate. The amount of solute incorporated into the cell interiors has a direct influence on the volume fraction of intercellular phases and the degree of precipitation (strengthening) which can occur in the cell interiors during subsequent thermomechanical treatment. The cell spacings for this range of growth rates are between $2.5 \mu \mathrm{m}$ and $0.25 \mu \mathrm{m}$, respectively, and the measurement of microsegregation profiles was performed by STEM in collaboration with L. Bendersky of The Johns Hopkins University. The average $\mathrm{Cu}$ content of the cells increases with increasing solidification rate at a rate faster than predicted by existing theory. Also the shapes of the profiles are flat compared to profiles from cells formed at slower rates. Both of these results suggest potentlal areas for detalled theoretical modelling of cellular solidification.

\section{Powder Processing}

The effect of consolidation processes on alloy microstructure can be especially critical for application of rapldly solidified alloys such as high temperature aluminum alloys. These alloys obtain their improved properties from the fine distribution of precipitate particles that can be produced during rapid solidification. The rate at which these assolidified structures change during subsequent consolidation is dictated by the nucleation, growth, and coarsening of precipitates, and thus, careful control of the precipitation processes is required.

Figure 3 summarizes the microstructure differences which exist in Al-8 wt\% $\mathrm{Fe}$ alloys as a function of powder size. As a result of these microstructural differences, the microstructural response of different size powder particles as well as different regions within individual powder particles could vary significantly under different consolidation conditions. In particular, it is important to distinguish between the thermal effects and the deformation effects in the consolidation processes in order to minimize precipitate coarsening. The coarsening behavior of the varlous microstructures was investigated by optical and transmission electron microscopy and precipitate coarsening data for selected microstructures was obtained. Substantial variations in precipitate coarsening behavior were observed with the microcellular coarsening rates being the slowest. The activation energy for volume diffusion computed from the precipitate coarsening data was found to be consistent with literature values for the diffusion of iron in aluminum. Based on these results, additional experiments have been started to investigate the effect of simultaneous application of deformation and temperature on the as-solidified microstructures.

Controlled Solidification

Subtask 2 of Task 15443

S. R. Coriell, R. L. Parker, R. J. Schaefer, and J. R. Manning

In this research, the fluid flow, solute segregation, and interface morphologies which occur during solidification are being studied and 
techniques for monitoring solidification velocities are being developed. Numerical calculations in collaboration with G. B. McFadden, R. F. Boisvert, and R. G. Rehm of the NBS Center for Applied Mathematics have modelled convection occurring during alloy solidification and cellular interface morphologies during directional solidification. This predictive modelling can be used to guide alloy designers in choosing experimental conditions that will optimize properties of the solidified materials, for example, in providing homogeneous defect-free material needed for electronic applications. U1trasonic techniques are being developed to measure interface position, velocity, and morphology during the solidification of steel and other metals. This work is directed toward monitoring of continuous casting processes to provide real-time feedback and control, thus aiding in maintaining a uniform product and avoiding catastrophic breakouts. It also can be regarded as real-time ultrasonic metallography.

\section{Convection during Directional Solidification}

During directional solidification of a binary alloy, double-diffusive convection may occur and cause solute inhomogeneities in the resultant solid. Our previous two-dimensional time-dependent calculations of doublediffusive convection assumed periodic boundary conditions on the vertical boundaries. This is a reasonable approximation when the horizontal wavelength of the flow is small compared to the lateral dimensions of the sample. For the wavelength comparable to the lateral dimensions of the sample, our numerical algorithm has been modified to use boundary conditions appropriate for rigid walls. At a rigid wall the fluid velocity and the solute flux vanish. The boundary condition on the temperature variation depends on the thermal properties of the boundary, with two limiting possibilities being vanishing temperature variation (perfectly conducting) or vanishing heat flux (perfectly insulating). Numerical calculations indicated that for certain parametric ranges convective instabilities occurred at lower solutal Rayleigh numbers in the finite system with rigid walls than in the infinite system with periodic boundary conditions. This result was unexpected since for a single component system side walls stabilize the flow.

The linear stability analysis for the directional solidification system in these ranges is intractable, and a simpler problem has been treated in order to clarify the role of lateral boundaries in a double diffusive system. The effect of rigid vertical boundaries on the onset of convective instability for the salt finger regime of double diffusive convection has been calculated. The unperturbed state is a quiescent fluld with constant vertical gradients of temperature and solute, which are stabilizing and destabilizing, respectively. The horizontal boundaries are stress-free and perfectly conducting. The lateral boundaries are perfectly insulating for solute. Changing from thermally insulating to thermally conducting side walis results in a strong destabilization of the flow for large thermal Rayleigh numbers even in the limit that the separation between the side walls approaches infinity. Further, for thermally conducting side walls, a decrease in the separation of the side walls may destabilize the system. 
A series of calculations have been carried out for a model material with a Schmidt number of unity in order to describe a number of the flow transitions that can occur during the directional solidification of a binary alloy. Distinct steady states can arise from different initial conditions for identical values of the processing conditions and materials properties. In addition, these steady states can transform to time periodic states.

If the crystal-melt interface is planar and there is no fluid flow in the melt, then at steady state the solidified material will have a uniform solute distribution equal to the bulk concentration in the melt. It is well known that for sufficiently high solute concentrations, a planar crystal-melt interface will be morphologically unstable, and develop into a cellular or dendritic interface with lateral solute segregation (microsegregation). A review of the present theoretical and experimental status of cellular growth during directional solidification was recently completed as part of the current work. It appears that the theory is on the verge of providing a quantitative understanding of cellular growth. Critical wavelengths predicted by linear stability analysis agree with measured cell spacings near the onset of instability to within about a factor of two. For conditions far from the onset of instability, definitive experiments would provide valuable guidance for theoretical advances. Modern computers have made possible calculations of nonplanar interface morphologies that differ significantly from planarity. In collaboration with the NBS Center for Applied Mathematics, numerical algorithms are being developed for calculation of three-dimensional solute and temperature fields and the accompanying interface morphologies. Such calculations will provide insight into the complex morphologies and transitions which occur during directional solidification, for example. the occurrence of nodes, elongated cells, and regular cells for different processing conditions.

\section{Ultrasonic Measurements of Solidification Interfaces in Metals}

Ultrasonic techniques are being developed to provide real-time, in-situ, nondestructive measurement of the position, motion, and shape of solidif1cation interfaces in opaque materials. Such a technique would be useful for feedback and closed-loop process control of solidification to achieve improved quality control and productivity in continuous casting of steel or other metals. The technique can be regarded as real-time ultrasonic metallography.

The use of pulse-echo ultrasonic flaw detectors to detect the presence and location of cracks, voids, and other flaws in metals and non-metals is well known. The solid-liquid interface in a melting or freezing metal should also produce a reflected echo, in that there is a measurable difference in both sound velocity and density across the interface. Results from the present work have shown that the melting and freezing of pure iron can be followed satisfactorily by this technique; however, for 304 stainless steel at $1 \mathrm{MHz}$, weaker signals were obtained resulting from (1) attenuating effects on beam strength caused by Rayle1gh scattering from enlarged grains produced by rapid grain growth in the solld portion of the specimen, and (2) weaker reflection from the solid-liquid mushy 
zone due to 1 ts more gradual change in acougtical impedance compared to the sharp solid-liquid interface for pure iron.

During the past year, a series of measurements on 304 stainless steel and on pure iron was completed, with an improved digital signal processing system being utilized. In addition, a tungsten-argon arc was used to establish more planar controlled interfaces. The results showed that the solid/liquid interface can be followed during both melting and freezing even in concentrated alloys with substantial mushy zone width, and even in the presence of substantial bulk beam attenuation due to grain growth in the solid. A simple optical-type interference theory was proposed to account for the reduced reflectivity observed from the mushy zone in concentrated alloys.

Further development of signal processing has proceeded with the assistance of Professor N. C. Peterson of the Polytechnic Institute of New York. Software has been written to permit faster averaging to improve signal/noise ratios in measurements in alloys. This will be particularly important for practical applications where non-contact transducers, with lower sensitivities than those that directly contact the metal, must be used to avoid damage from hot metal contact.

Solid State Processes and Alloy Interfaces Subtask 3 of Task 15443

J. R. Manning, C. A. Handwerker, S. C. Hardy, P. W. Voorhees, J. W. Cahn, and S. A. Hackney

Kinetic processes in solids can be strongly affected by interactions between stress fields and composition gradients. Diffusion processes modify and in turn are influenced by the forces from these fields and gradients. Studies have been initiated in this task to investigate these types of interactions, especially those influenced by interfaces in alloys. The solid state processes considered here can strongly influence the microstructure and composition profiles in alloys and hence alloy properties. Diffusion-induced grain boundary migration may be important for production of protective coatings, reactions at nonequilibrium interfaces influence bonding in composite materials, and alloy coarsening strongly affects mechanical properties.

Diffusion-Induced Grain Boundary Migration and Liquid Film Migration

When an alloying element diffuses into a strain-free, chemically homogeneous polycrystal, diffusion theory predicts that solid solutions will form by a combination of grain boundary diffusion and lattice diffusion. For fcc metals, diffusion is isotropic and concentration profiles that are symmetric across the grain boundaries are thus expected. In contrast to these expectations, grain boundaries in polycrystals when exposed to a diffusion source have been found to migrate agalnst their radil of curvature with solid solutions being formed only in the reglons swept by the moving grain boundaries. This recently discovered process, known as diffusioninduced grain boundary migration, has now been found in numerous binary 
metal systems and provides a new method of surface alloying as well as influencing discontinuous precipitation. When the grain boundary is replaced by a liquid $\mathrm{film}$, as in liquid phase sintering, the liquid film can migrate with concomitant alloying under diffusion conditions analogous to the grain boundary case.

In current work, the driving forces for both grain boundary and liquid film migration were found to arise from the same source, that is, from coherency stress. Diffusion of the solute from the grain boundary or the liquid into the solid creates a stressed diffusion layer if the lattice parameters of the alloyed and the unalloyed regions are different. Diffusion-induced migration of liquid films and grain boundaries was analyzed for a variety of liquid phase sintering systems in cooperation with Professor Duk N. Yoon, guest scientist from the Korea Advanced Institute of Science and Technology. By simultaneously changing the concentrations of two solute atoms in liquid phase sintered Mo-Ni alloys, a perfect lattice matching can be achieved between the parent grains and the thin diffusion zone, thereby reducing the coherency strain to zero. In these alloys, it was found that migrations of grain boundaries within the particles being sintered as well as migration of the liquid films between neighboring particles ceased at the lattice matching compositions and increased as one moved away from these compositions. An analysis of liquid film migration based on the thermodynamics of stressed solids was developed which explains many features of both diffusion-induced grain boundary and liquid film migration, including the initiation of migration, the direction of motion, and the morphology based on the elastic anisotropy of the dissolving grain alone.

The discontinuous precipitation of liquid droplets at the migrating grain boundaries induced by temperature decrease has been studied in Mo-Ni and $\mathrm{Co}-\mathrm{Cu}$ alloys which have retrograde solidus curves. The solids formed behind the migrating grain boundaries were found to have the equilibrium compositions. Recrystallization was found to occur on the grain surfaces when the liquid matrix of Mo-Ni alloy was replaced by a $\mathrm{Cu}-\mathrm{Fe}$ melt. A similar phenomenon occurred when a KCl single crystal was immersed into aqueous solutions saturated with $\mathrm{KCl}$ and $\mathrm{KBr}$ at room temperature. The composition analyses showed that the solute concentrations at the migrating interface decreased because of the increasing length of the diffusion paths for solute atoms.

Chemical Thermodynamics and Kinetics of Reactions at Non-Equilibrium Interfaces

The presence of an interface in a system undergoing chemical mixing by interdiffusion can lead to complex reactions, changes in interfacial structure during diffusion, and mass transport along and across the interface not predicted by standard diffusion theory. The most important issues which are being addressed in our current work are the establishment of the thermodynamic rules governing interface reactions and the determination of the forces and kinetic effects controlling these various interface reactions. Results provided by this work are applicable to a wide range of interface problems, including matrix-fiber bonding in metal matrix composites. During the first phase of the study, simple interfaces and 
diffusion within single phases in $\mathrm{Cu}-\mathrm{Mn}, \mathrm{Cu}-\mathrm{N} 1$, and $\mathrm{Al}-\mathrm{Zn}$ systems are being used to isolate the effect of self-stress (stress due to compositional gradients) on the thermodynamics and kinetics at interfaces. The theory of the thermodynamics of stressed solids developed in this work predicts that a compositional discontinuity will exist at interfaces in these systems as a result of coherency stresses.

\section{Alloy Coarsening}

Standard theories of coarsening all assume that the matrix and precipitate phase behave thermodynamically as fluids, and thus the presence of nonhydrostatic stresses is neglected. As a result, standard coarsening theory does not describe adequately coarsening phenomena in solids. This is particularly true in certain precipitation-strengthened alloys where significant non-hydrostatic stresses exist. In an effort to redress these deficiencies in our current understanding of ripening phemonena, work has been undertaken in conjunction with Professor W. C. Johnson of Carnegie-Mellon University to develop a self-consistent theory of late stage phase transformation processes in solids. During the course of this work, examinations have been made of (1) the equilibrium conditions at the interface of a growing spherical precipitate and (2) the relationship between the interfacial energy of a coherent precipitate and the mismatch between the precipitate and matrix.

A thermodynamic description of curved solid-solid interfaces has been used to determine the equilibrium interfacial solute concentrations in the precipitate and matrix phases in a system consisting of an isolated spherical precipitate possessing a pure dilational mismatch and different elastic constants than the matrix. A result of this investigation is that the equilibrium concentrations at the interface depend strongly on the stress state of the two bulk phases and the interface itself. This dependence gives rise to a strong coupling between the interfacial concentrations and the stress generated by the non-uniform composition field, $1 . e .$, the degree of matrix supersaturation, in the matrix. Since such stresses do not exist in fluids, results for solids will differ considerably from those given by previous fluid models. In contrast to fluids, capillarity in a system with a coherent precipitate was found to depend on both the surface stress, through the surface residual stress and surface elastic coefficients, and the surface energy. In addition, the magnitude of the shift in interfacial concentration due to capillarity was found to depend on the degree of matrix supersaturation.

Using the thermodynamic description of the equilibrium conditions at the interface of a spherical misfitting precipitate developed above, the relationship between the precipitate mismatch and surface energy was derived. It was shown that the change in the magnitude of the surface energy with mismatch depends on the sign of the surface stress and the surface elastic constants. For example, if the interfacial elastic constants are small and the surface residual stress is negative, increasing the mismatch can decrease the surface energy. The ramifications of this unusual result for Ostwald ripening theory are currently being examined. 


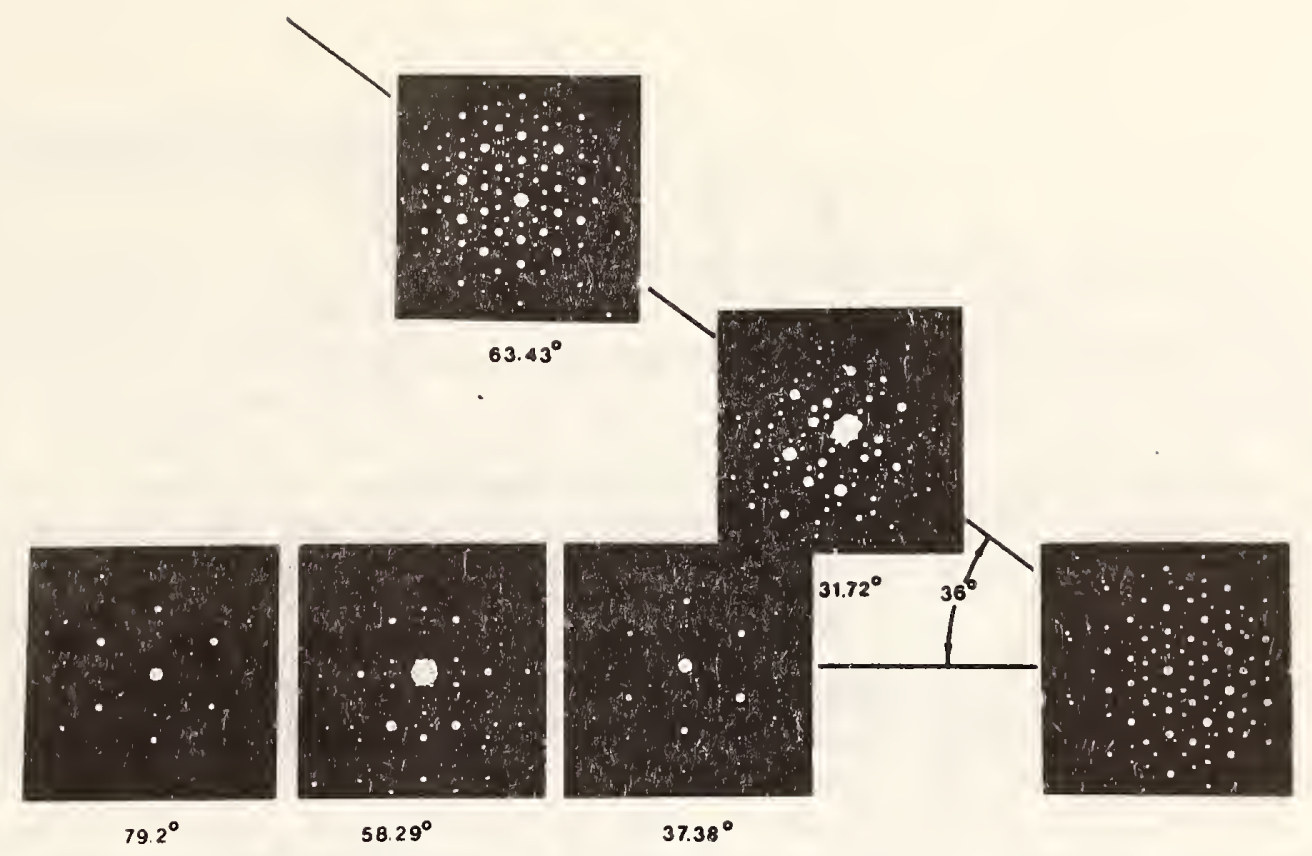

Figure 1. Selected-area electron diffraction patterns taken from a single grain of the icosahedral phase. Rotations between 5-fold and the varfous $2-$ and 3 -fold orientations match the non-crystallographic point group $m \overline{3} \overline{5}$.

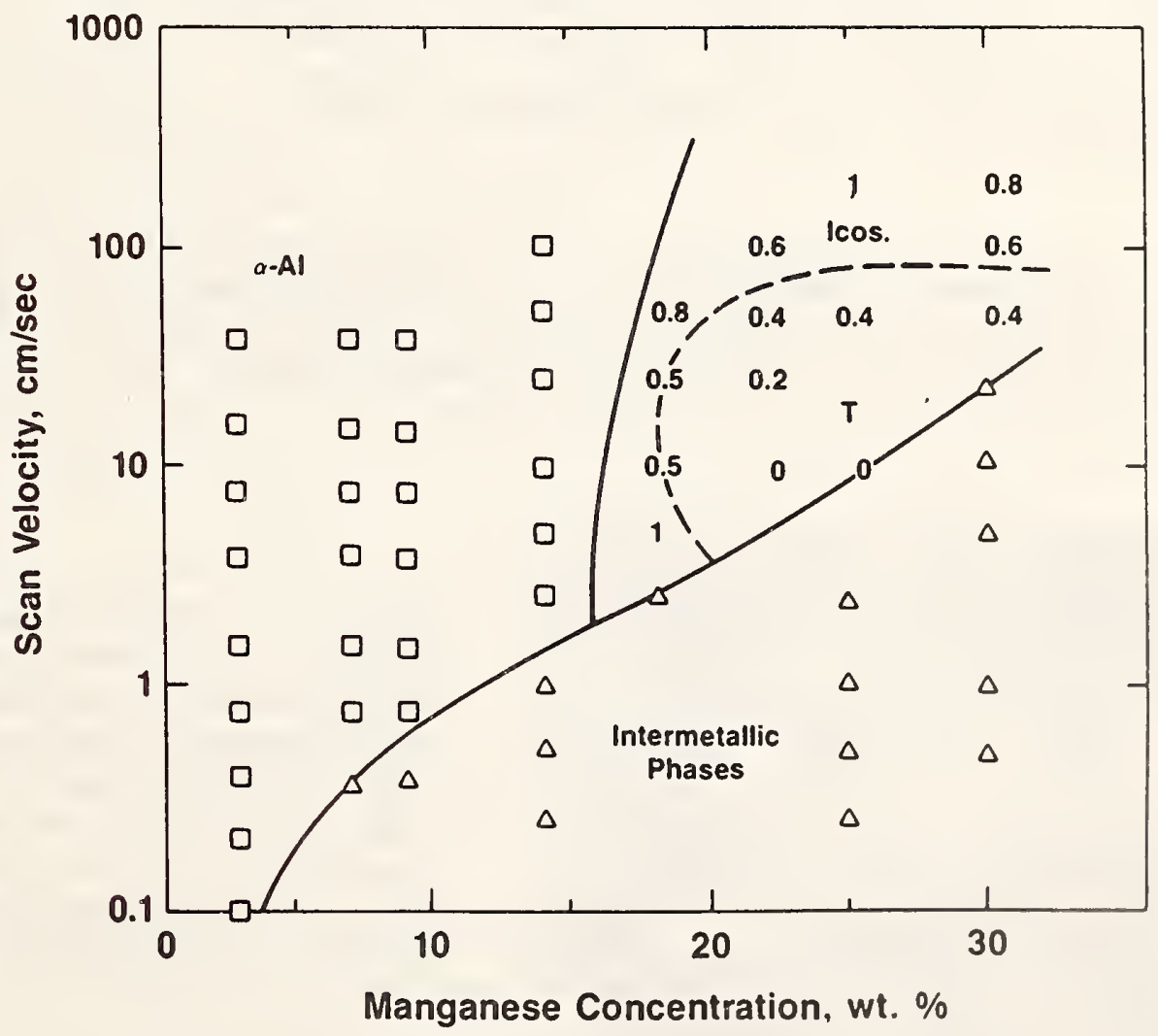

Figure 2. Mapping of primary phases in electron beam Al-Mn melts of different velocity and composition. In the icosahedral $+T$ region, the numbers indicate the relative fraction of the intermetallics which are icosahedral, from x-ray intensities. 


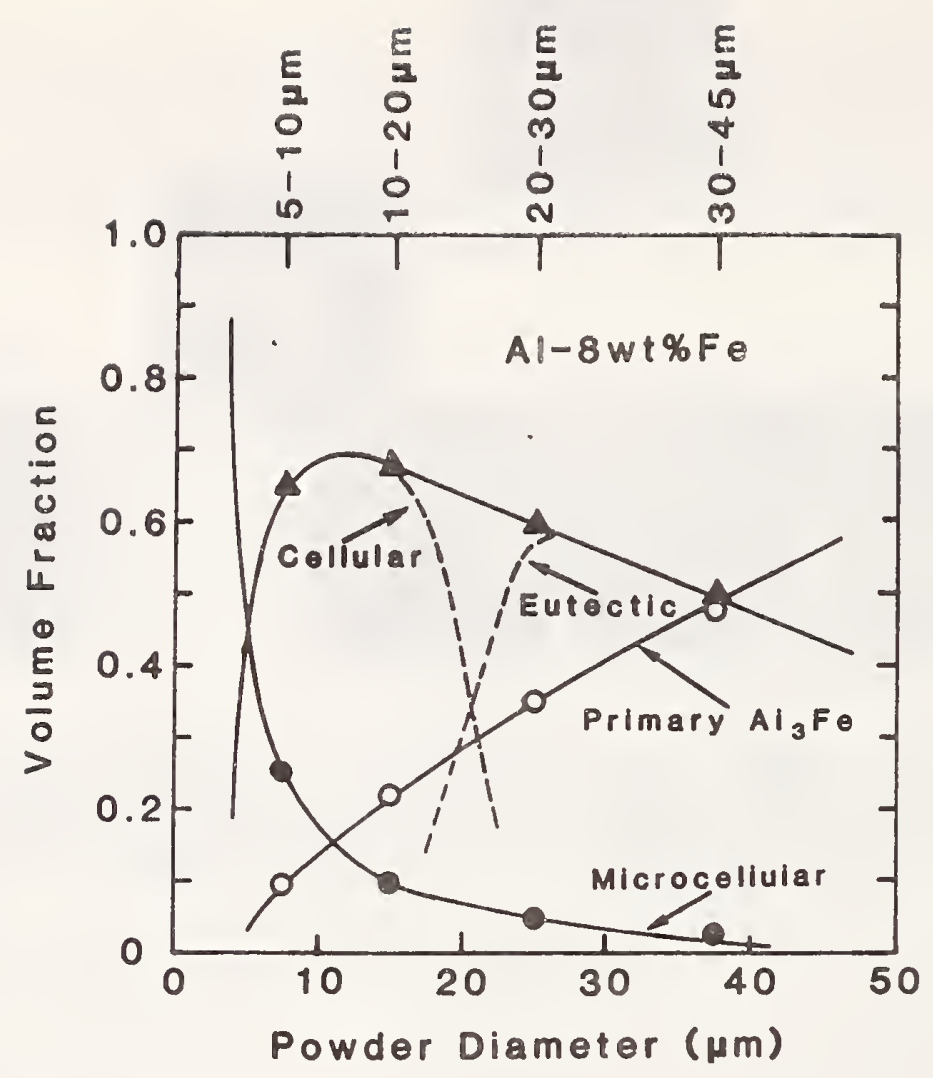

Figure 3. Volume fraction of the microcellular, combined cellular and eutectic, and primary intermetallic structures as a function of powder diameter of rapidly solidified Al-8 wt\% Fe. Possible separate curves for the cellular and eutectic structures are shown dashed.

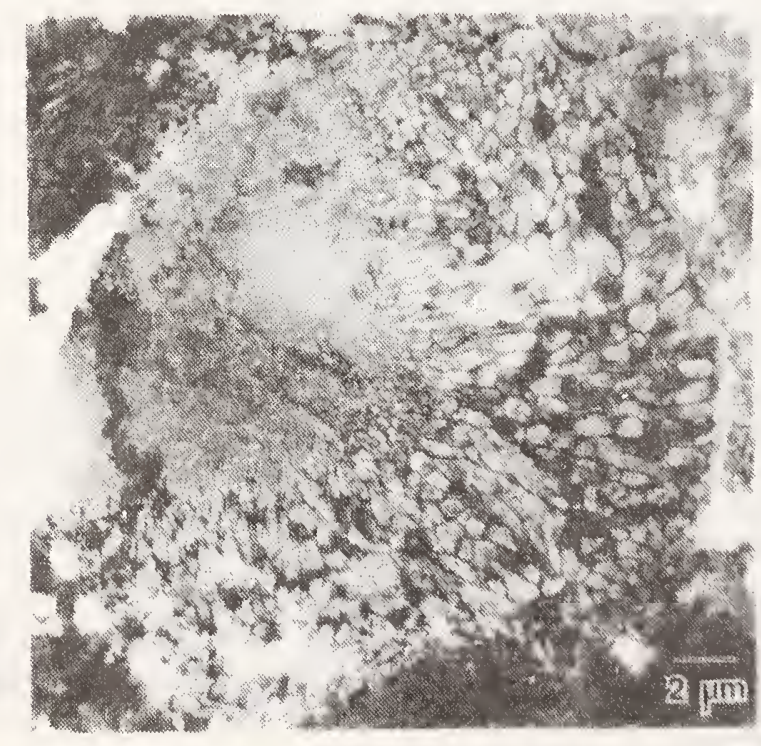

Figure 4. TEM micrograph of a Al-8 wt\% Fe powder particle. A single nucleation site (left) initiates solidification at a high interface rate to produce a fine cellular structure. Recalescence slows the interface rate to produce the coarser cellular structure at the right. 
WEAR AND MECHANICAL PROPERTIES

Task 15444

Research is carried out to improve measurement methods and to develop standards related to wear and mechanical properties of metals. A significant portion of the effort is directed towards an improved understanding of the physical mechanisms involved in wear, friction, and mechanical behavior. The methods used include wear and mechanical testing, optical and electron microscopy, microlndentation measurements, metallography, surface analysis, and wear particle analysis. An additional activity in the task includes corrosion and fatigue behavior of alloys used in synthetic implants.

Wear and mechanical performance of industrial systems of all levels of complexity, including also a wide range of consumer products, is an important part of the nation's industrlal effort. Costs assoclated with fallure and inadequate performance in these areas have a significant economic effect. Greater use of stronger, more wear-resistant materials can improve productivity and our competitive position world-wide. This task is developing test methods suitable for evaluating new materials having improved mechanical and wear properties. This work leads to data on such materials that may be used by design engineers in applying new materials to use. One example of a currently important area is that of metallic coatings. There are no adequate standard methods for measuring the wear performance of coatings. In their absence, users have no basis for making choices among avallable coatings for better wear performance. One new area of emphasis in this task is that of wear data for commerically important alloys and coatings.

\section{FY 85 Significant Accomplishments}

- Application of the new technique of thermal wave microscopy (TWM) to the study of wear debris accumulations on sliding contact surfaces was accomplished. TWM of wear tracks on an oxidized $\mathrm{Cu}-15 \mathrm{wt} . \% \mathrm{Zn}$ alloy showed evidence for periodic density differences in debris compacts. The presence of such compacts may help explain the differences in the frictional running-in behavior between reversed sliding and unidirectional sliding. Fabricated specimens with induced defects also have been examined systematically using TWM. The data collected indicates that while TWM does reveal the fabricated defects, other parameters (1.e., sample mounting, shapes, position of defect in relation to the beam, specimen tilt) play an important role that needs to be understood.

- Standard reference material 1891, a Co-Cr-Mo material for use with ASTM F 746, was completed and is now avallable for monitoring the corrosion behavior of that and similar synthetic implant alloys. Corrosion and fatigue data from porous metal coated surglcal implant metals show effects of porous coating production on material properties and Indicate microstructural changes to be avolded during processing steps on such alloys. 
Design and test criterla based on fracture mechanics analysis were developed to establish the basis for constructing seamless pressure vessels from oignificantly higher strength steels while maintaining the same level of safety. Research is continuing to develop valid criteria for determining the ductility of metals used for pressure vessels. A technique has been developed for the use of acoustic emission to periodically inspect large pressure vessels.

A method has been developed for the quantitative measurement of the severity of galling wear damage. The method employs topographic parameters obtained from data acquired by means of an automated prof1lometer system developed at NBS. The system permits quantitative assessment of the amount of galling damage, and the results can then be compared with others using different test methods or involving other alloys. NBS is recommending a particular standard configuration for the measurement of galling wear; the matter is now under consideration in the ASTM-G2 Wear and Erosion Committee.

Wear Properties of Metals

Subtask 1 of Task 15444

A. W. Ruff, L. K. Ives, P. J. Blau, J. Harris, C. O1son, P. Boyer, and E. Whitenton

Friction and Wear of Alloys

The running-in behavior differences between three copper-based alloys tested under unlubricated sliding conditions were compared. The effects of direction reversal were of particular interest. The three alloys ( $\mathrm{Cu}-3.5$ wt.\% $\mathrm{Al},-15 \mathrm{wt} . \% \mathrm{Sn}$, and $-5 \mathrm{wt} . \% \mathrm{Sn}$ ) were chosen to represent similar stacking fault energy, single-phase alloys with three different solute species. In this way, the role of subsurface deformation modes during sliding could be compared with any differences in sliding friction and wear behavior. The standard test geometry involved using 52100 alloy steel bearing balls as the fixed sliders on two computer-controlled traversing stages, one which stroked the surface in one direction then raised, reset, and repeated, and the other which slid back and forth without raising the slider. The average friction per stroke was quite different between unidirectional and reciprocating cases as the surfaces ran-in. (fig. 1) The nature of the debris distribution and track morphology also differed. The reciprocating cases had much more debris accumulation, and this probably accounted for the friction differences which were observed. Alloy to alloy differences in both friction and wear running-in were also observed when testing with the same sliding direction. From these studies it was clear that friction and wear running-in characteristic depend on both sliding direction and alloy composition.

The effects of oxide films on the running-in friction and wear behavior of three copper alloys ( $\mathrm{Cu}-3.5 \mathrm{wt} . \% \mathrm{Al},-5 \mathrm{wt} . \% \mathrm{Sn},-15 \mathrm{wt} . \% \mathrm{Sn}$ ) tested in unidirectional and reversed sliding were also investigated. The standard sliders were 52100 steel balls (unlubricated). Using baseline 
data from a companion study of the same alloys tested unoxidized, the role of oxide surface films of about $5.0 \mu \mathrm{m}$ thickness was evaluated.

Aiding in the investigation, a newly acquired thermal wave microscope (TWM) provided additional insights into the density of debris compacts on the wear tracks. The use of the TWM represented one of the first applications of this technique to wear debris studies. Using average track width as a measure of relative wear behavior gave the following overall ranking of alloys (low to high): $\mathrm{Cu}-\mathrm{Sn}, \mathrm{Cu}-\mathrm{Zn}, \mathrm{Cu}-\mathrm{Al}$. Differences in friction coefficient were more pronounced than those in wear rate because friction is more reflective of sliding interfacial conditions whereas the subsurface deformation and fracture properties influence wear. Further work on this project will be directed at modeling the variations in friction during the running-in period and in microstructurally characterizing the surface film/ substrate interface as it changes during wear.

Non-destructive testing methods for locating defects in materials, both near-surface or subsurface, have received increased interest. Thermal Wave Microscopy (TWM) affords this capability using a pulsed electron beam in a modififed SEM, to generate thermal/accoustic resonance within the material. Thermal wave image contrast is affected by thermal conductivity, microstructural homogenity, and thermoelastic properties of the materials observed. Practical applications in this area would be defects in materials relating to inclusions, porosity, and wear.

Galling Wear of Metals

A comprehensive investigation of the process and mechanism of galling of metals is being conducted under the sponsorship of the Department of Energy. Galling is a severe form of wear which occurs at sliding surfaces. Surfaces that have been subjected to galling are markedly roughened as a result of plastic deformation, fracture, and transfer of metal from one surface to the other. The Department of Energy has identified galling as a significant cause of failure of valves which are employed to control the flow of gasses and fluids in many energy conversion systems. Roughening of the valve sealing faces by galling results in an increased rate of leakage. Galling may also lead to the complete seizure of the valve. An important aspect of our program has been the development of quantitative methods to characterize the severity of galling damage. In the past visual examination had been employed to obtain a qualitative description of the damage. An automated profilometer system has been constructed which yields a digitized record of the topography of the galled surface. Having acquired such a record, parameters descriptive of the surface are then obtained by computer analysis of the data. In addition the measured topography can be displayed from a perspective that is most useful for comparison of different specimens. An example of a profilometer tracing of a galled surface is shown in figure 2. So far, galling mechanism studies have concentrated on pure metals. Metals having the BCC, FCC and HCP structures have been examined. Using topographic parameters as the basis for comparison, it found that damage is most severe in BCC and FCC structures and less so with the HCP structure. HCP cobalt is most notable for 
its resistance to galling. In the future galling mechanism studies will focus on alloys. In particular, a series of $\mathrm{Cu}-\mathrm{Al}$ and $\mathrm{Cu}-\mathrm{Ge}$ alloys will be studied in order to determine the effect of stacking fault energy.

This project also involves an Industrial Research Associate from Deere and Co. A number of machine components employed in agricultural and industrial equipment are subject to galling damage. There is a need for suitable design data on the galling behavior of commercial alloys as well as for test and measurement methods. It is the purpose of this cooperative program to address some of these problems. During the past year tests and measurements using NBS methods have been made on several different steel alloys that are employed in components where galling is an important design factor.

Wear of Currency Printing Plates

The purpose of this project is to develop methods to improve the wear life of plates employed by the Bureau of Engraving and Printing to produce U.S. paper currency. The project is being conducted jointly with members of the Electrodeposition Group. There are three major objectives; 1) determine the mechanism(s) responsible for the wear of printing plates, 2) develop a laboratory wear test for the evaluation of materials employed in the printing process, and 3 ) carry out laboratory wear tests to evaluate the wear performance of experimental electroplatings. All U.S. paper currency is printed by the intaglio process. A plate with a design in depressed relief corresponding to the printed image is coated with ink. The plate is then wiped leaving ink only in depressed areas. Pressing the plate against the currency paper with sufficient force transfers the remaining ink to the paper. The plate itself is a replica of an original engraving made by electroforming. The initial electroformed plate is of a relatively soft nickel. Without a protective hard surface layer or coating the plate would have a relatively short service life. Currently a layer of hard chromium approximately $12 \mu \mathrm{m}$ thick is electrodeposited onto the nickel. Based on an investigation of the printing process and an examination of used plates, we have concluded that the main source of $\mathrm{Cr}$ wear is in the wiping step to remove excess ink from the plate. The ink contains pigments and certain other solid particulate materials which are used to control consistency of properties. Some of these particulates or contaminants in them may abrade the chrome electroplate. In addition the polyvinyl chloride wiping material contains hard particles which can contribute to the abrasion. The abrasive wear probably consists of direct loss from the chrome electroplate as well as loss by removal of the oxide film that forms on the surface of the chrome as a result of chemical reaction with the atmosphere and the ink.

Two laboratory wear test devices have been developed for the study of chrome electroplate wear under conditions simulating critical aspects of the printing process. The tests have been used to gain insight into the printing plate wear process and for the evaluation of experimental chrome electro- 
plates. Future work on this project will involve the continued analysis of the wear process as well as the development of test methods and the evaluation of experimental plating materials.

\section{Wear Properties of Metal Coatings}

Further studies of micromechanical properties have been carried out on a set of nickel-phosphorous alloy coatings that were previously subjected to wear measurements. Those results under non-lubricated conditions against 52100 bearing steel showed a difference by a factor of $x 16$ between the most and the least wear resistant alloy coating. However, the hardness difference among the four coatings was only a factor of $x 1.2$, hence, the wear difference was ascribed to other factors such as microstructure differences and intrinsically different wear processes. Studies of these same alloy coatings have been done on the instrumented microindenter system (described below) and have revealed several new differences in mechanical response. Table 1 shows the product of load $x$ displacement for both worn and unworn coatings, as well as the substrate steel. The microindenter test separates out the elastic (recoverable) material response and the plastic (nonrecoverable) response. The ratio of these (elastic/ plastic) shown in the table is greatest for the most wear resistant coating, Ni-5P (electroless). That coating also shows the greatest elastic response change between unworn and worn condition (1-WE/UWE). These effects are related to the work-hardening characteristics of the alloy, and thereby to its wear resistance. The studies are continuing to further understand this connection.

Mechanical Properties of Metals

Subtask 2 of Task 15444

J. H. Smith, R. S. Polvani, and E. Whitenton

An accurate assessment of the mechanical properties of materials is necessary in order to design and build mechanical components that can be used under a wide range of loading and environmental conditions. The objectives of this task are to (1) accurately characterize the mechanical properties of materials, (2) develop test criteria and test methods for evaluating the mechanical properties of materials, and (3) demonstrate the applicability of the test criteria and properties for use in the design and evaluation of mechanical components.

\section{Micromechanical Properties}

Conventional mechanical tests that are used to measure such properties as strength, ductility, fracture resistance and hardness can not be used reliably to determine the properties of very small bodies such as particles, thin films, fibers, and coatings and for nonhomogeneous materials such as composites. Therefore, test methods and criteria for characterizing the properties of these materials are needed. One area of the present work is to identify mechanical properties requirements and develop test methods 
that can be used to evaluate the mechanical properties of components used in microelectronic devices and packages. The emphasis on this work is to improve methods for determining the strength, fracture resistance, ductility and fatigue strength of fine wires and coatings used in microelectronics devices.

Test Methods and Design Criteria for Pressure Vessels

Research and technical assistance is provided to the office of Hazardous Materlals in the Department of Transportation to develop safety standards for metallic and composite pressure vessels used in the transportation of hazardous materlals and high pressure gases. During the present year, design and test criterla have been developed, based on fracture mechanics technology, to permit the manufacture of seamless steel pressure vessels from significantly higher strength new steel alloys while maintaining the same level of safety previously obtained with much lower strength steels. A second project has established acceptance criteria and test methods for using acoustic emission techniques to periodically inspect large seamless pressure vessels used to transport compressed gases. Research is continuing to develop valid criterla for determining the ductility of metals used in the construction of metallic pressure vessels.

\section{Evaluation of Metallic Chimneys}

Under the sponsorship of the Consumer Product Safety Commission, extensive metallurgical and mechanical properties evaluations were undertaken of metallic chimneys used for wood burning stoves. These types of chimneys have been associated with numerous house fires and therefore it was required to determine if degradation of the chimney material during use was a significant cause of the fires. Extensive evaluation was made of chimneys that had been removed from service and of chimneys that had been tested in the laboratory under controlled conditions. Chimneys made from AISI type 304 stainless steel did not show significant degradation of the metal after long term exposure to flue gas environments in laboratory tests and after lengthy use in service. Chimneys made from AISI type 430 stainless steel did not show significant microstructural changes or embrittlement after extended periods of normal use. Degradation of the properties of the stainless steel was not identified as a significant cause of the chimney fires.

\section{Dynamic Microindentation}

Facing a wide varlety of applications, industrial parts and equipment designers need test methods for measuring dynamic mechanical properties. A new and nondestructive approach to dynamic mechanical testing is being developed in this project. Derlved from conventional hardness testing there are two important innovations in this approach. The indentation is described by the load-displacement curve, and is performed over a wide range of times, from hours to milliseconds. Recent modifications to the NBS microindentation tester include a transient digital oscilloscope, 
improved load and displacement measurements that are now made with respect to the sample itself (eliminating the need for a compliance correction), and, a variable duration pause between the test event and residual indentation depth measurement to give a means of determining anelastic recovery. Table 2 offers preliminary data illustrating the effect of dynamic loadings for a metal-matrix composite sample. The values report the loaded condition, and reflect the combined elastic and plastic deformation response. Explaining the relative softening at the extremes of load duration requires conjecture. At the slowest rate, creep is a significant factor. At the highest rate, the input of deformation energy is dissipated as both plastic deformation and local heating. For near impact conditions, theory predicts about an 80 percent conversion of the deformation energy into local heating.

Figures 3 a and b report typical test data for a 0-2 hardened and tempered tool steel. Combining the results for driving into and withdrawing from the sample, Figure $3 \mathrm{~b}$ is the load-displacement curve for the indent. Loaddisplacement curves can serve two different functions. First, the deformation energy, the area under the curve, can be partitioned into elastic, plastic and anelastic components. For example, the total work to indent the 0-2 steel was $430 \mathrm{gf}-\mu \mathrm{m}$, and 26 percent was elastically recoverable. Second, the load-displacement and stress-strain curves may be interchangeable. The interchangeability has been already shown for copper, but cannot be generally made. A primary goal of this task is developing a way to make that general conversion to stress-strain behavior of materials.

Metallic Surgical Implants

Subtask 3 of 15444

\section{A. C. Fraker and J. Harris}

Metallurgical aspects of porous metal coatings which are applied to metal orthopedic devices to support bony ingrowth and provide stabilizaion of the implant were studied. Continuing work relating to corrosion and mechanical hehavior of surgical implant metals and the production of a standard reference material were carried out. The work planned and conducted is based on the needs of the implant community which uses approximately 100,000 total hips, 50,000 total knees and 20,000 other joints in the United States annually. Metals are also used for other needs including heart pacemakers, heart valves, dental implants and cosmetic purposes. Three important factors for metals to be used in the body are biocompatibility, corrosion resistance and mechanical strength. Metallurgical studies are needed to assure that appropriate materials are chosen and that processing methods used do not adversely affect the integrity of the material for 1 ts intended use. The nature of this year's studies was'microstructural, electrochemical and mechanical, and the materials tested were Ti-6Al-4V and Co-Cr-Mo alloys. 
Microstructures of the $T 1-6 \mathrm{Al} 4 \mathrm{~V}$ porous coated materials revealed effects of sintering and could be correlated with corrosion-fatigue strength. Sintering above the beta transus lowered the fatigue strength due to the formation of a lamellar grain structure, and sintering, in general, lowered the fatigue strength to a lesser degree by causing diffusion of oxygen. Some impurities were found in the arc plasma sprayed porous coatings. Microstructures of sintered porous Co-Cr-Mo coatings were studied and attempts were made to identify the second phases. Positive identification of these phases is not easy, and studles in this regard are continuing. Methods employed in microstructural analyses included light microscopy, scanning electron microscopy, electron probe microanalysis, $x$-ray difraction and microhardness measurements.

Electrochemical measurements were made on the sintered porous Co-Cr-Mo and arc plasma sprayed porous $\mathrm{Ti}-6 \mathrm{Al}-4 \mathrm{~V}$. Anodic polarization measurements were made in physiological saline solution at a pH of 7.4 and a temperature of $37 \mathrm{C}$. Results for the porous Co-Cr-Mo materlals showed an increase in current density but no change in the breakdown potential. The results with the porous $\mathrm{Ti}-6 \mathrm{Al}-4 \mathrm{~V}$ show an increase in current due to the increased surface area and a lower breakdown potential which probably is caused by contamination that occurs during the application of the arc plasma sprayed coating. The breakdown potential of the uncoated Ti-6Al-4V is +2.4 volts vs. a standard calomel electrode (s.c.e.) and the breakdown potential of the coated material ranges from to.7 to +1.2 volts vs. s.c.e.

Mechanical property measurements consisted of corrosion-fatigue tests to determine the effects of applying porous metal coatings and were conducted in fully reversible torsion at a frequency of $1 \mathrm{~Hz}$ and in flowing physiological saline solution at $37 \mathrm{C}$. The process of applying Ti-6Al-4V coatings by arc plasma spraying did not affect the corrosion-fatigue life adversely. Heat treating the porous coated $\mathrm{T} 1-6 \mathrm{Al}-4 \mathrm{~V}$ materlals reduced the fatigue life due to microstructural changes and contamination. Microhardness of the coating and the substrate increased after heat treating. Inttial studies of corrosion-fatigue behavior of sintered CoCr-Mo material show a slight decrease in fatigue life. The change is small and more data are needed before results can be fully analyzed.

Standard Reference Material 1891 was prepared. Sixty untts containing two specimens each of Co-Cr-Mo were delivered to the Office of Standard Reference Materials and are avallable for use with the ASTM test method F-746 for pitting and crevice corrosion. 

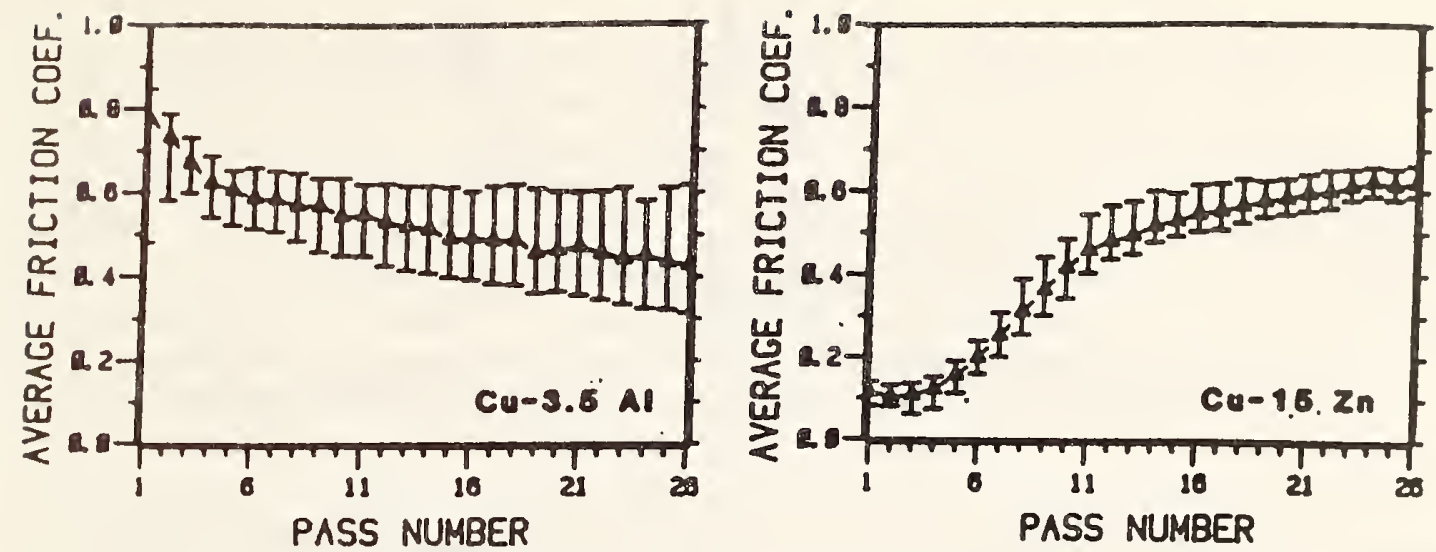

Figure 1. These two plots compare the break-in friction paths to steady state for two Cu-based alloys tested in unidirectional sliding and using similar surface preparation techniques. Compositional and microstructural reasons for the differences in behavior are the focus of such studies.

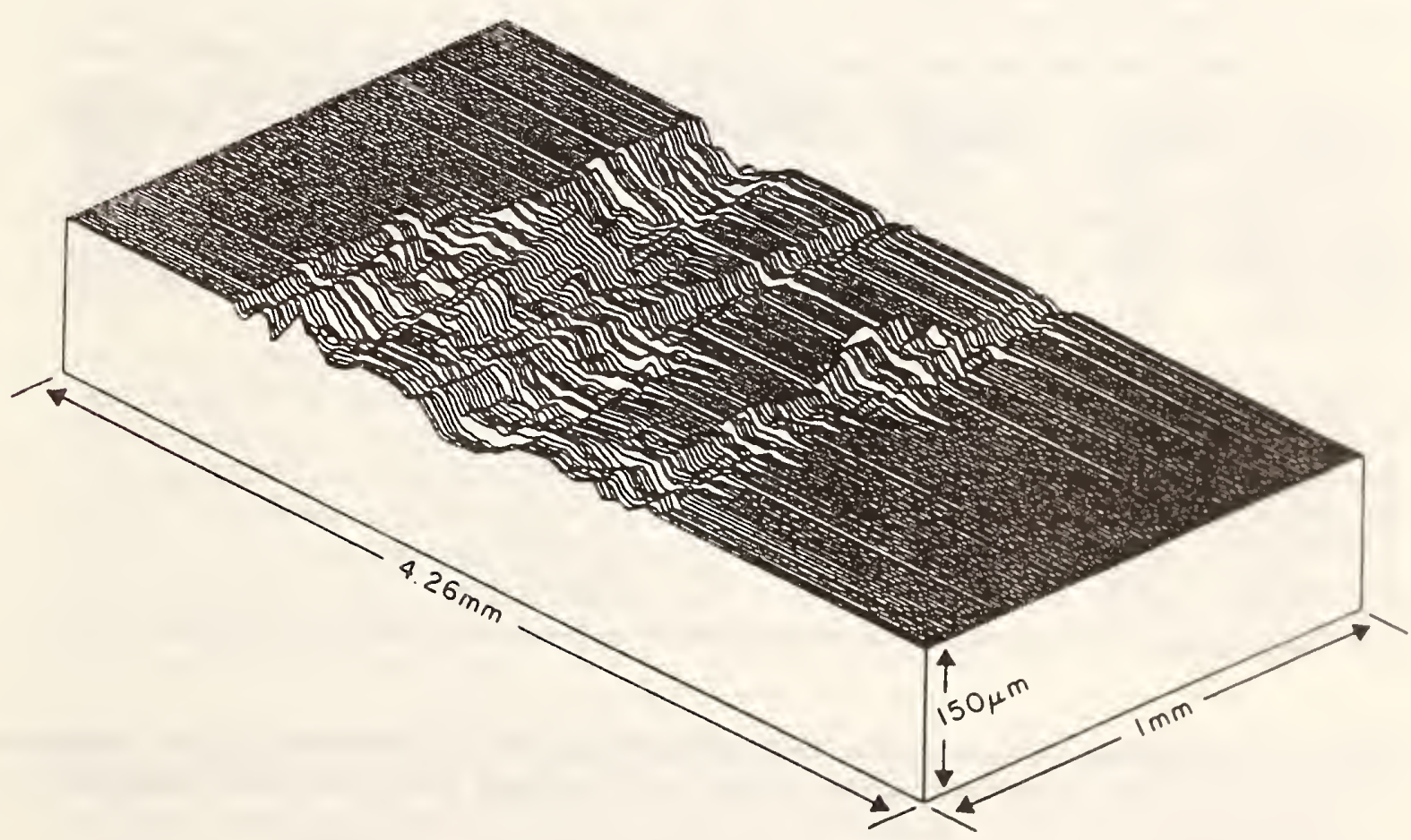

Figure 2. Profile tracing of small section of galled track on Mo speclmen. 

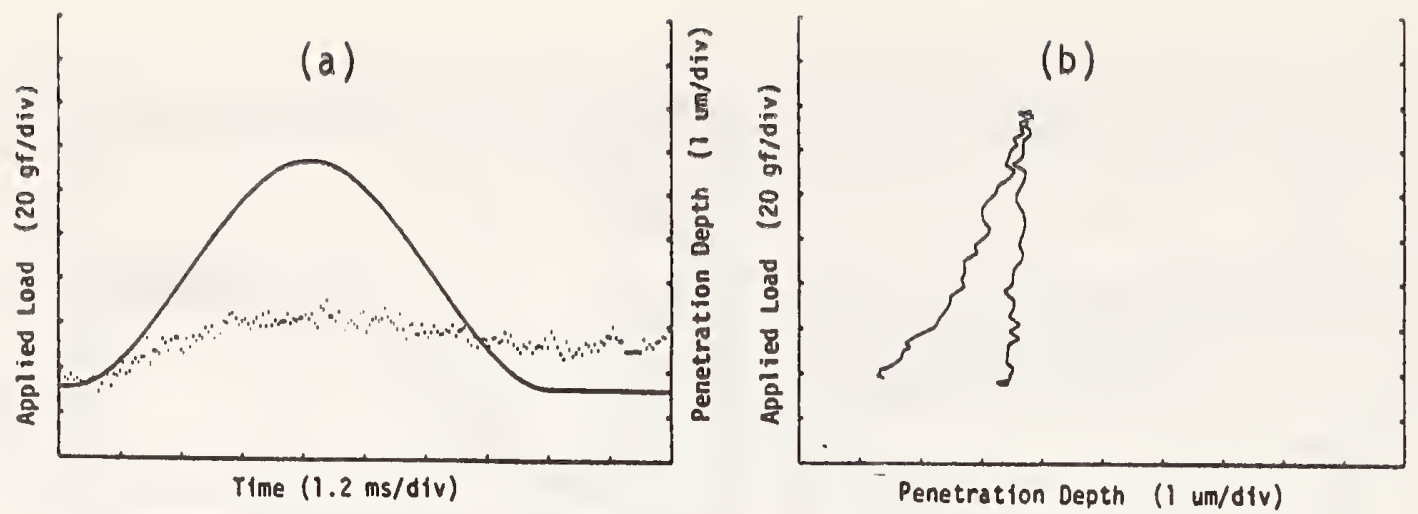

Figure 3 Dynamic results for a 100 gram Knoop indentation of a hardened and tempered 0-2 tool steel.

(a) Applied load and penetration depth curves versus time.

(b) The load-displacement curve.

Table 1. Load $x$ displacement products for the Ni-P coatings in worn and unworn condition.

\begin{tabular}{|c|c|c|c|c|c|c|}
\hline \multirow[b]{2}{*}{ UNWORN } & \multicolumn{6}{|c|}{ LOAD X DISPLACEMENT } \\
\hline & TOTAL & ELASTIC & PLASTIC & EL/PL & $1-\mathrm{WP} / \mathrm{UWP}$ & 1-WE/UWE \\
\hline $0-2$ steel & 430 & 89 & 341 & $\overline{0.261}$ & -0.04 & -0.17 \\
\hline$N 1-12 P(D C)$ & 475 & 134 & 341 & 0.393 & 0.17 & 0.22 \\
\hline $\mathrm{NI}-5 \mathrm{P}(\mathrm{DC})$ & 504 & 178 & 326 & 0.546 & 0.04 & 0.58 \\
\hline$N i-12 P(P P)$ & 430 & 89 & 341 & 0.261 & 0.13 & -0.66 \\
\hline$N 1-5 P(X)$ & 327 & 45 & 282 & 0.160 & 0.13 & -1.98 \\
\hline \multicolumn{7}{|l|}{ WORN } \\
\hline$\overline{0-2}$ steel & 460 & 104 & 356 & 0.292 & & \\
\hline$N i-12 P(D C)$ & 386 & 104 & 282 & 0.369 & & \\
\hline $\mathrm{Ni}-5 \mathrm{P}(\mathrm{DC})$ & 386 & 74 & 312 & 0.237 & & \\
\hline $\mathrm{Ni}-12 \mathrm{P}(\mathrm{PP})$ & 445 & 148 & 297 & 0.498 & & \\
\hline $\mathrm{N} 1-5 \mathrm{P}(\mathrm{X})$ & 379 & 134 & 245 & 0.547 & & \\
\hline
\end{tabular}

Table 2. A comparison of the Knoop Hardness as a function of the duration of the applied loading for an aluminum alloy matrix composite.

$\begin{array}{llllll}\text { LOAD DURATION (seconds) } & 100 & 10 & 1 & 0.1 & 0.01\end{array}$

$\begin{array}{lllllll}\text { KNOOP HARDNESS }\left(\mathrm{kg} / \mathrm{mm}^{2}\right) & 80 & 156 & 160 & 147 & 133\end{array}$


CHEMICAL METALLURGY

Task 15445

The principal activity of this task is the collaborative effort with the American Society for Metals (ASM) in the joint ASM-NBS Alloy Phase Diagram Data Center. This program continues to provide critically evaluated phase diagrams and other constitutional data as well as related bibliographic material. ASM provides overall program guidance, bibliographic support, and dissemination of program outputs. NBS provides overall technical guidance to insure the data reliability and accuracy of the evaluated phase diagrams, development of a model evaluation procedure and style guide by the three binary category editors (titanium, aluminum, and iron) located within the group for use by the other binary category editors, and the development of a prototype database for on-line retrieval of the phase diagram and related data. The program has a strong international content through the alloy category editors who are responsible for the selection and evaluation of the data. Currently, there are thirty binary and 20 ternary category editors participating in this program. During the past year, the three NBS category editors completed evaluations on thirteen titanium, seven aluminum, and three iron systems. The titanium binary alloy systems have now been completed and preparations are underway to issue the evaluated titanium phase diagrams as an ASM monograph.

A major new effort was initiated during the year to digitize over 1500 binary phase diagrams for the new ASM compendium updating the compilations of Hansen, Elliott, and Shunk. All of the evaluated diagrams will be included in this new book together with diagrams from other sources. When finished, a complete on-line database will be available with consistent pure element properties, nomenclature, diagram style and format, and agreement with basic thermodynamic rules of construction.

The experimental efforts in support of the alloy phase diagram work continued with emphasis on aluminum-manganese and titanium-aluminum binary alloys. Recrystallization of the recently discovered quasicrystalline icosahedral and decagonal phases in rapidly solidified Al-Mn alloys was studied as part of the evaluation of the metastable phases in the Al-Mn phase diagram. Additional studies have been carried out on the single phase field on the titanium rich side of the Ti-Al system to aid in the interpretation of features observed in earlier DTA experiments.

Other activities in this task include an experimental program to improve standards for magnetic particle inspection and dye penetrant testing, and to evaluate the need for standards and specifications in the field of Barkhausen Noise NDE. These efforts involve substantial interactions with standards writing organizations such as ASTM. 


\section{FY 85 Significant Accomplishments}

- Graphics programs to provide publication quality diagrams for the Bulletin of Alloy Phase Diagrams and provide input programs for the phase diagrams database were made fully operational.

- An inter-phase diagram database has been set up to allow for efficient searching of the metallurgically important information embedded in a phase diagram. This subset is extracted by a newly written program which performs a topological analysis of the curves in the phase diagram.

- Graphing algorithms to allow isotherms or isopleth color representation of ternary phase diagrams have been developed. Algorithms which allow real time translation and rotation of diagrams on the (b/w) Evans and Sutherland terminal are now available.

- Theoretical and experimental results in the area of magnetic particle inspection led to the incorporation into a new military standard of a new method for using Hall-effect probes to determine proper magnetization levels for effective inspection.

\section{Alloy Phase Stability} Subtask 1 of Task 15445

L. K. Charlton ${ }^{1}$, R. M. Hayes, D. J. Kahan, A. J. McAlister, J. L. Murray, C. L. Qualey ${ }^{1}$, H. E. Rubin, J.S. Sims ${ }^{1}$, C. E. Sirofohuck ${ }^{1}$, L. J. Swartzendruber, and L. B. Wilkinson

${ }_{1}^{1}$ American Society for Metals Research Associate

We are pursuing a program of four interconnected parts: critical evaluation, compilation and thermodynamic modeling of binary phase diagram data; designing and setting up a prototype database for on-line retrieval of the graphical and numeric phase diagram and ancillary data (crystal structure, lattice parameters); experimental work on phase stability of alloy systems, selected with a view to complement the evaluation program; and the theory of phase stability.

\section{Alloy Phase Diagram Data Center Activities}

All activities revolve about a collaborative data evaluation program for alloy phase diagrams with the American Society for Metals. At NBS, the scope of the phase diagram program has been greatly extended. During the last year, the Alloy Phase Diagram Data Center has continued to be the focal point for the entire ASM/NBS Phase Diagram Program.

Phase diagram evaluation projects are being carried out by three category editors at NBS, Joanne L. Murray for Titanium alloys, Archie $\mathrm{J}$. MCAlister and Joanne L. Murray for Aluminum alloys, and Lydon $\mathrm{J}$. 
Swartzendruber for Iron alloys. Thirteen Ti-, seven Al-, and three Fe-based systems have been assessed this year including: elemental $\mathrm{Ti}$, $\mathrm{Ti}-\mathrm{B},-\mathrm{C},-\mathrm{Ca},-\mathrm{Er},-\mathrm{Eu},-\mathrm{Gd},-\mathrm{Mg},-\mathrm{N},-\mathrm{Nd},-\mathrm{O},-\mathrm{Pu},-\mathrm{S}, \mathrm{Al}-\mathrm{Ag},-\mathrm{Au}$, $-\mathrm{Cr},-\mathrm{Hg},-\mathrm{Mn},-\mathrm{Ni},-\mathrm{P}, \mathrm{Fe}-\mathrm{Cu},-\mathrm{Ni},-\mathrm{Nb}$. Coverage of the system includes crystal structures, metastable and constrained equilibria, and high temperature thermodynamic properties as well as the stable equilibrium diagrams. Calculations of the phase diagram from thermodynamic data are carried out using a number of computer programs available at NBS.

In addition data center staff are responsible for technical editing and graphics digitization for the Bulletin of Alloy Phase Diagrams, for the prototype database project, the editing and computer graphics for a book, Constitution of Binary Alloys, which is to update the compilations of Hansen, Elliott, and Shunk.

Major changes have been made in procedures for peer review, editing and computer graphics for the Bulletin which have greatly increased the efficiency of the staff. A style Guide for authors has been written and distributed; it defines thermodynamics, crystallographic and phase nomemclature as well as standard format for the evaluations. Reviewers are provided with guidelines for the assessment of the manuscripts. Procedures for graphics data entry have also been standardized. Graphics and crystal structure data are now loaded into the on-line database immediately upon publication of the Bulletin. A backlog of previously published diagrams is also being revised and loaded to the database. Technical editing of manuscripts is done by the editor and associate editor, J. L. Murray and B. Burton, ASM Research Associate.

The prototype user-friendly phase diagrams database of graphical and numerical information is now complete. Before it can be made commercially available on-line it must be tested by a small number of users, revised to their specification and documented. More importantly the bulk of the data needs to be loaded, a very time-consuming data entry task.

The digitization of figures for the book, Constitution of Binary Alloys was undertaken at NBS to take the opportunity to load the database while providing figures for the book that would otherwise have been drawn by draftsmen. This is a major effect, involving the digitization of over 1500 phase diagrams in approximately a four-month period. New diagrams available through the data program are used, the remainder coming from standard compilations. The project requires considerable editing on the part of NBS technical staff, increased support for the VAX software and hardware, tracking and quality control of phase diagrams, in addition to the actual data entry. To date 700 diagrams have been digitized and it is anticipated that camera-ready copy will be available for the entire collection of diagrams by the end of 1985 .

This project represents a major accomplishment of the data center in several respects. First, a complete on-line database will be available. Second, the diagrams are mutually consistent in pure element 
properties, phase nomenclature, and drawing conventions, a first for phase diagram compilations. Diagrams are required to "pass" computer checks for the validity of phase diagram construction. They are also checked by the editors for violations of basic thermodynamic rules of construction. As a result, the diagrams being entered are all of extremely high quality.

\section{Experimental Phase Diagrams}

A major fraction of the past year's experimental effort was devoted to the study of the complex recrystallization of the quasicrystalline icosahedral and decagonal phases formed on rapid quenching of Al rich Al-Mn alloys. Heats of transformation and activation energies have been determined by differential thermal analysis (DTA), and the phases occuring during the process identified by $x$-ray diffraction and transmission electron microscopy. Apart from their inherent interest, these results have proved most useful in the evaluation of the Al-Mn phase diagram. Metastability of the $\mathrm{Al}_{10} \mathrm{Mn}_{3}$ phase was confirmed and that of ' $\mathrm{Al}_{4} \mathrm{Mn}$ ' established. Certain other features of recent experimental studies of the system were confirmed. The measured heats of transformation facilitated modeling of the non-equilibrium phases and permitted estimates of the true liquidus in this region of the diagram to be made.

The topological similarity of the Al-rich $\mathrm{Al}-\mathrm{Cr}$ and $\mathrm{Al}-\mathrm{Pd}$ systems, in which the icosahedral phase is known to occur, as well as Al-Mo strongly suggests that these systems too may contain long lived metastable phases, and that their presently accepted equilibrium diagrams are incorrect. Studies of these systems similar in scope to that of $\mathrm{Al}-\mathrm{Mn}$ will be undertaken in the coming year.

Expansion of our DTA capability is underway. Equipment is being acquired which will raise the maximum achievable temperature from $1200^{\circ} \mathrm{C}$ to $2000^{\circ} \mathrm{C}$. Moreover, the equipment is being tallored to permit use of the Dils blackbody temperature sensor in lieu of the traditional thermocouples. This will enable more precise determination of tranformation temperatures in the $600^{\circ} \mathrm{C}$ to $2000^{\circ} \mathrm{C}$ range, and offer improved accuracy in the heats of tranformation, as well as expanding the scope of our work.

The low temperature 'thermal event' observed within the single phase $\alpha_{2}$ (ordered hcp) field on the Ti-rich side of the Ti-Al binary has been further studied this year. Earlier work had been done on samples of low oxygen and nitrogen $(\mathrm{O} / \mathrm{N})$ content. Selected samples of relatively high gas content were studied, and display the same thermal effect, which suggests ordering at the composition $\mathrm{Ti}_{3} \mathrm{Al}$. At this composition, the effect, a weak one, appears at $-740^{\circ} \mathrm{C}$. Mechanical properties change at this temperature, ductility for example being higher above $740^{\circ} \mathrm{C}$. Three independent attempts have been made to associate this phenomenon with a structural change, via high temperature $x$-ray, neutron and electron diffraction. No change was discernable in the superlattice diffraction peaks between room temperature and $900^{\circ} \mathrm{C}$. At 
present, interstitial ordering is suspected as the cause. A similar situation is encountered in the $\alpha$ (ordered bcc) field in Fe-rich Fe-Al alloys. Distinct reversible changes are observed thermally and in mechanical properties, without structural change detectable by $\mathrm{X}$-ray or neutron diffraction. In this latter case, vacancy ordering is the likely culprit. The two cases should be thermodynamically similar, and thermodynamic modeling will be undertaken to assess the validity of these views.

The experimental staff will be augmented in the coming year by the arrivals of U. Kattner, a guest worker from the Max Planck Institute and D. Moffat, an NRC post doctoral fellow from the University of Wisconsin.

NDE Activities

Subtask 2 of Task 15445

L. J. Swartzendruber

A number of the results obtained previously in the area of magnetic particle testing have now been incorporated into a new military standard on magnetic particle inspection, MIL-STD-1949, which supersedes the Air Force document MIL-I-6868E, and the Army document MIL-M-11472 (actual preparation of the document was funded by AMMRC). The new standard includes a method for using Hall-effect probes or equivalent to determine proper magnetization levels for effective inspection. This is possible because we have shown, both theoretically and experimentally, that the tangential value of the $\mathrm{H}$ field at the surface of the part being inspected is the primary factor which determines the magnitude of the leakage field from a defect of a given size. Previously it had been assumed that optimum results would be obtained when the value of $\mathrm{B} / \mathrm{H}$ was a maximum, thus making the best value of applied field very difficult to measure and strongly dependent on the material under test. Our results have shown that, for the majority of materials, the optimum applied fields drive the material well into the saturation region. In this case the material properties are of secondary importance for determining the optimum applied field. Correctly instrumented Hall probes can then be used to test for proper magnetization when using either alternating or direct currents.

Another important factor in improving standards for magnetic particle inspection is testing of magnetic inks and powders for proper physical characteristics, including particle size, shape, and magnetic properties. Current specifications, both in the existing ASTM document, and in the Military standard are inadequate in this regard. Future work will be concerned with improving this area, primarily in cooperation with the ASTM subcommittee.

In the area of dye penetrant testing we have participated in designing and conducting a round-robin test of three proposed new ASTM dye penetrant documents (this was done in cooperation with J.J. Hsia and 
K.L. Eckerle of the Radiometric Physics Division, Center for Radiation Research). The round-robin results for one of these draft documents were considered encouraging enough to warrant submission for subcommittee balloting. Results for the other two documents, one for measuring thermal stability and the other for measuring ultraviolet radiation stability, appeared unacceptable. Improvements of the techniques spelled out in these two documents and a new round-robin are in the planning stage. This work has pointed out the considerable importance for a strong effort at NBS to provide a mechanism for the calibration of the ultraviolet intensity meters used in NDE and for providing standards against which the fluorescence of dye penetrants (and magnetic inks) may be compared.

Because of the potential need for standards and specifications in the field of Barkhausen noise NDE, an evaluation of this field, its applications, and possible requirements for specifications and standards, is being conducted. Although the field of Barkhausen noise is an old one, serious efforts on NDE applications appear to have started around 1975 with the design of commercial apparatus by the Southwest Research Institute in the United States, by the Technical Research Center in Finland, and by a number of groups in the USSR. Barkhausen noise analysis on metals using inductive sensors is basically a surface technique, being most sensitive to material within approximately $0.3 \mathrm{~mm}$ of the surface. A number of studies have shown that Barkhausen noise from deeper regions in a metal can be observed by sensing the acoustic emission which accompanies a Barkhausen discontinuity. This has also been called "magnetomechanical acoustic emission" and is due to the presence of magnetostriction. Although this technique is generally less sensitive than the inductive method, it can be expected to have a number of specialized applications.

Barkhausen noise analysis (BNA) has been shown to be correlated to various material properties including grain size, hardness, internal stress, and microstructure. It has also been suggested that BNA could be used for flaw detection. Besides its evident application in quality control of magnetic material such as silicon steel and ferrites, one of the most interesting possibilities for BNA is in automated on-line testing in a steel mill, heat treating plant, or similar facility. There appear to be two important areas where NBS might make a contribution to the field of NDE using Barkhausen noise. One is in the area of coil characterization, and the other the provision of reference materials with well characterized noise spectra which could be useful for system comparison and calibration. 
The activities in this task are designed to combat the effect of metallic corrosion, which continues to cause severe economic losses in virtually all sectors of industrial and government endeavor and also poses a serious threat to safety and reliability. Our efforts in FY 85 can be divided into four main areas, namely basic research into the mechanisms of the major forms of corrosion, many of which remain poorly understood; the development of measurement techniques, both for laboratory and field use; the evaluation, organization and dissemination of corrosion data from the literature, conducted in joint National Association of Corrosion Engineers (NACE)-NBS Corrosion Data Program; and studies of problems associated with the disposal of high level nuclear waste in geologic repositories.

The mechanistic studies continued to focus on two forms of localized corrosion, namely environmentally induced cracking and pitting. The former centered on stress corrosion cracking (SCC) and hydrogen embrittlement (HE), both of which are delayed failure phenomena which lead to catastrophic and often unexpected failures in virtually all engineering alloys. Current examples of SCC include the cracking of austenitic stainless steels and nickel alloys in nuclear reactors; HE most commonly occurs in steels, particularly in sulfide bearing media such as those encountered in sour oil wells. Research on the structure of passive films, traditionally a major strength at NBS, continued in FY 85 . These thin oxide films are responsible for the excellent corrosion resistance of materials such as austenitic stainless steels, aluminum and titanium, but unfortunately they undergo local breakdown in the presence of certain chemical species, leading to the widespread practical problem of pitting.

In FY 85, the development measurement techniques focused on the corrosion of steel reinforcing bars in concrete, a major problem in bridges and highways where salt is used for deicing. Our efforts here are designed to develop an in-situ technique for measuring the corrosion rates of the steel in the field. This activity is sponsored by the Federal Highway Administration. Other ongoing programs involve the use of the linear polarization method to measure corrosion rates of steel in soll, an activity supported by the American Iron and steel Institute, and the development of the electrochemical noise technique to study pitting and other localized corrosion processes. The latter is also being used in the nuclear waste program described below.

The Corrosion Data Center, the NBS component of the Joint NACE-NBS program, has continued to grow in FY 85. Begun in FY 83, the program was developed in response to the clear need for a central source of reliable, evaluated data which are essential in the selection of materials to combat corrosion. Rapid access to the data by means of a central computerized system is an essential feature of this program. A highlight of thls year's activities was the organization of a Corrosion Data Workshop, in whlch representatives of various sectors of industry and government came together to identify the major needs in corrosion data. 
A new activity in FY 85 concerns a critical national problem, the disposal of high level nuclear waste. Beginning in the next decade, waste packages w11l be burled at several different geologlc sites and will be expected to maintain their integrity for times much in excess of normal service 11 fetimes. Localized corrosion, particularly SCC and pitting, have been identified as a major threat to the metall1c outer containers, and, in view of our expert1se in these areas, we have inltiated a long term program with the Nuclear Regulatory Commission to address this complex yet critical set of problems.

Our programs were strengthened during the year by the participation of several guest workers: T. B Cassagne, The Johns Hopkins UnIversity; V. H. Desa1, University of Central Flor1da; A. J. Forty, University of Warwick, Unlted KIngdom, and F. Q1u, Fujlan Inst1tute of Research on the structure of Matter, Peoples Republic of China.

\section{FY 85 Significant Accomplishments}

- Substantial progress has been made towards understanding the discontinuous nature of cleavage crack propagation in ductile fcc alloys undergoing transgranular stress corrosion cracking

- Modeling of the chemistry and electrochemistry inside transgranular cracks has been extended to $\mathrm{Cu}-\mathrm{Au}$ alloys in chloride solutions. The results confirm that hydrogen embrittlement can be excluded as a cause of brittle fracture.

Portable computer systems have been developed to measure corrosion rates in the field and are being used to monitor the corrosion of steel reinforcing bars in concrete bridge decks and underground steel piling.

A Corrosion Data Workshop, organized Jointly with the National Association of Corrosion Engineers (NACE), was attended by approximately fifty corrosion specialists from industry, government, and academe; the Proceedings w1ll be used to help direct the future activities of the NACE-NBS Corrosion Data Program.

Analysis of the statistical properties of the random fluctuations of the passive current during pit initiation has shown that the process cannot be modeled by renewal processes or homogeneous Markov chains, but more complicated stochastic models have to be employed.

Environmentally Induced Cracking

Subtask 1 of Task 15446

\section{Stress Corrosion Cracking}

E. N. Pugh, U. Bertocci, T. Cassagne 1, V. H. Desai ${ }^{2}$, J. L. Fink, A. J. Forty ${ }^{3}$, M. J. Kaufman, and R.D. Shull.

${ }_{2}^{1}$ Guest Worker, Johns Hopkins University

2 Guest Worker, University of Central Florida

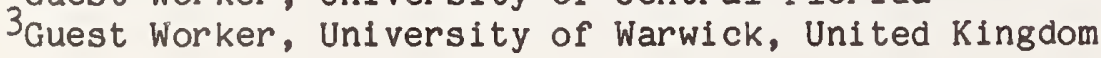


During FY 85, we continued to concentrate on the transgranular stress corrosion cracking (SCC) of ductile fcc materials. Our studies have focused on what we consider to be the two primary issues in T-SCC, firstly, how is a brittle cleavage crack initiated in these ductile materials during T-SCC and, secondly, once initiated, why does it stop. In the terms of the latter issue, our experimental observations of the T-SCC fracture surfaces of susceptible alloys, such as $\alpha$-brass and austenitic stainless steels, and less susceptible materials, such a high strength $\mathrm{Al}-\mathrm{Zn}-\mathrm{Mg}$ and pure $\mathrm{Cu}$, have indicated the possible signiflcance of the cleavage step formation process in arresting a brittle cleavage crack. For Instance, it appears that the cleavage steps, which connect the parallel, but displaced, cleavage facets on transgranular fracture surfaces are formed by basically different processes; for susceptible alloys, the steps form by some low energy process such as localized plastic shearing or dissolution, whereas for the less susceptible materials, they form by higher energy processes such as plastic necking (pure $\mathrm{Cu}$ ) or secondary cleavage $(\mathrm{Al}-\mathrm{Zn}-\mathrm{Mg})$. For the two plastic processes it seems probable that the velocity of cleavage step formation is much less than that of brittle cleavage. As a result during brittle crack propagation the unfractured ligaments (the material which eventually fractures to form cleavage steps) which are believed to lag behind the main crack front, will lengthen. Since these ligaments are load bearing and become increasingly so as they lengthen, their restraining effect will increase as the crack propagates. Thus, it seems likely that the ligaments will effectively lower the stress Intensity at the crack tip to values insufficient for sustaining cleavage, thereby arresting the crack. This process is illustrated in figure 1. When the unfractured ligaments reach a critical value, $1_{s}$, the crack will propagate, provided "embrittlement" has occurred, until the stress intensity at the crack tip falls below the critical value for cleavage. As indicated, arrest occurs when the ligament length reaches $l_{a}$ and the propagation distance $\Delta x$, simply equals $1_{a}{ }^{-1} \cdot$

To pursue the above ideas concerning the role of unfractured ligaments, we have continued our work on the high purity $\mathrm{Al}-\mathrm{Zn}-\mathrm{Mg}$ aqueous chloride system. Originally, it was felt that by varying the hardness of the material, it might be possible to alter the process by which the cleavage steps are formed and, thereby, affect to some extent the susceptibility to transgranular cracking. As a result, samples were tested in the underaged, fully hardened and overaged conditions. For all conditions transgranular cracking was observed (e.g. figure 2), but the cleavage steps varied significantly in appearance as suspected. Further work almed at understanding these differences in cleavage step appearance and their importance during crack propagation is underway.

Efforts are also underway to investigate the intergranular stress corrosion cracking (SCC) of the 7000 series aluminum alloys when exposed to aqueous $\mathrm{NaCl}$ solutions or wet atmospheres. In particular, attempts are being made to determine whether the fracture in these systems occurs by stress assisted anodic dissolution or hydrogen embrittlement (HE). The role played by the $\mathrm{MgZn}_{2}$ precipitate that forms at the grain boundary in these alloys is being determined by careful analysis of the effect of precipitation on the crack velocity. Varlation of the precipitate size and distribution is belng per- 
formed by careful control of the alloy heat treatment and composition." The width of the precipltation free zone (PFZ) near the grain boundaries is belng monitored, and any grain orlentation effect on the crack velocity is being checked. Several speciallzed experimental methods (e.g. small angle scattering, neutron activation and inelastic scattering) are also presently being evaluated to determine their usefulness in the detection of small amounts of the metastable aluminum hydride $\left(\mathrm{AlH}_{3}\right)$ phase. The presence of this phase wlll then be checked in the 7000 serles aluminum alloys subjected to the harsh environments mentioned above.

The studies concerning charge and matter transport in cracks, in order to define the localized chemistry which ultimately is responsible for the accelerated fallure, have continued. Since one of the alms of this work is to 1dentify cases where transgranular stress corrosion cracking cannot be attributed to hydrogen embrittlement, the modeling of the crack tip conditions under discontinuous crack advance was extended to the case of Cu-Au alloys in acldic chloride solutions. These alloys undergo brittle fracture which is morphologically quite similar to that of brasses. Open circuit potentlal measurements show that if a freshly abraded Cu-Au spec1men is rapidly immersed in a ferric chloride solution, an initial steep transient minimum can be observed, but, since the potential varies rapidly, the determination of the minlmum is uncertain. The modeling calculations, therefore, have been undertaken to establish what could possibly be the minimum potential attained at the crack tip at the instant of crack advance. Even taking "worst case" values for the kinetlc parameters involved in the calculations, the results have conclusively shown that hydrogen discharge cannot occur in these alloy/solution systems, indicating that brittle fracture mechanisms other than hydrogen embrittlement have to be postulated.

\section{Hydrogen Embrittlement}

C. G. Interrante and S. A. Harrison

Industrlal users of steels must often employ costly strategles to reduce the possibility of the occurrence of hydrogen embrittlement. Knowledge of bulk properties and average stress levels is often not sufficlent to predict the damaging effects of hydrogen because local property differences may enhance embrittlement susceptibllity. Work in this area at NBS has centered on relating the fundamental parameters controlling hydrogenassisted crack growth in structural and pressure vessel steels. The objective is to relate the measurable effects of hydrogen, such as crack growth rate for various stress-intenslty $(K)$ levels and the threshold value of $K$ for hydrogen-assisted cracking, to the driving force (the fugacity of hydrogen assoclated with a given metal/environment system) and to the 1mportant metallurglcal factors, such as hardness and inclusion size, shape, and orientation. These empirical relationships will be useful in predicting conditions under which cracking is to be expected. These relations can also be useful in the development of our understanding of the cracking process. When taken with other information they aid in the development of theoretical models that describe the mechanlsm of hydrogen embrittlement. In our program, the effects of hydrogen are assessed with fracture mechanics specimens of steels used commercially in the petrochemical industry, and 
with severe hydrogen-charging environments containing hydrogen sulfide, a common contaminant found in that industry. To date these NBS studies have included development of methods (and techniques) for: (1) measurement of permeation of hydrogen in steels; (2) removal of iron sulfides from fracture surfaces; and (3) automated real-time electric resistance measurement of crack length; and in cooperation with the University of Notre Dame, a method for measurement of the effective fugacity of hydrogen in steels and environments of interest to this program.

These methods have been used to study and describe conditions that promote crack branch formation in steels tested. in high-fugacity environments. An area of research initiated in FY 84 involves the use of acoustic measurements to supplement the other measurements in developing a better understanding of the cracking process and the mechanism of embrittlement. This work is being interfaced with other studies being conducted within the Division in the Nondestructive Characterization Group. Preliminary results are encouraging. The aim is to characterize the cracking process in more than one way and then measure the size of each increment of cracking, so as to gain insight into the nature of the cracking (e.g. Its intermittent character: the magnitude of the crack jumps, their location in relation to the crack front, the microstructural features, etc.) In this way, models can be developed to describe the process and mechanism of hydrogen-assisted cracking in steels. Real-time, electric resistance crack length measurements will be used to estimate the rate of strain energy released at the crack front. Acoustic energy detected over various intervals of time will be compared with and related to the estimates of the energy released. Using this information, it will be possible to evaluate whether the magnitude of the crack extension and of the fracture area associated with each acoustic emission can be estimated from the acoustic emission alone.

Both a new computer and a servo-hydraulic test system have been installed for use in these studies. The servo-hydraulic test machine will be use for precracking of fracture mechanics test specimens and for conducting fracture mechanics tests that require complex loading, such as the J-integral, constant $\mathrm{K}$, and others. This year, computer codes have been written and techniques have been developed and implemented for the measurements of acoustic energy and crack length. Next year, wedge-loaded, fixed displacement tests will be conducted using $2.25 \mathrm{Cr}-1$ Mo steel, and with various partial pressures of $\mathrm{H}_{2} \mathrm{~S}$ in an aqueous acetic acid environment. These studies of hydrogen embrittlement of steels have been conducted under the guidance of the Subcommittee on Hydrogen Effects of the Pressure Vessel Research Committee (PVRC) of the Welding Research Council (WRC).

Corrosion Rate Measurements for Practical Applications

Subtask 2 of Task 15446

E. Escalante and D. E. Mathews

In FY 85, we have continued the application of the linear polarization method to the measurement of corrosion rates in three diverse practlcal cases: 
This project, sponsored by the Federal Highway Administration, was undertaken in response to the problem of corrosion damage to concrete bridge decks and overpasses resulting from the use of delcing salts. The specific objective was to develop a non-destructive test to measure the corrosion of the steel bars in situ. A portable, battery operated, corrosion measuring system has now been assembled and applied to laboratory and field measurements. The laboratory data show very good correlation to actual weight loss, and the system is currently being used to measure corrosion on bridge decks located in Frederick County, Maryland.

Steel Piling in Soll

The American Iron and Steel Institute has supported this project since 1958. In FY 85, the first measurements of underground corrosion have been made by a computerized, portable, battery-operated system capable of performing the corrosion measurement, collecting data in memory, and calculating the corrosion rate. This system has been applied to piling located in Turcot Yard, Canada.

\section{Atmospheric Corrosion of Structural Materials}

This project, started in FY 83 as part of a program directed by the Federal Acid Rain Task Force, was completed in FY 85. Over the past year, attention was focused on the feasibility of using the three-electrode linear polarization technique to measure rates of atmospheric corrosion. Inltial laboratory tests indicated that there are limitations to the method but that rates of attack on a material in different atmospheres could be determined on a relative scale. Experiments were then conducted on samples exposed on our roof site and monitored from the laboratory. It was found very difficult to compensate for IR drop using conventional wheatstone bridge circuits or by calculating IR and subtracting it from the potential measurement. However using a current interrupt technlque the corrosion measurement was improved, resulting in better agreement between weight loss measurements and the electrochemical measurements. Thus it was concluded that the linear polarization technique is in fact a promising method for this application.

Corrosion Data Center

Subtask 3 of Task 15446

G. M. Ugiansky, U. Bertocci, D. E. Clausen', D. F. Derr, E. Escalante, M. Marek, E. N. Pugh, and A. C. Van Orden

${ }^{1}$ NACE Research Associate

The highlight of this year's activities in the NACE-NBS Corrosion Data Center was the Corrosion Data Workshop, held June 24-27. This workshop, sponsored jointly with the Office of Standard Reference Data and NACE, attracted attendees from industry, academia, and government to discuss their corrosion data needs and the technology to address those needs. Issues such as the priority of users needs, quality of corrosion data and 
how corrosion data will be accessed and used in the future were discussed. A draft version of a standard format for data taking and database input was produced and will be submitted to ASTM for possible inclusion in Committee G1 as a standard format. The results from this workshop will be published and available to the corrosion community and will be used by the Corrosion Data Program to help plan future work.

Work continued on the three pilot projects on kinetic data described in the previous report:

\section{Atmospheric Corrosion}

The database for atmospheric corrosion of structural materials was extended in FY 85 by the inclusion of literature data back to 1934; new data are being added as they become available. This year, the software that generates the map of corrosion across the United States was modified to allow easier access and manipulation of the data, and, at the same time, the generation of graphics has been improved. Through the correlation of the atmospheric corrosion data and the atmospheric pollution data, preliminary damage function equations have been developed that allow calculation of corrosion deterioration from pollution data for the six metals studied.

\section{Localized Corrosion}

Software has been developed for graphical display of data for pitting and crevice corrosion of austenitic stainless steels in aqueous chlorides. The computer program permits autoscaling and statistical analysis of the data. The database is also being expanded by incorporation of additional data from the literature.

\section{Uniform Corrosion}

Data from the NACE Corrosion Data Survey is being digitized and entered into our database. Software has been developed to display these data in a similar but improved format to that in the Survey; also the file can be searched by material, environment, concentration, temperature and corrosion rate, and the data printed in tabular form.

Sof tware has also been developed to represent selected uniform corrosion data in the form of isocorrosion charts. The program permits the temperature and concentration for any point on the graph to be displayed digitally.

In the area of thermodynamic corrosion data, attention has focussed on developing programs for calculating and plotting Pourbaix diagrams on a personal computer. During FY 85, software was completed to generate h1gh temperature diagrams using the Criss and Cobble approximation for est1mating high temperature thermodynamic properties. 
Nuclear Waste Disposal

Subtask 4 of Task 15446

C. G. Interrante, U. Bertocci, E. Escalante, S. Harrison, M. Kaufman, E. N. Pugh, F. Qiul, R. D. Shull, and G. M. Uglansky

${ }^{1}$ Guest Worker, Fujian Institute of Research on the Structure of Matter, Peoples Republic of China.

Two programs on nuclear waste disposal were initiated in FY 85, both supported by the Nuclear Regulatory Commission (NRC). In April, a program was begun in support of NRC's High Level Waste Management Program, which is designed to achieve a permanent solution to the problem of disposing of nuclear waste generated principally from civilian power plants. The work, centered in the Corrosion Group, will involve scientists from throughout the Bureau who will assess information concerned with long-term ( 300 to 1000 years) performance of the nuclear-waste package that will be enclosed in a geologic repository. Major problems threatening the integrity of the package are pitting, stress corrosion cracking, and hydrogen embrittlement, which are the main thrust of research in the NBS Corrosion Group. While about twenty percent of the NBS effort is expected to be laboratory work, the main task will be the evaluation of both data and technical models (used for extrapolation) being developed by the Department of Energy (DOE); the evaluated data will enable NRC to provide guidance to DOE on the waste package portions of the disposal system. The NBS work this fiscal year has involved familiarization with background literature, attendance of meetings at NRC and DOE and other meetings, and the establishment of an NBS team of specialists for our long-term future participation in this program.

The second program, sponsored by NRC's Office of Nuclear Regulatory Research, deals specifically with pitting corrosion which, as indicated above, is considered a potential threat to the integrity of the waste package. The program is concerned with the statistics of pitting. Once a pit is initiated, the mechanisms of its growth are reasonably understood; however, the causes of pit initiation are still obscure. Since pitting is, on the whole, a rare event, a number of researchers maintain that the phenomenon is a stochastic process, and some statistical models have been recently proposed. These models assume that the underlying stochastic processes have rather simple properties, but an experimental check that this is the case has not been carried out.

In the past year, a statistical analysis of the current fluctuations observed before pit initiation on $\mathrm{Fe}-\mathrm{Cr}$ alloys has been completed. The results have shown that the process cannot be modeled by single renewals processes or homogeneous Markov chains, but more complicated models have to be employed. Figure 3, for instance contains plots of the intensity of the process of breakdown of the passive film for 4 experiments, each one estimated in three different ways. Wide fluctuations with time are evident, indicating that pit initiation cannot be modeled by a simple Poisson process. This work is being extended to pure iron in chloride-containing solutions, and the development of adequate statistical models has been initiated. 


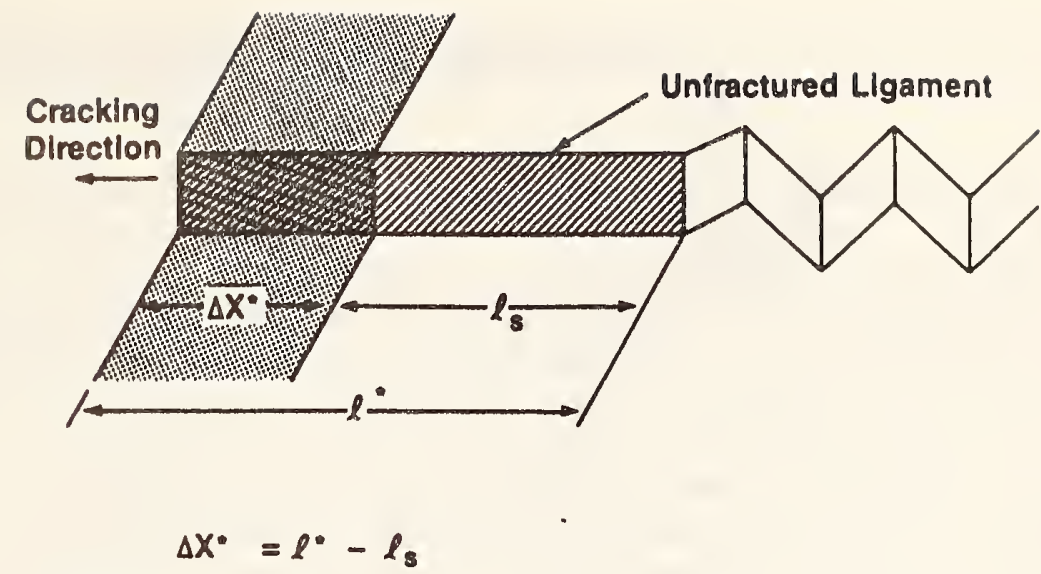

where:

$$
\begin{aligned}
\Delta X^{*} & =\text { Crack advance distance } \\
\ell_{3} & =\text { Length of unfractured ligament before propagation } \\
\ell^{*} & =\text { Length of unfractured ligament after propagation }
\end{aligned}
$$

Figure 1. Schemat1c 1llustration depicting the manner in which the unfractured ligaments are belleved to lengthen during'a brittle cleavage event resulting in crack arrest.

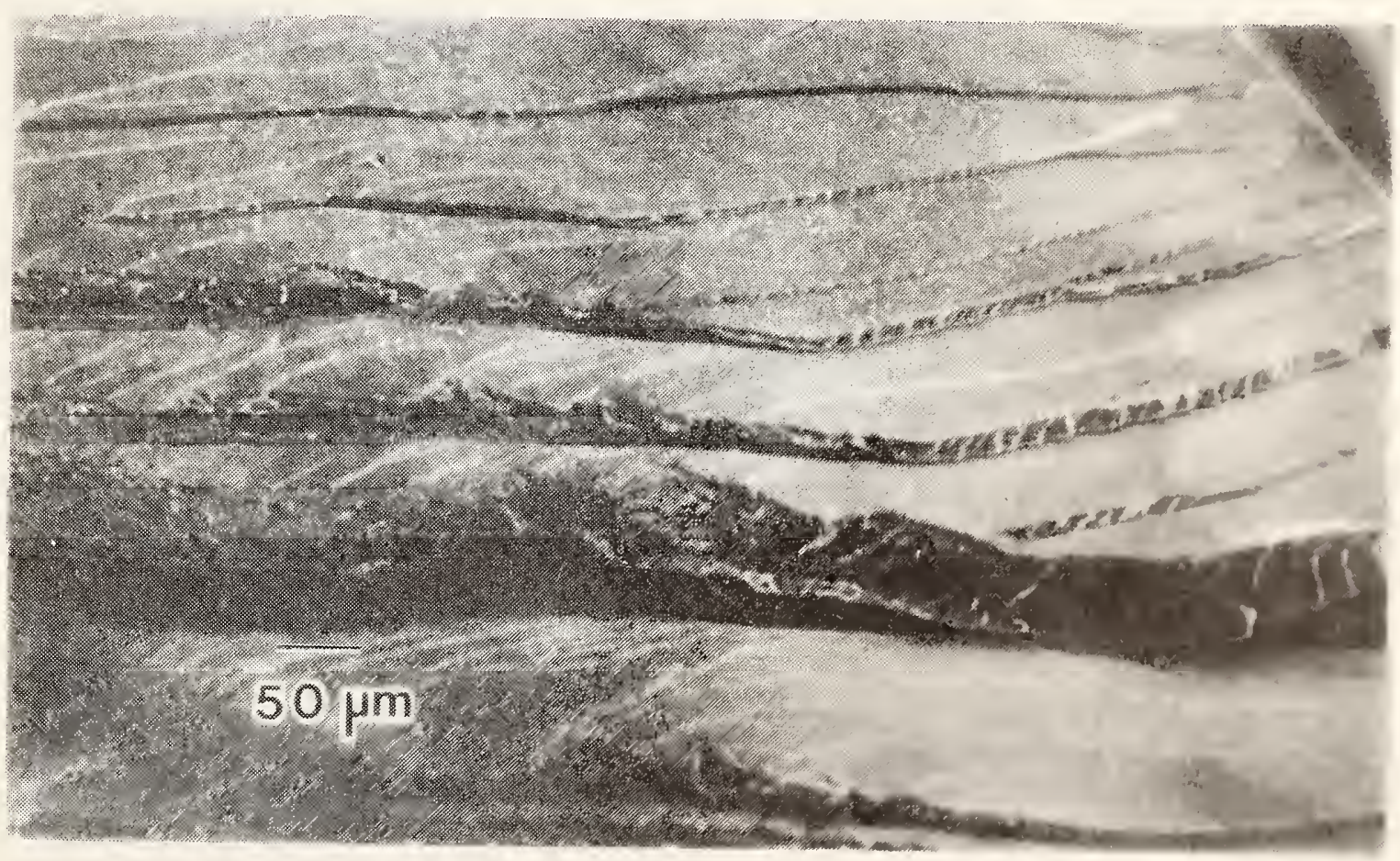

Figure 2. Low magnification secondary electron 1mage of a transgranular fracture surface of an overaged $\mathrm{Al}-\mathrm{Zn}-\mathrm{Mg}$ alloy displaying the brittle "cleavage-like" appearance. 


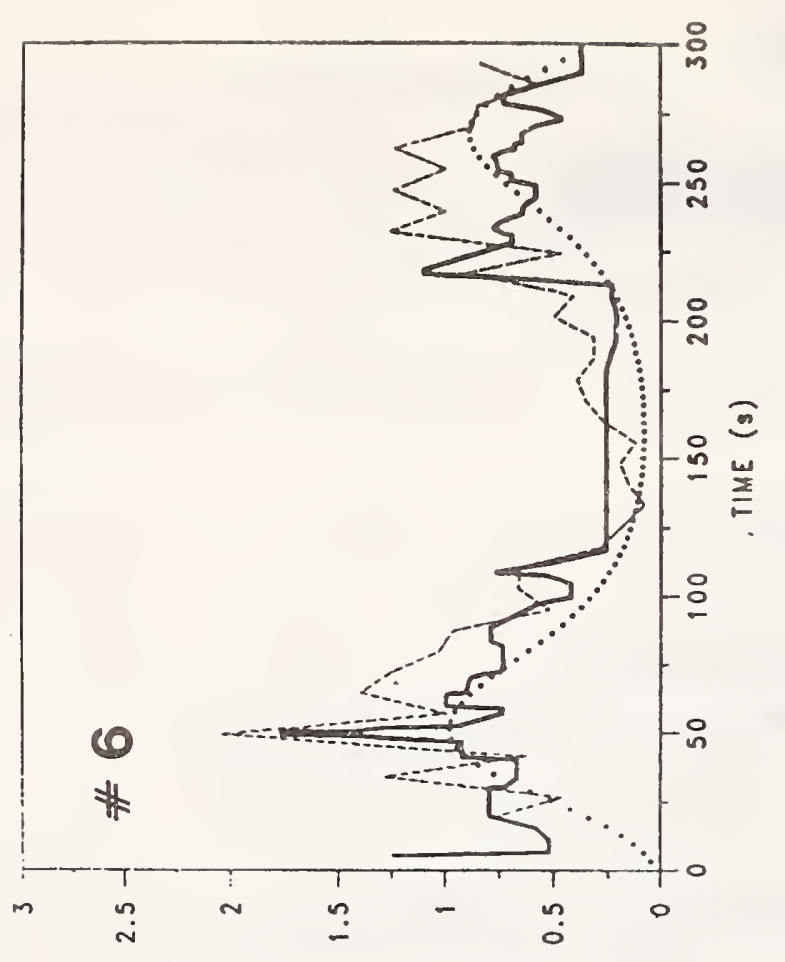

$(s / \sin \theta A \theta)(1) Y$ AIISNIINI

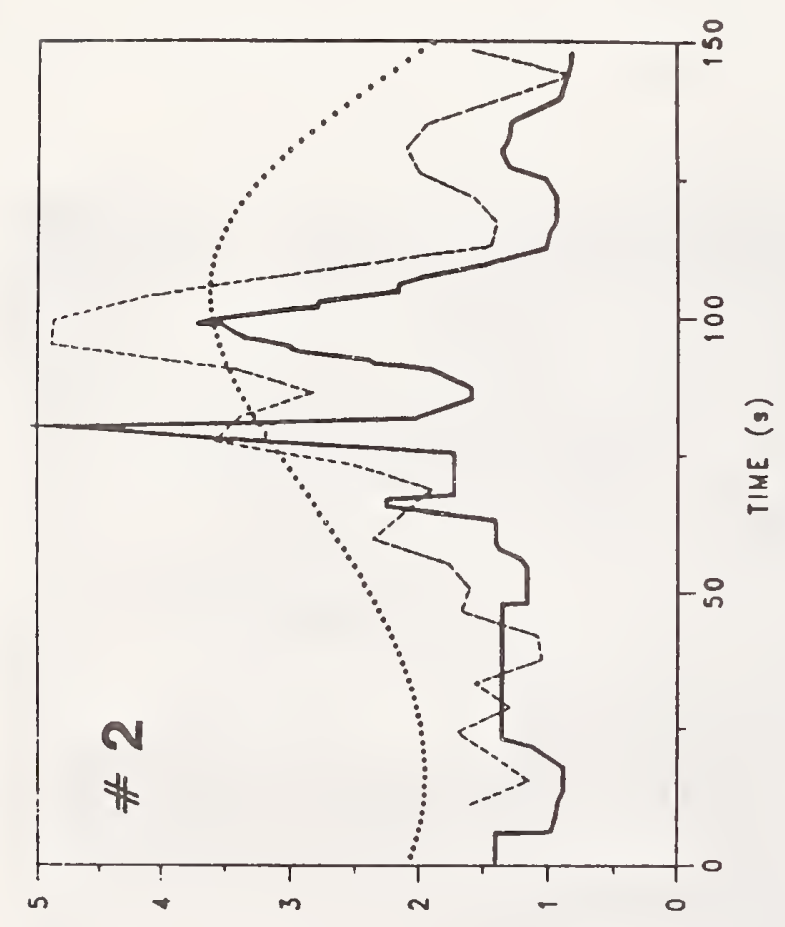

$(s /$ s/UOAO) (1)K ALISNJINI

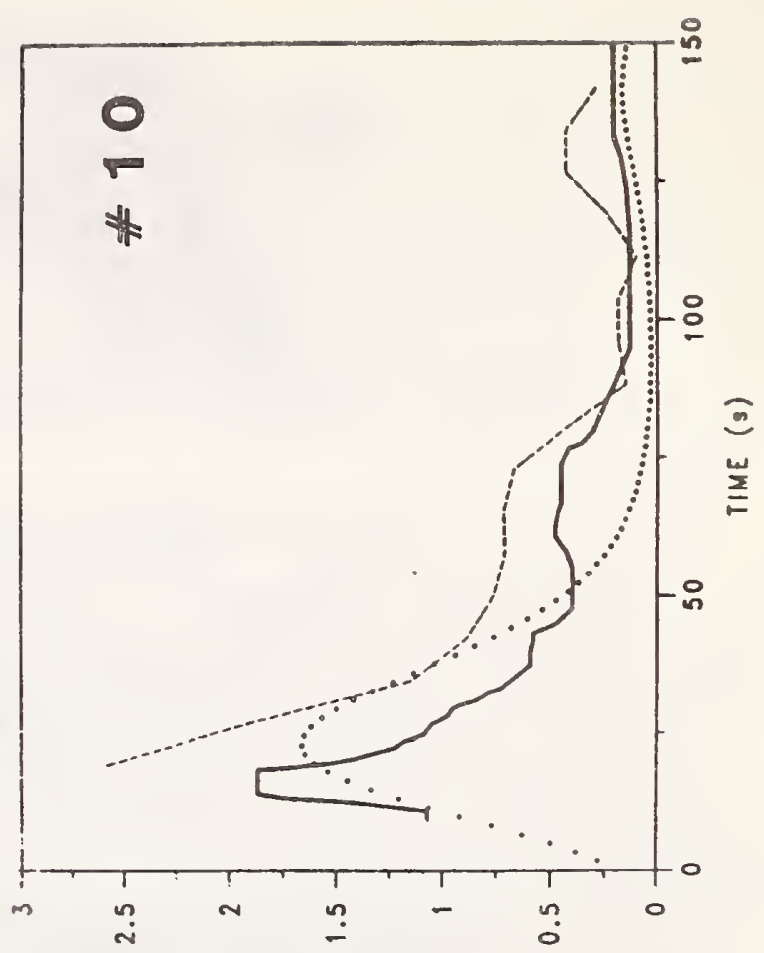

$(s / s \mid 40 A 0)(1) Y \quad A I I S N 3 I N I$

Figure 3. Intensity plots obtalned from four recordings of passive fim breakdown, each calculated with three different methods. 


\section{Task 15447}

The Electrodeposition Group is responsible for measurements and standards associated with electrodeposited pure metals and alloys. The objectives of the group are: (1) the determination of the critical mechanistic, material, and process variables controlling the structure/property relationships of electrodeposited coatings and the development of approaches that will result in entirely new materials; (2) the provision of standards such as coating thickness standards, microhardness standards, dye penetrant crack standards, and corrosion step test standards; (3) the development of new standards requiring electrodeposition for their fabrication or utilizing the unique properties of electrodeposited alloys; and (4) the provision of expertise in this field to industry, through research associates and standards organizations, and to other government agencies, through appropriate contracts and consulting arrangements.

Following are some of the many areas in which coatings are important to industry in the United States. (1) Strategic Materials - It has been shown that coatings have been estimated to provide a $30 \%$ savings of imported raw chromium. Research on coatings of amorphous alloys and nickel chromium alloys, in progress, indicates that in many applications coatings can replace bulk stainless steels. (2) Corrosion - Coatings are the most common form of corrosion protection. It has been estimated that the cost of corrosion to the U.S. economy is about 167 billion dollars/year. Research in the use of metallic glass coatings and chromium containing alloys is in progress. (3) Wear - The cost of wear to the U.S. economy has been estimated to be from 30 to 50 billion dollars per year. Electrodeposited coatings play an important role in improving wear properties so that the substrate alloy can be optimized for mechanical properties and surface coatings can be optimized for wear. Studies in this area are in progress to aid the Bureau of Engraving and Printing with solving problems they are having in wear of their printing plates.

Electrodeposition is one of the few metals processing techniques that in principle provides the opportunity to control, on an atomic scale, both composition and structure of the alloy. This technology has been exploited for many years without an in-depth understanding of the process both to apply coatings for wear and corrosion protection and to electroform large items. It seems clear that development of such an understanding would provide information leading to very new and unique types of materials. Significant progress in this area was made last year in modeling the alloy deposition process and in developing a new kind of alloy whose composition is modulated perpendicular to the growth direction.

\section{FY 85 Significant Accomplishments}

- Completion of the first stage of a mathematical model of the alloy deposition process taking into account diffusion migration and convection. The model is capable of predicting composition of alloys of up to 15 components using pulsed or direct current. The model was tested for the electrodeposition of $\mathrm{Sn}-\mathrm{Pb}$ (solder). Future work will focus on the effects of the substrate on exchange current and on nucleation and growth. 
- Electrodeposition from a single lectrolyte of composition modulated alloys of copper-nickel and nickel-palladium with layer spacings as low as Inm. Comparison made between potentiostatic and galvanostatic deposition indicated that potentiostatic deposition provided significantly sharper interfaces.

- Development and production of 150 corrosion step-test Standard Reference Materials samples were completed and have now been made avallable to the automotive industry.

- An automated microhardness system was developed and was shown to be capable, not only of measuring microhardness but also of yielding information on modulus and ultimate tensile strength.

Modeling of the Deposition Process and Metals Processing Subtask 1 of 15447

C. R. Beauchamp, D. S. Lashmore, R. R. Oberle, and M. Ratzker

A model using a finite difference technique to solve the one dimensional diffusion equation for a multicomponent system under forced convection has been developed for the rotating disk electrode. The purpose of this model is to predict the composition of the deposit and to provide information on concentration profiles in the electrolyte. This model can easily be adapted to other convection situations and can be used for both direct current and pulsed current deposition. The model takes into account migration and has been tested for electrodeposition of $\mathrm{Sn}-\mathrm{Pb}$ (solder). A summary of these results is shown in table 1.

The feasibility of applying the model to predict alloy composition of a nickel-chromium electrolyte is now under investigation. The required parameters for the execution of the model were measured for nickel using a rotating disk electrode system. The software required to control the instrumentation responsible for current-potential measurements synchronized with rotational speed was developed for a microcomputer using the CPM operating system. In addition, an algorithm for the analysis of the data, including noise suppression, was implemented. Partial results are shown in figure 1. Each point represents an experiment, and three experimental series have been plotted. The equivalent analysis for chromium parameters is presently under study. In this case, the rotating disk electrode is replaced by a dropping mercury electrode because of the higher hydrogen overvoltage of the second system.

Studies on the electrodeposition of modulated alloys of both nickel-copper and of nickel-palladium are in progress. These have indicated that conducting electrodeposition (from a single electrolyte) using potentiostatic control provides a sharper interface than the galvanostatic technique discussed in the literature. Layers of pure copper and 98 weight percent nickel have been made and an optical micrograph of $300 \mathrm{~nm}$ layers is shown in figure 2. Magnetic properties of copper-nickel composition modulated foils made in the electrodeposition group are being investigated, and some preliminary results will be reported in a conference this Fall. Material with layer spacings of down to $1 \mathrm{~nm}$ have been produced. These materials contain many thousands of layers and can be made millimeters 
thick. An investigation of the mechanical properties and a study of the structure of the interface by transmission electron microscopy and $\mathrm{X}$-ray diffraction is in progress.

Research on a nickel-chromium alloy deposition process has indicated that the corrosion currents for the direct current deposits are considerably higher than those for the pulsed currents and that a sharp transition exists for both types of coatings. This result as shown in figure 3 indicates that the passive film undergoes a sharp transition, probably from crystalline to amorphous at about 12 weight percent chromium and is consistent with results reported by other investigators on similar alloys.

Applied Research

Subtask 2 of 15447

C. E. Johnson, D. R. Kelley, D. S. Lashmore, and M. Ratzker

An investigation of electrodeposited nickel phosphorus metallic glasses indicated that their corrosion performance was strongly affected by their layered structure, shown in figure 4. This layered structure inhibits pitting because every other layer will always be cathodically protected by its neighbor so that once a pit is initiated, say at some defect, then corrosion will proceed laterally. This mechanism is indicated in figure 5 which shows dissolution in concentric circles in an amorphous alloy containing 12 weight percent phosphorus.

A study of the electrodeposition of engraving plates for the Bureau of Engraving and Printing (BEP) has been in progress for over a year in collaboration with $\mathrm{Dr}$. Ruff in the tribology group. The first portion of this focused on developing technical advice to the BEP to improve control over the process variables and to improve measurement of properties of electroformed printing plates. Subsequently the investigation focused on a characterization of abrasive wear of various coating materials under a simulated printing environment. Some of the results of this part of the investigation are shown in figure 6. A new kind of duplex chromium coating shown in figure 7 shows particular promise in this simulated environment and its wear performance is compared with various 'hard' chromium coatings in figure 8.

Standard Reference Material

Subtask 3 of 15447

H. J. Brown, C. E. Johnson, D. R. Kelley, D. S. Lashmore, S. P. Lewis, J. L. Mullen, P. N. Sharpless and T. C. VanVechten

The microhardness indentation process involves a sampling of a very small volume of material in the region of the indentor. The instantaneous values of hardness and load displacement characteristics provide information related to microdeformation and contain information related to the elastic properties and yield strength of the material. This project was designed to develop the instrumentation to characterize the process and to measure microindentation characteristics of important alloys. This project made use of commercially available instruments due to the desirability of 
rapidly transfering to industry a new technology. The development of this kind of a NDE technique is particularly important to the electrodeposition field because of the typically small volumes of material available for the measurement of mechanical properties. Significant improvements in the apparatus this last year have resulted in very clean load-displacement curves, an example of which is shown in figure 9 for very fine grained polycrystalline copper. The Vickers Hardness Number as a function of displacement is shown in figure 10 for the same material. From the unloading portion of this curve it is possible to calculate the Young's modulus, which was found to be $1,400 \mathrm{Kg} / \mathrm{mm}^{2}$ (20 million psi), consistent with the literature values. An estimate of the Ultimate Yield Stress obtained from the data using a value of 2.9 for the ratio of Vickers Hardness to ultimate tensile strength was found to be $46 \mathrm{Kg} / \mathrm{mm}^{2}$. $(65,320$ psi). This value is typical for very fine grain copper. Microhardness standards have been in production for two years and are selling well. Research is now in progress to a new very high hardness standard which should be available sometime next year.

An investigation of two major electrochemical techniques for the measurement of surface area has been completed. This project was undertaken in order to determine the feasibilty of fabricating surface area standards. The first of these techniques utilizes a measurement of the capacitance of the double layer as an indication of the surface area. This technique was found to be extremely accurate and very sensitive to the surface roughness. The second technique utilizes a measurement of the diffusion current, a much more convenient measurement for larger samples. Using the former technique the specific surface area for the NBS, "Ultra Black" electrodeposited coating was found to be about $100 \mathrm{~cm}^{2} / \mathrm{cm}^{2}$. The high specific surface area coupled with the well known catalytic activity of nickel oxide for the hydrogen evolution reaction has indicated that this coating may have application in hydrogen electrolysis. An example of the diffusion current measurement as a function of surface area is shown in figure 11 .

A new Corrosion Standard (SRM 2350) designed to assist the automotive industry in assessing the corrosion resistance of electroplated parts has been completed and has gone into production. The standard consists of two nickel layers, each of different sulfur content, electrodeposited over a copper layer. The function of this standard is to provide industry with a precise means of calibrating their 'step test' apparatus by providing a physical standard whose properties are well characterized. An example of a graph of electrochemical potential as a function of thickness for one of these standards is shown in figure 12. A computerized data reduction scheme has been developed to provide accurate values of potential and thickness.

A new gold thickness standard with a nominal thickness of $2.2 \mathrm{mg} / \mathrm{cm}^{2}$ was requested by the electronics industry and is now in production. The electrodeposition group now produces a total of seven different gold on nickel coating thickness standards.

The computer programs used to automatically measure the majority of nonmagnetic copper on steel coating thickness standards have been revised by Sharon Lewis to make them easier to use. A large manual has been written by Fielding Ogburn, Retta Brown, Sharon Lewis, and Carole Derr 
describing, in detail, the steps necessary to fabricate coating thickness standards and will be made available to those industries who wish to prepare their own secondary standards.

A dye penetrant crack standard made with a dull surface has been evaluated by industry and found to be the most representative material containing actual fatigue cracks of any crack standard now available.

Table 1. Comparison of computed and experimental results for the composition of lead in deposits of lead-tin alloys.

Direct Current Computed Values $\left(\mathrm{ma} / \mathrm{cm}^{2}\right)$ Molar \% $\mathrm{Pb}$

20

25

30

35

40
$64.6 \%$

51.68

43.07

36.92

32.31
Experimental

Results

45.48\%

48.89

50.13

39.25

37.29

44.01

65.00

47.54

45.5

45.89
Difference in percent

$19.12 \%$

2.79

$-7.06$

$-2.33$

$-4.98$

Pulsed Current

20

30

35

40
64.98

52.04

43.39

37.21

32.56
20.97

$-12.96$

$-4.15$

$-8.29$

$-13.55$ 


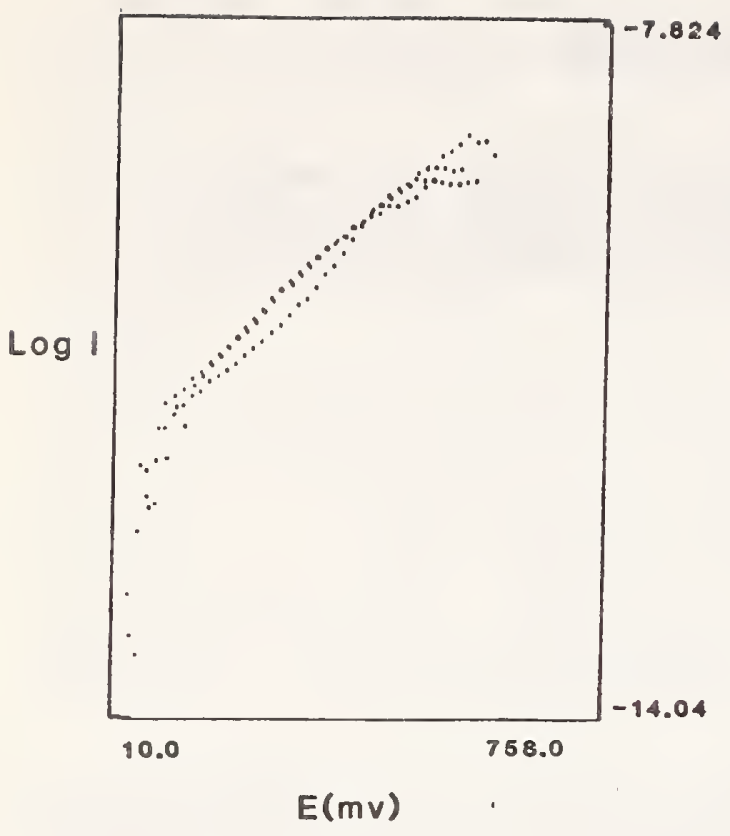

Figure 2. An optical micrograph of a cross section of a nickel-copper composition modulated alloy.

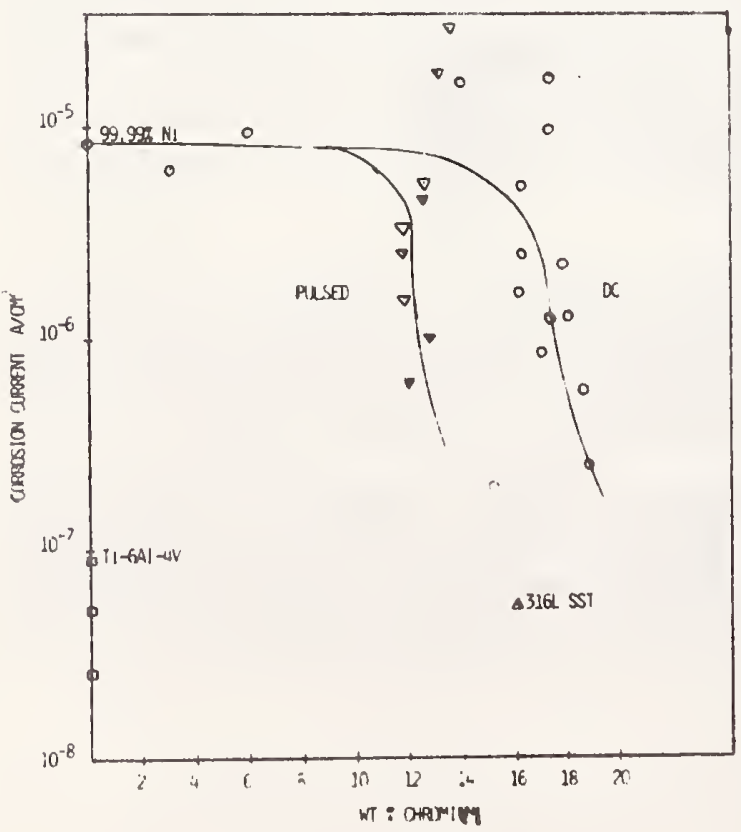

Figure 1. The Log of the current as a function of potential for nickel incorporating the noise reduction scheme.

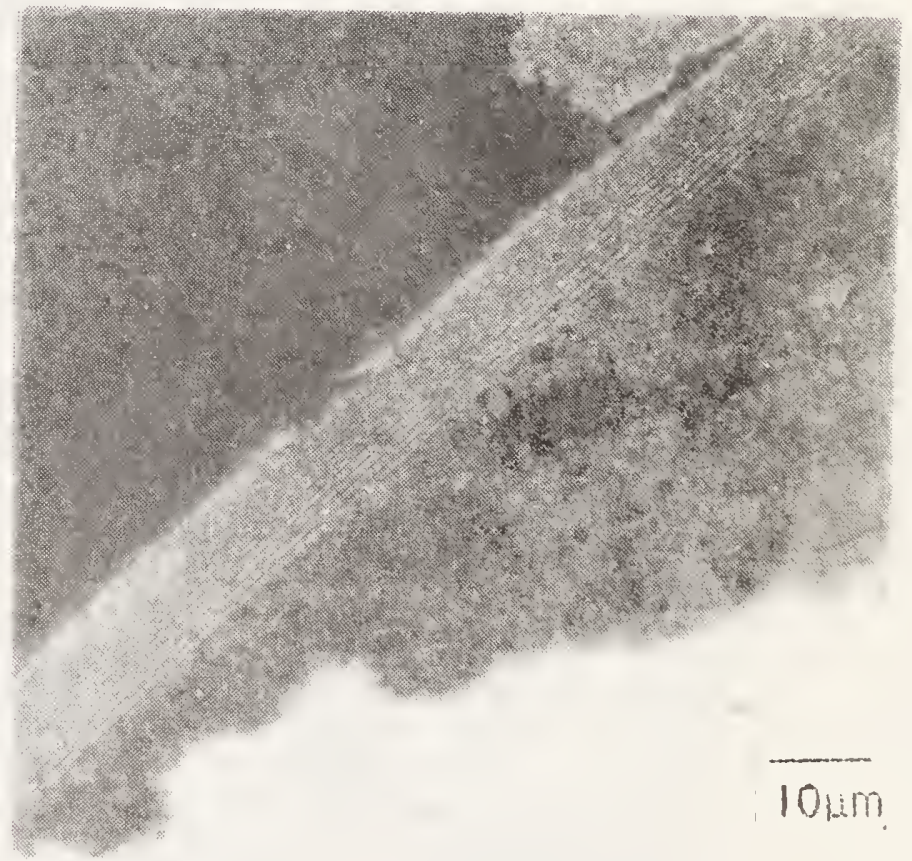

Figure 3. The corrosion current measured in Hank's solution for nickel-chromium alloy as a function of chromium content, for both direct and pulsed current deposition. 
Figure 4. An optical micrograph of an etched cross section of $\mathrm{Ni} 12 \% \mathrm{P}$ showing the layered structure. Unlike the composition modulated alloys (figure 2) this material undergoes only about $3-5 \%$ (by weight) variation in composition from layer to layer.
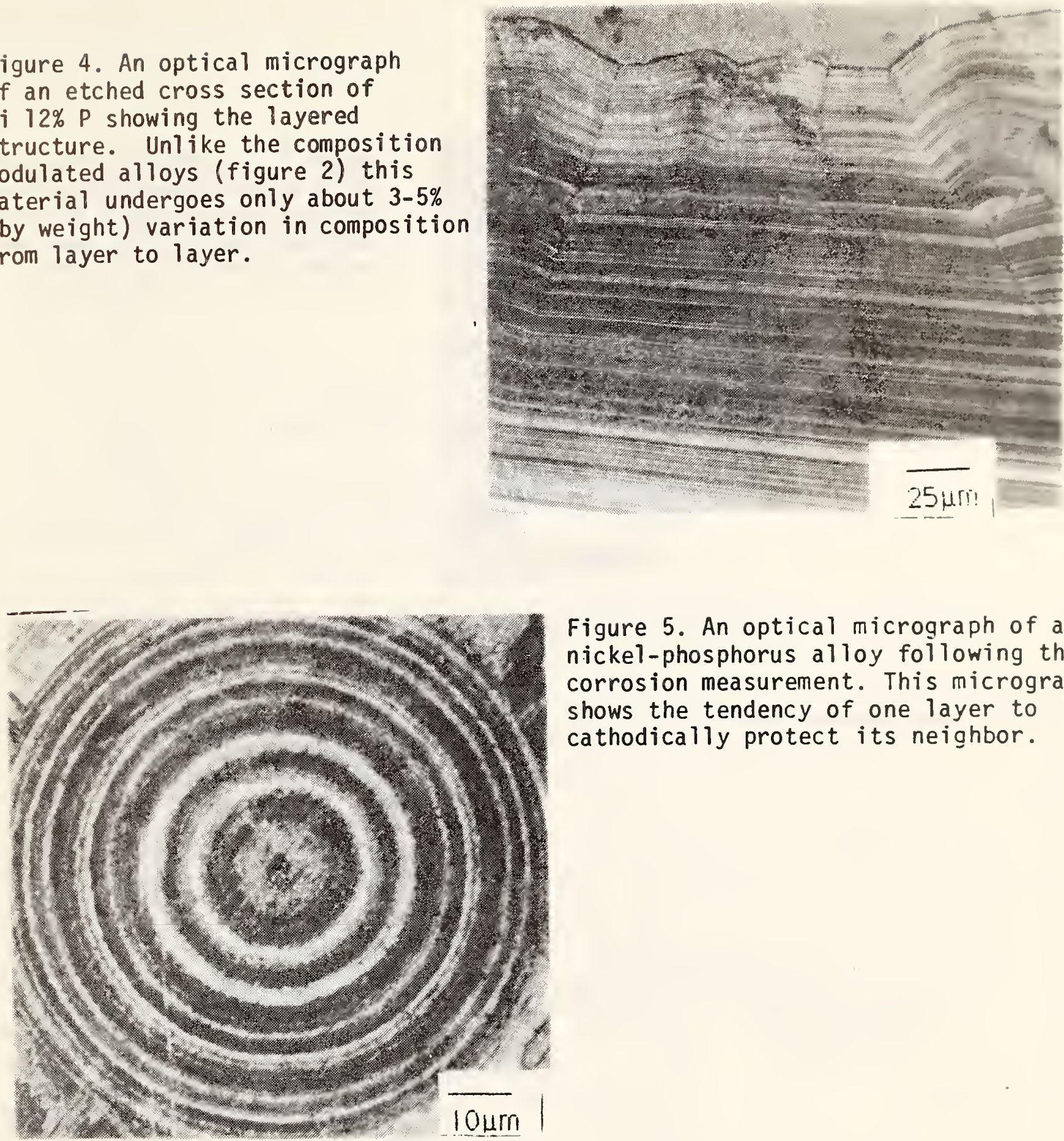

Figure 5. An optical micrograph of an nickel-phosphorus alloy following the corrosion measurement. This micrograph shows the tendency of one layer to cathodically protect its neighbor.

Figure 6 . The wear measured by weight loss for various coatings and counterfaces.

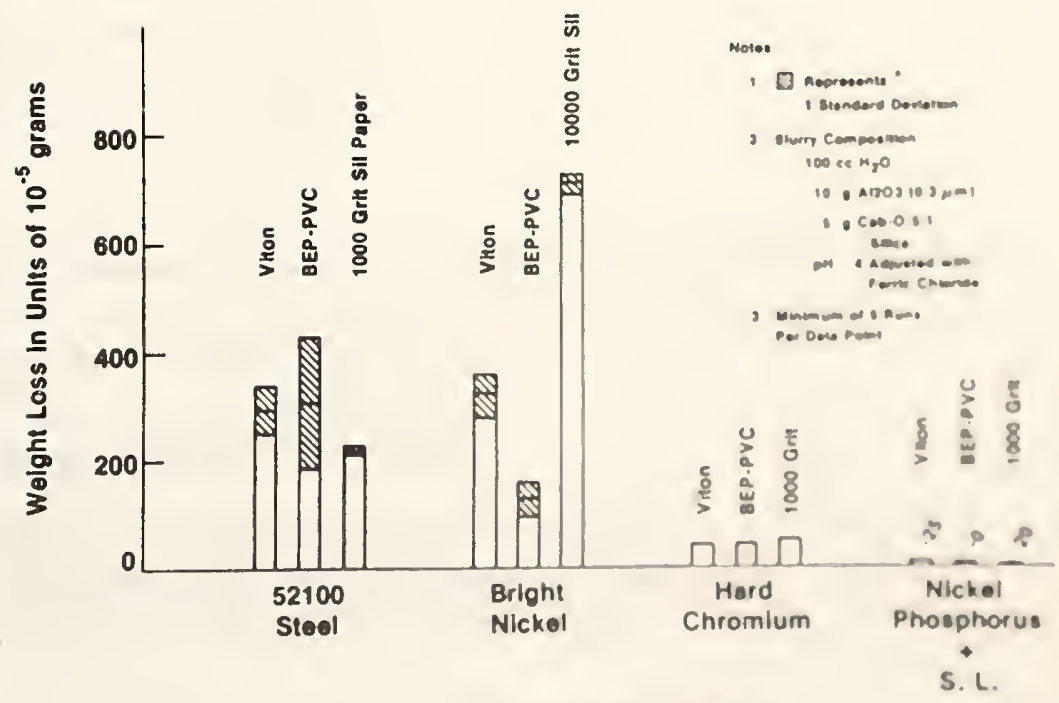

Worn Materlal or Cosilno 


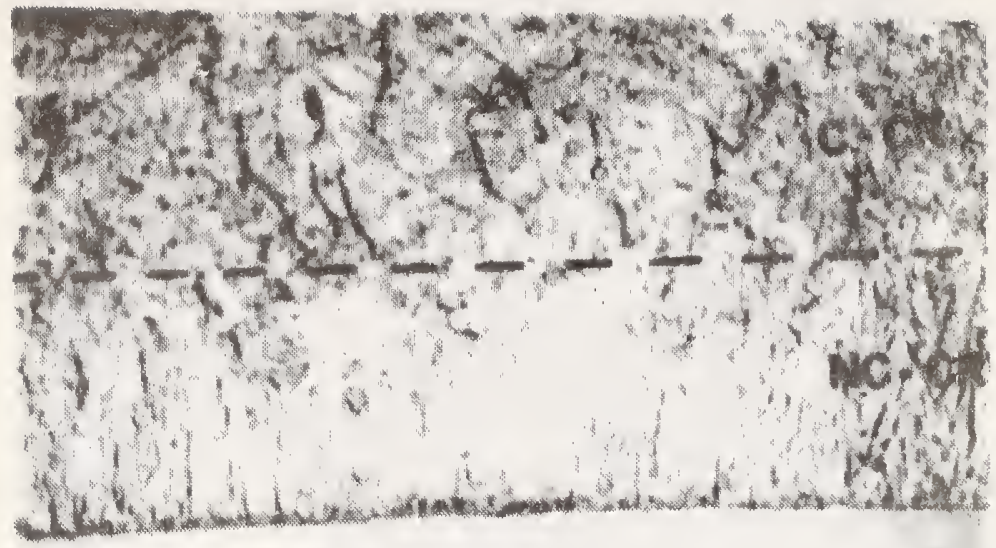

Figure 7. An optical micrograph of an etched cross section of duplex chronium consisting of a ductile base layer and a very hard but mifrocracked surface layer.

$10 \mu \mathrm{m}$

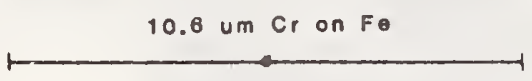

$12.5 \mathrm{um} \mathrm{Cr}$ on $\mathrm{Fe}$

16 um $\mathrm{Cr}$ on $\mathrm{Fe}$

18.5 um Cr on $\mathrm{Fe}$

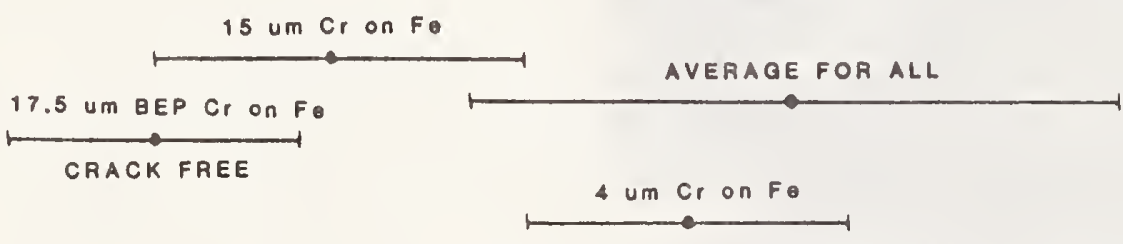

12.5 UM BEP $\mathrm{Cr}$ on NI On Fe

6 Um BEP Cr on $\mathrm{NI}$ on $\mathrm{Fe}$

12.6 UM BEP $\mathrm{Cr}$ on $\mathrm{Fo}$

6 um BEP Cr on Fo

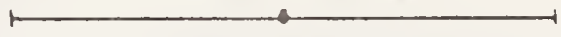

0

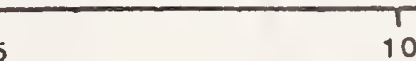

10

15

Figure 8. The wear in weight loss per cycle for many types of chromium. 


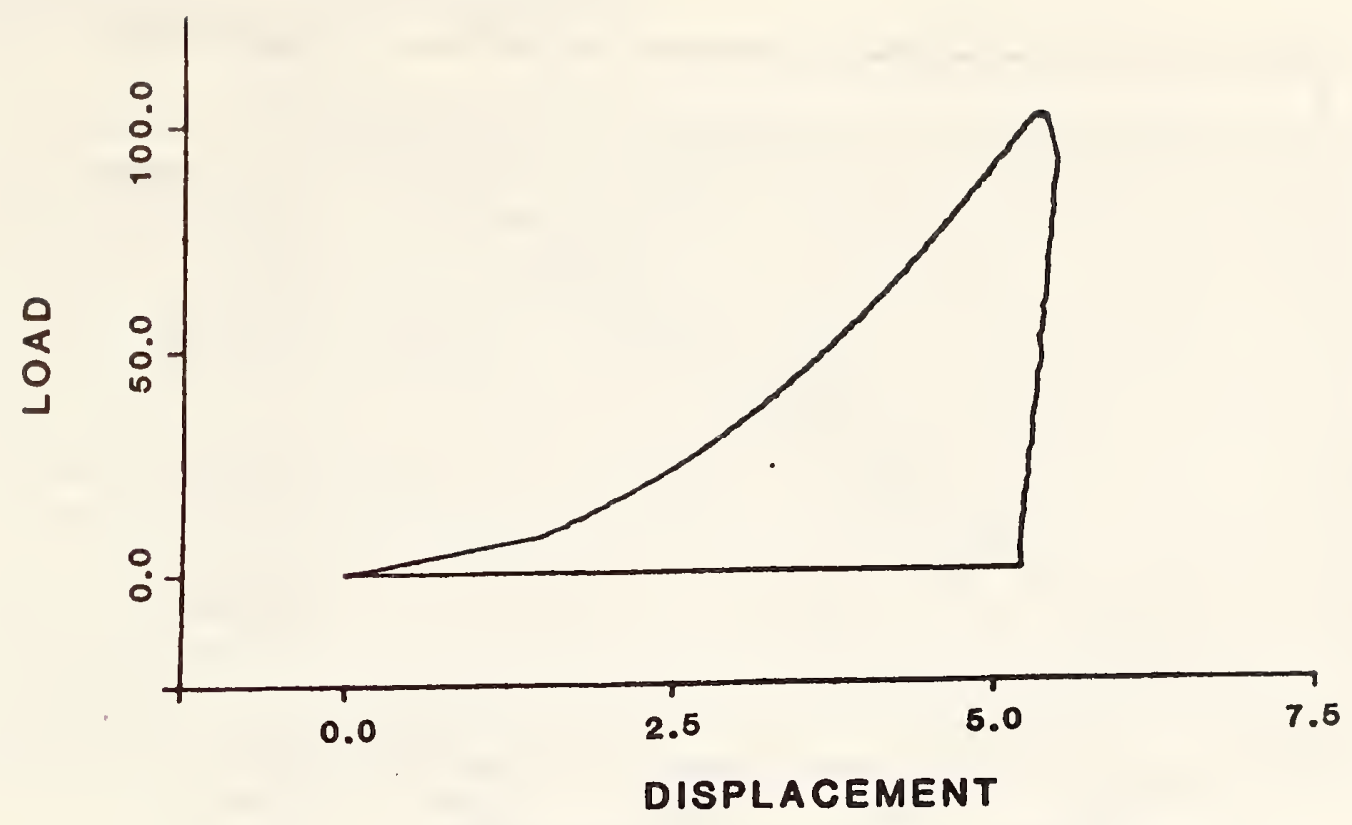

Figure 9. The load as a function of displacement for copper using a Vickers diamond indentor.

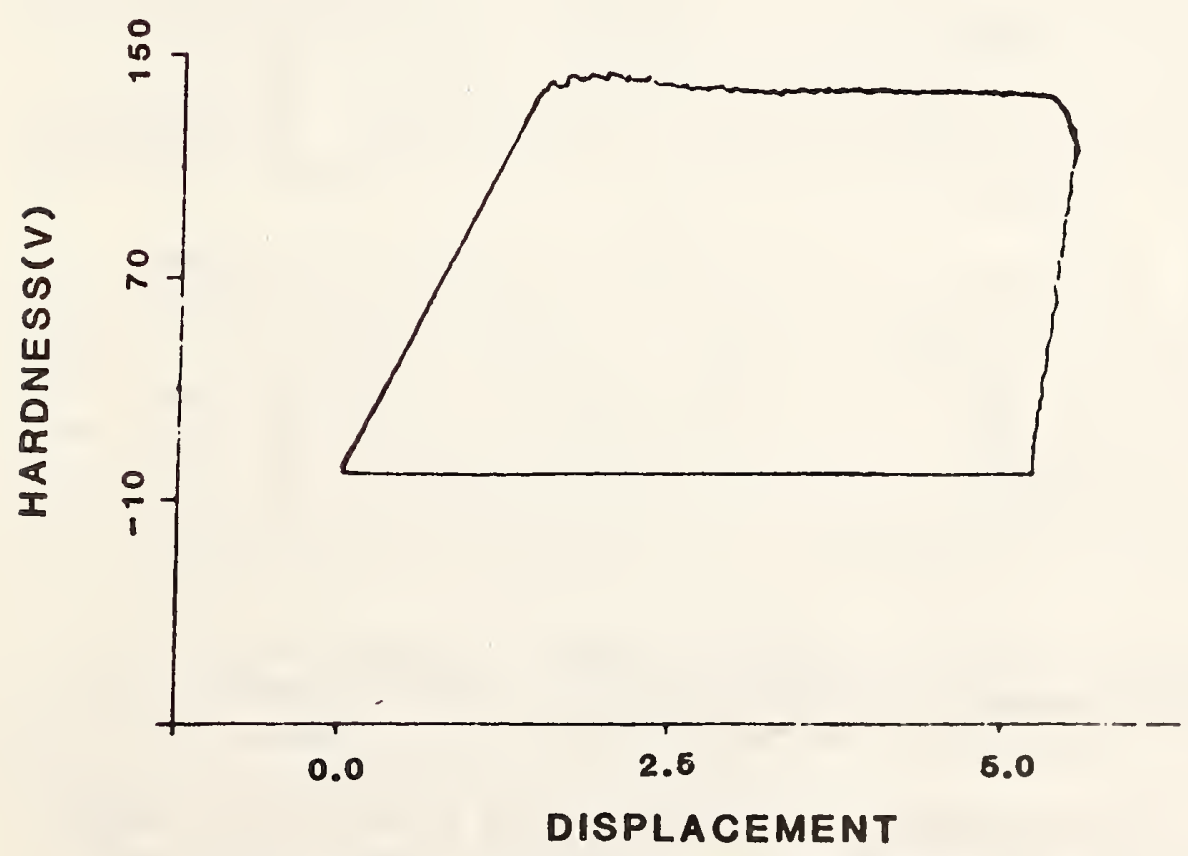

Figure 10. Vickers hardness (projected area hardness) as a function of displacement. This figure shows $8 \%$ strain upon unloading and from this data both modulus and ultimate yield stress can be found. 


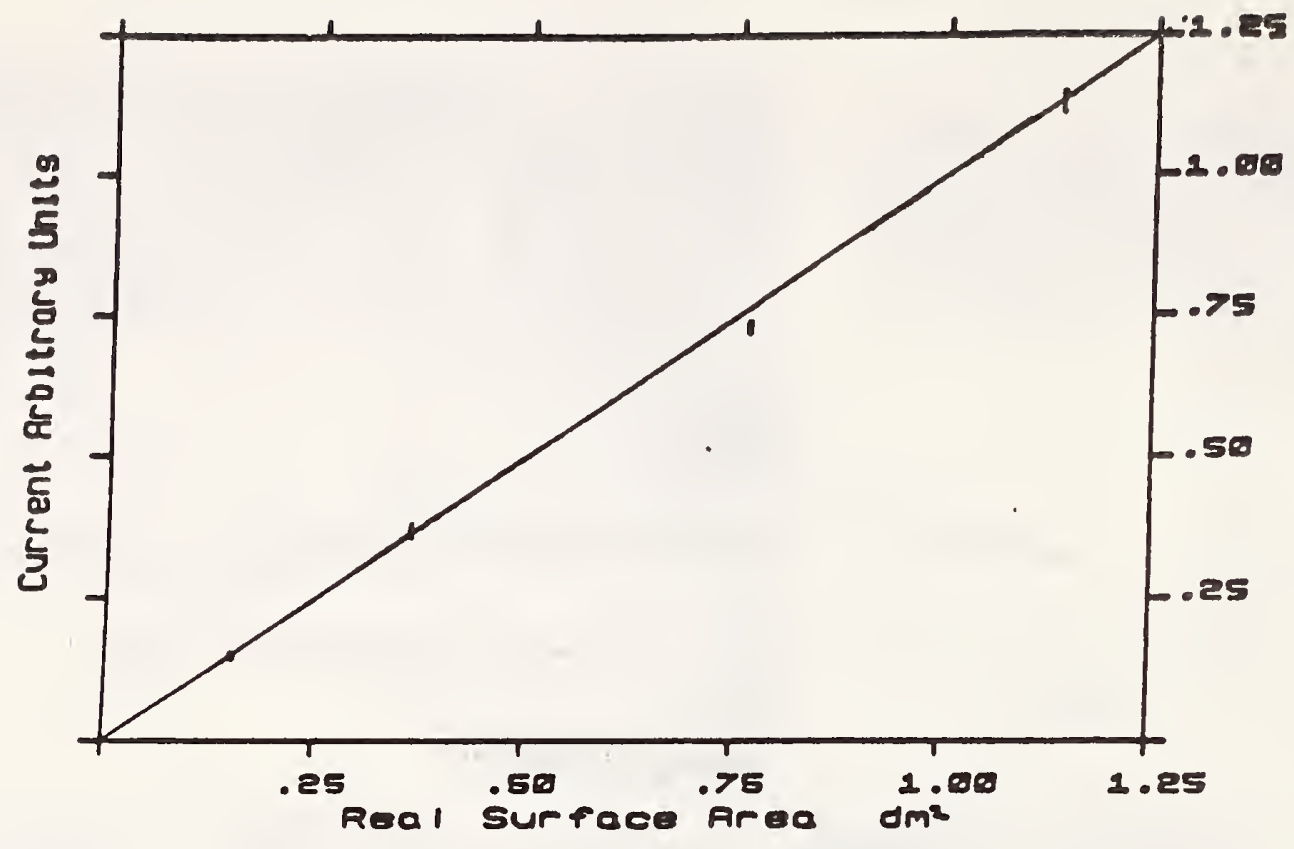

Figure 11. The diffusion current as a function of measured surface area for copper in copper sulfate. The error bars are standard deviations.

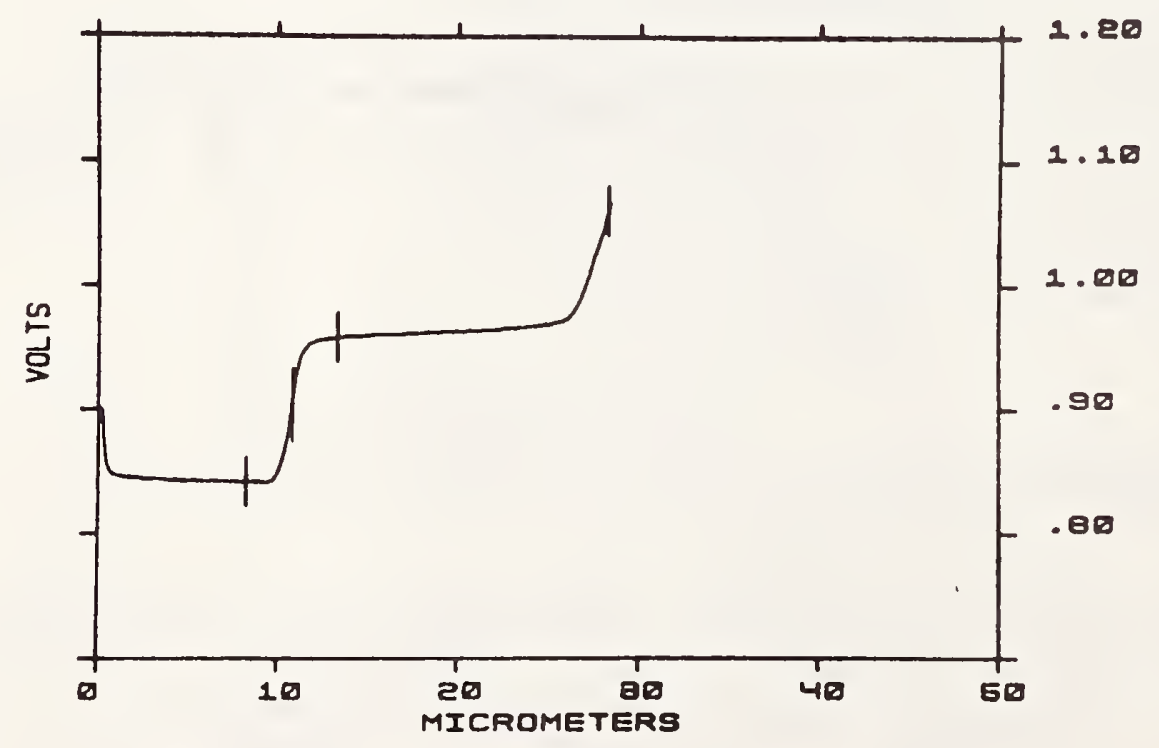

Figure 12. The electrochemical potential as a function of depth for a duplex nickel corrosion 'step-test' standard. The point at which potential measurements are made by the computerized data reduction system are illustrated by the vertical lines. 
This task is concerned with the development of basic nondestructive measurement methodologies and their application to both process control and Nondestructive Evaluation (NDE). The demand for improvements in materials performance drives both the development of advanced materials and quality enhancement (homogeneous optimal microstructures free of defects) of basic materials. This, in part, is being addressed by the development of automated materials processing techniques featuring process control sensors. The juncture of expertise in Nondestructive Evaluation and materials processing has created the unique opportunity for the Nondestructive Characterization Group to make significant contributions to the development of sensors for materials processing. During the past three years research on sensors has become a major component of the work of the group. Research has been conducted (in a collaborative program with the American Iron and Steel Institute) to develop sensors for a) detecting porosity/pipe in hot steel ingots and b) for measuring the internal temperature distributions in solidifying/ solid steel bodies.

Considerable national interest has been shown in this sensor research. One tangible result of this is an instruction from Congress to develop further sensors in support of a "leap frog" technology program in the Federal Laboratories--a new FY 86 initiative. A second tangible result is the imminent start of a new collaborative program with the Aluminum Association directed at the noncontact measurement of internal temperature profiles during high speed aluminum extrusion.

As the group's research programs in sensors matures, a new program has been initiated on interface characterization. Interfaces in general, but particularly those in composite materials, play a very important role in determining properties and performance. However, the physical and mechanical properties of interfaces are notoriously difficult to measure and thus predictive models relating these quantities to performance are not verifiable. Partially supported by Strategic Defense Initiative (SDI) funding, we are exploring techniques for characterizing the interfaces in metal matrix composites with ultrasonics and acoustic emission.

We have conducted basic measurement science in acoustic emission (an area in which NBS enjoys a world renowned reputation) and in eddy current research. For acoustic emission, this has involved research on the inverse problem and on an approximate calibration technique for commercial measurement systems (scalar calibration). For eddy current research, the inverse problem of determining the electrical conductivity depth profile from eddy current measurements at different frequencies has progressed well, and a multitude of potential applications are now emerging.

During FY 85 a strong collaborative interaction has continued and includes a cooperative research agreement with the AISI, steel industry research associates, cooperative research with The Johns Hopkins University, and several guest worker collaborations. 
- Research on an ultrasonic sensor for detecting gross porosity/pipe in hot steel ingots has been completed, and a prototype system incorporating the NBS approach is undergoing trials at the Argonne National Laboratory.

- Improved tomographic algorithms for reconstructing internal temperature distributions have been developed and successfully experimentally evaluated on austenitic stainless steel samples at temperatures up to $750^{\circ} \mathrm{C}$.

- Noncontact laser/EMAT measurement methodologies for high temperature ultrasonic sensors have been developed and successfully tested on steel up to $750^{\circ} \mathrm{C}$.

- The eddy current inverse problem of determining the depth profile of the electrical conductivity has been implemented and applied to laboratory models.

Acoustic Emission in Metallurgy

Subtask 1 of Task 15448

R. B. Clough, J.A. Simmons, and H. N. G. Wadley

If in a solid a defect suddenly grows, elastic waves are emitted. These waves are known as acoustic emission and by properly analyzing such acoustic emission signals at one or more locations, one can obtain unique information about the event. This work on multichannel source characterization attempts to develop the measurement methodologies necessary for extracting quantitative source information from the emitted signals.

\section{Multichannel Tensor Source Characterization}

Studies were made of microcrack propagation in a plate of embrittled 02 tool steel. It was generated by indenting the surface with a Vickers indenter. Figure 1a. shows an example of the set of waveforms generated by the microcrack. The signals were not deconvolved because after the plate was sectioned, additional large cracks were found. This problem and others can be eliminated using an in-situ calibration technique which has been developed. To test the system, indentation microcracks are being created in soda glass before proceeding to cracking in other brittle metallic materials (e. g. metal matrix composites).

\section{Scalar Source Characterization}

During the past year methods have been developed for scalar calibration of acoustic emission source strengths. In these methods, a test configuration is stimulated by a series of sources of known strengths (produced, for example by laser absorption) at the site of the natural source. The ensuing acoustic emission is measured to provide a calibration curve, figure 1b. This curve is then used to deduce the strength of the natural source $[1,2]$. A significant result found is that the measured energy is approx- 
imately independent of the source position, which greatly simplifies interpretation of data. These calibration methods will be used extensively in future characterization of materials by acoustic emission [3-5].

[1] H. N. G. Wadley and R. B. Clough, submitted to Materials Evaluation.

[2] R. B. Clough, submitted to Materials Evaluation.

[3] R. B. Clough, R. J. Schaefer and H. N. G. Wadley, Adv. Mat. Proc.,ed. H. N. G. Wadley, American Society of Metals, Metals Park, OH, (1985). [4] Y. Berlinsky, H. N. G. Wadley, R. B. Clough, J. A. Simmons and M. Rosen, Review of Progress in Quantitative Nondestructive Evaluation, ed. D. 0. Thompson, Plenum Press, NY, Vol.-5, (1986).

[5] H. N. G. Wadley, Review of Progress in Quantitative Nondestructive Evaluation, ed. D. O. Thompson, Plenum Press, NY., Vol. 5, (1986).

Eddy Current Conductivity in Metals

Subtask 2 of Task 15448

A. H. Kahn, K. R. Long, S. A. Ryckebusch, and L. R. Testardi

It is necessary to develop a theoretical and experimental basis for the determination of electrical conductivity depth profiles of metallic materials by eddy current methods. Traditional eddy current testing, based on a comparison with selective calibration samples, is commonly used for quality control but samples only some average depth. This research is aimed at introducing quantitative profiling methods. The methods are generic and may be used for the study of a conductivity profile, no matter how produced. One area of emerging interest is that of temperature profiling, since in many materials the conductivity is a unique and monotonic function of temperature. Discussions with The Aluminum Association have indicated that such an approach could be very useful for determining temperature profiles during the extrusion of aluminum. The Association and the National Bureau of Standards have joined in announcing the initiation of a Joint Research Associateship to pursue research in non-contact methods of temperature measurement in FY 86 .

The approach to conductivity profiling is based on the depth of penetration of induced eddy currents which varies inversely with the square root of the excitation frequency. By performing impedance measurements at high frequencies one can measure the conductivity near the surface. Low frequency measurements reflect the conductivity averaged over varying depths beneath the surface. The inversion methods under study allow one to construct the conductivity profile by unfolding the multi-frequency data [1].

Results of typical impedance measurements and their inversions are shown in figures 2 and 3 . In figure 3 the solid lines give the step-like approximation of the reconstruction process; the dashed lines give the input profile. It is clear that at the present level of operation the location of a change of conductivity is quite well detected, but the calculated magnitude of the conductivity change is only qualitative. Effort is now being applied toward improvement in the computational algorithms and in the selection of the frequency range of the input data. 
[1] A. H. Kahn, K. R. Long, S. Rykebusch, T. Hsleh and L. R. Testard1, Review of Progress in Quant1t1ve Nondestruct1ve Evaluation, ed. D. 0 . Thompson, Plenum Press, NY., Vol. 6, (1986).

Ultrasonics In Metallurgy

Subtask 3 of Task 15448

B. Droney, J. Martinez, J. Cook, F. Mauer, S. Norton, K. Sandstrom, C. Turner, L. Testard1, T. Hsleh, M. Rosen, B. Elkind, M. Linzer, D. Rogers, J. Simmons, K. Hershman, and H. N. G. Wadley

U1trasonic Measurement of Temperature

In 1982, a workshop sponsored jolntly by the National Bureau of Standards (NBS) and the American Iron and Steel Institute (AISI) 1dentifled an urgent need for four types of sensors for use during automated process control in the steel industry. One of these sensors was for the measurement of the internal temperature distribution in hot steel bodies. Scientists from NBS and AISI are now collaborating to develop methods based on ultrasonic time of flight (TOF) tomography.

Much of our effort during the past year has gone into consideration of ways of formulating the temperature-profile reconstruction (tomography) problem in order to take full advantage of constraints based on the heat-conduction equation. Because a set of measurements cannot be completed (by present, manual methods) in a time period that is negligible compared to the cooling rate, it has also been necessary to include the time dependence of the TOF explicitly in the formulation. Our approach has been to express the unknown temperature distribution as an expansion in the eigenfunctions of the heat-conduction equation. Spatial resolution is determined by the number of terms retained in the expansion. In general, numerical ill-conditioning of the inversion problem increases rapidly with the number of retained terms. Thus, there is a trade off between resolution and sensitivity to measurement errors. However, heat flow simulations suggest that, for most metals (whlch have relatively high thermal conductivity), higher order terms damp out very quickly. Reconstructions based on the first term only have been quite successful and can be estimated from a set of from 4 to 10 TOF measurements by minimizing the error in a least-squares fashion.

The formulation of the reconstruction problem that has resulted from these considerations has been tested using data obtained with a manualiy operated test $\mathrm{rig}[1]$. Ultrasonic pulses were generated by laser excitation and recelved by an electromagnetic acoustic transducer (EMAT) so that TOF data could be obtained without making physical contact with the hot steel. Measurements were carried out on two 304 austenitic stainless steel bodies, one a 6 inch diameter cylinder and the other a 6 inch square block. Apparatus used for measurements on the square block is shown schematically in figure 4. The received wave was digitized at 5 ns intervals, and the time of arrival was determined by fitting the leading edge by linear regression and extrapolating to the baseline. An example of a reconstruction from ten first-arrival TOF measurements (corrected for temperature drift between measurements) is shown in figure 5 . Thermocouple 
readings at three points in the block are shown for comparison. Agreement is within $10^{\circ} \mathrm{C}$, which is adequate for most practical purposes and can be expected to improve when measurements are automated to reduce the effect of temperature drift.

Meanwhile, components needed for a fully automated system have been purchased. Software drivers for stepping motors that position beamsteering mirrors have been written. Other software needed for readout of four waveform digitizers is under development. A schematic drawing of the automated system is shown in figure 6 .

[1] H. N. G. Wadley, F. Mauer, S. Nortion and B. Droney, Proc. Roy Soc. series A (London), 1985 (in press).

Dimensional Resonance Profiling

The search for sensor techniques to be used in steel processing has led to the discovery of a new method for nondestructive characterization [1]. Combining the simplicity and precision of acoustic dimensional resonance measurements with the spatial mapping advantage of tomography, the new method allows one to quantitatively map the variation of the elastic modulus and density of a material or structure from measurements of only its resonant frequencies. The technique is physically rooted in the fact that each different mode pattern of an overtone will sample, and be affected by, only a single component in the Fourier expansion of the inhomogeneity. If a number of successive resonant frequencies are excited and measured, then the inhomogeneity may be recovered by Fourier summation. The advantages of the dimensional resonance method are that it can utilize narrow bandwidth detection, has its signal enhanced by the resonant $Q$, generally utilizes lower frequencies (than pulse-echo techniques) where attenuation and scattering are less of a problem, and allows the separation of modulus and density defects for localized defects. Its largest advantage may be that it is one of the few methods for mapping spatially broad inhomogeneities in modulus and density.

A complete theoretical analysis of the dimensional resonance problem was carried out for one-dimensional structures [2]. Earlier theory has been extended to show how both the symmetric and antisymmetric parts of an arbitrary inhomogeneity (corresponding, respectively, to its even and odd Fourier components) can be recovered by measuring two sets of resonant frequencies associated with free-free and free-fixed boundary conditions at the ends of the structure. The more recent theory also includes a second-order analysis of the dimensional resonance problem which provides an estimate of the error resulting when higher-order terms are neglected in the first-order theory [3]. We show that under most conditions, when the material perturbation is small (up to 5 percent of its mean value), the higher-order contribution can be safely neglected.

Finally, we have obtained, this year, a new result showing that the thermal diffusivity of a one-dimensional rod can be directly measured by heating the rod and then observing the change in resonant frequency of the cooling rod as a function of time [3]. This latter technique provides quantitative diffusivity data while allowing an arbitrary and unknown 
initial temperature distribution.

[1] L. R. Testardi, S. J. Norton and T. Hsieh, J. Appl. Phys. 56, $2681-2685(1984)$.

[2] S. J. Norton and L. R. Testardi, J. Acoust. Soc. Amer. submitted.

[3] L. R. Testardi, S.J. Norton and T. Hsieh, J. Appl. Phys. submitted.

Characterization of the Age Hardening Behavior of 2024 Al by Resonance

Methods

In $\mathrm{Al}-\mathrm{Cu}$ alloys, a diffusion controlled nucleation and growth process forms precipitates from the supersaturated solid solution. By measuring the changes in acoustic properties, the effect of the presence of the precipitates on the elastic moduli may be determined as a function of aging time and temperature.

The experimental results are shown in figure 7 and figure 8 and are plotted as the change in elastic moduli as a function of aging time. The low aging temperatures favor nucleation of the precipitates while the higher aging temperatures favor growth of the precipitates. The aging temperaature also has an effect on the fractional volume of the precipitates in the matrix. The specimens aged at the lower temperatures will have a higher volume fraction of precipitates relative to those aged at the higher temperatures. This effect causes the relative change in moduli to be greater for those samples undergoing aging at the lower temperatures.

Ultrasonic Characterization of Microstructurally Modified Surfaces of Steels Subjected to Electron-Beam Irradiation

A nondestructive method has been developed for the determination of the depth and the elastic properties of surface modified layers. Both parameters can be conveniently observed as variations in velocity with changes in frequency of Rayleigh surface waves because the waves sample a depth that is frequency dependent. As a test of this technique, studies were conducted on AISI 1053 plain carbon steel that has been subjected to an electron-beam treatment that created a thin, microstructurally modified surface layer. On samples with an approximate $1 \mathrm{~mm}$ thick rapidly solidified, martensitic surface layer on a pearlitic substrate, the Rayleigh velocity varied from $2984 \mathrm{~m} / \mathrm{s}$ at low frequency (deep penetration into the substrate) to $2960 \mathrm{~m} / \mathrm{s}$ at high frequency (penetration confined to the surface layer): see figure 9. The nondestructive determination of the layer thickness was found to be $1080 \mu \mathrm{m}$, compared to $1034 \mu \mathrm{m}$ determined from metallography.

\section{Pipe/Porosity Detection}

In the past year, a technique for measuring pipe and porosity in hot steel has been developed. Ultrasonic inspection with piezoelectric transducers is a classical approach for the detection of flaws in metals. The principal technical challenge in the NBS program was to develop a means of thermally isolating the transducers from the hot steel surface while still maintaining good acoustic contact with the surface. This is because 
piezoelectric transducers, such as the ceramic PZT-5A, become depolarized above their Curie point $\left(290^{\circ} \mathrm{C}\right.$ for PZT-5A) and cease to be piezoelectric. Additional problems inherent in the use of contact transducers are irregularities in the steel surfaces and the presence of surface oxide (scale). Both of these surface characteristics produce air gaps between the transducer and steel surface. This in turn can lead to very large acoustic attenuation and make pipe/porosity signals virtually undetectable.

The NBS approach was to isolate the piezoelectric transducers from the steel surface wi th buffer rods which have good mechanical and ultrasonic transmission properties but lower thermal conductivity, figure 10 . Stainless steel was chosen as the buffer material which best satisfies these requirements. Good acoustic contact between the steel buffer rods and steel surface was insured by using a high temperature glass, Borax, as a couplant. Borax not only melts at a temperature suitable for inspection of hot steel surfaces $\left(-750^{\circ} \mathrm{C}\right)$ but also very effectively fills in the air gaps between the steel surface and the oxide scale. This ability to penetrate the scale may well be due to its fluxing properties.

Ultrasonic signals reflected from a $1 / 4$ inch hole side-drilled in a block of steel with a $4 \times 4$ inch cross section are shown in figures 11 and 12 . The flaw signals from both the cold and hot steel are seen to be of comparable amplitude. The feasibility of a pipe/porosity sensor based on a piezoelectric transducer-buffer rod-liquid couplant configuration has been established. Emphasis has now shifted to developing, at the Argonne National Laboratory, a scanning arrangement for field applications.

\section{Ultrasonic Characterization of Interfaces}

The characterization of interfaces in metal matrix composites is a new area of investigation. An extensive literature search is underway for finding interrelations between ultrasonic properties, particularly those of interfaces waves, and a characterization of the elastic properties in the vicinity of the interface. Stoneley waves have been generated on a polished contact interface between several aluminum, steel and titanium alloys to confirm the effect of pressure upon the interface velocity. As the pressure was increased, the interface velocity also increased, reaching an asymptotic value which agreed with that of the Stoneley velocity for the particular pair of materials involved.

A study was also initiated on the effect of incidence angle on the generation of leaky interface waves both at the interfaces between two materials and in the so-called $A B C$ sandwich configuration in which a very thin intermediate layer of material $B$ is interposed between materials $A$ and $C$. Such waves are more easily generated than pure Stoneley waves, and the $A B C$ sandwich can be expected to give a better model of real interfaces in composites where reaction products are always present. 

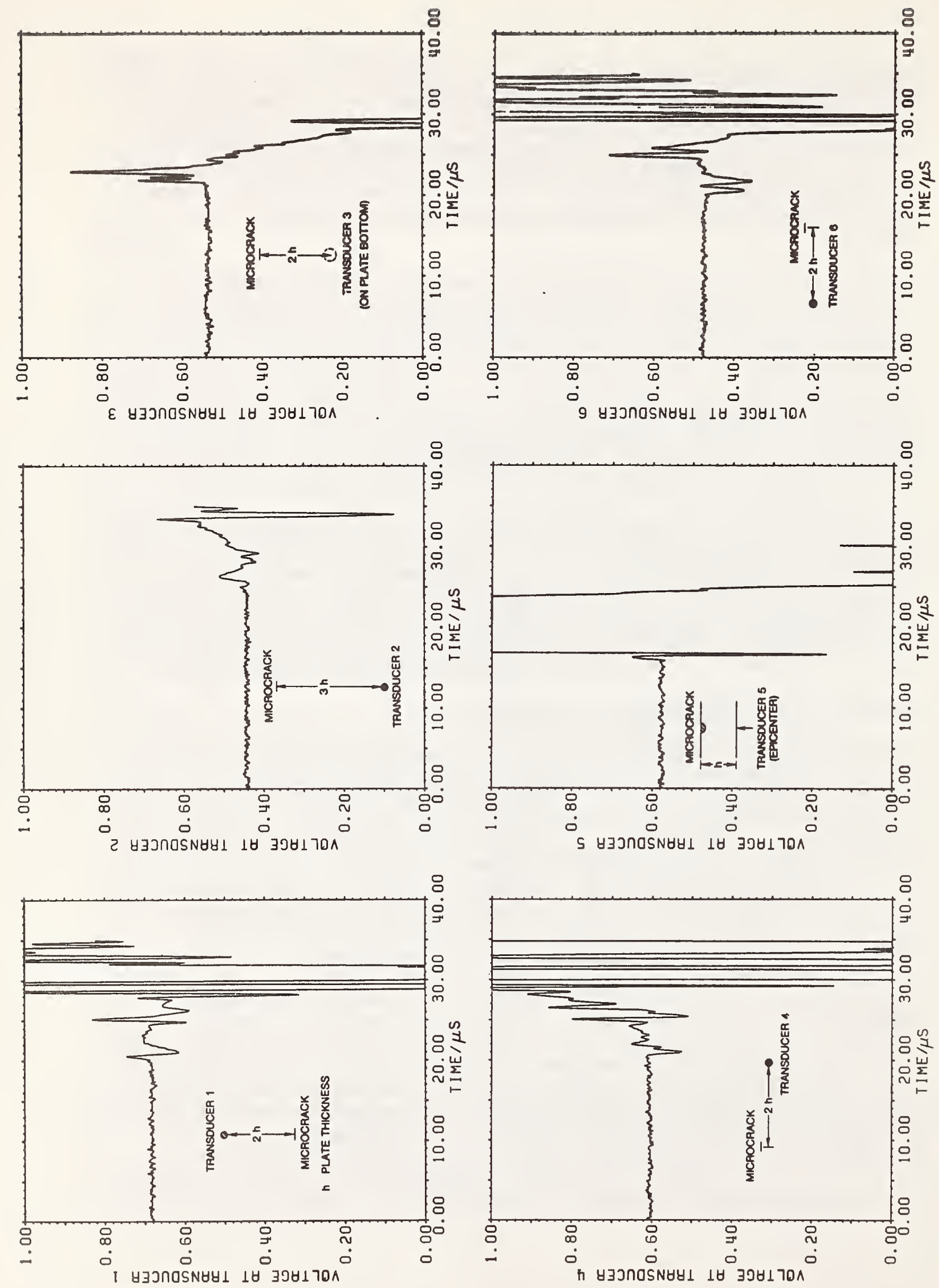
$E_{\ell} / \tau$, Absorbed Power per Pulse/Mw

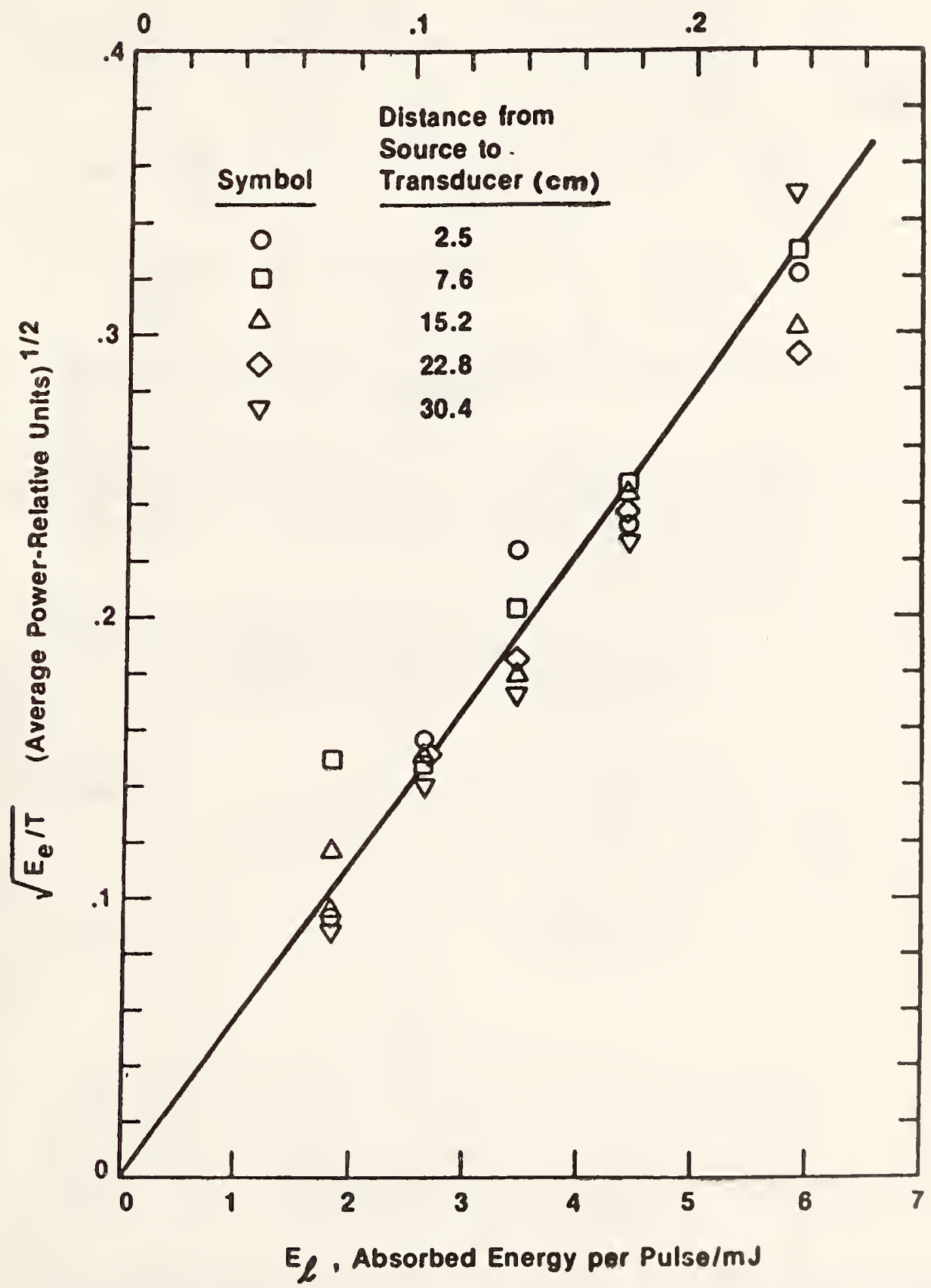

Figure 1b. Laser calibration of aluminum alloy plate showing insensitivity of calibration to source position. 

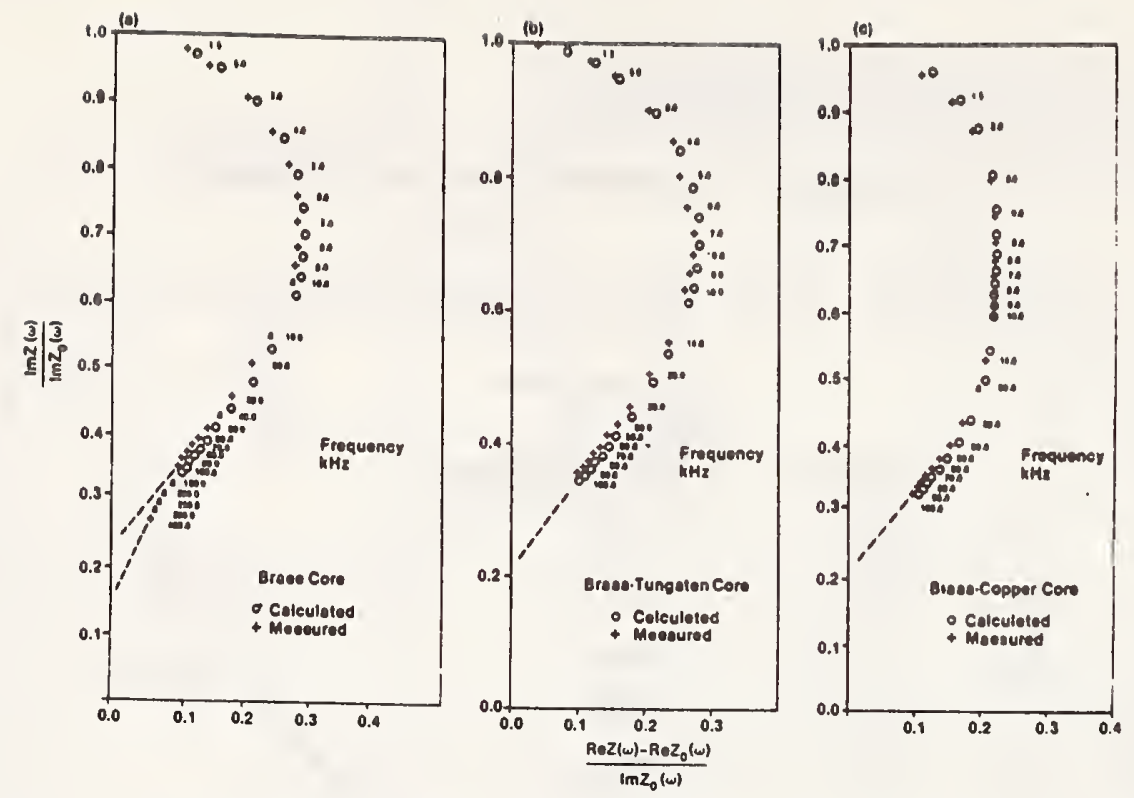

Figure 2. Impedance diagrams for several cylindrical rods. Plots show imaginary vs real parts of impedance ( $Z$ ) of a solenoid surrounding the rods. Subscript 0 indicates empty coil.
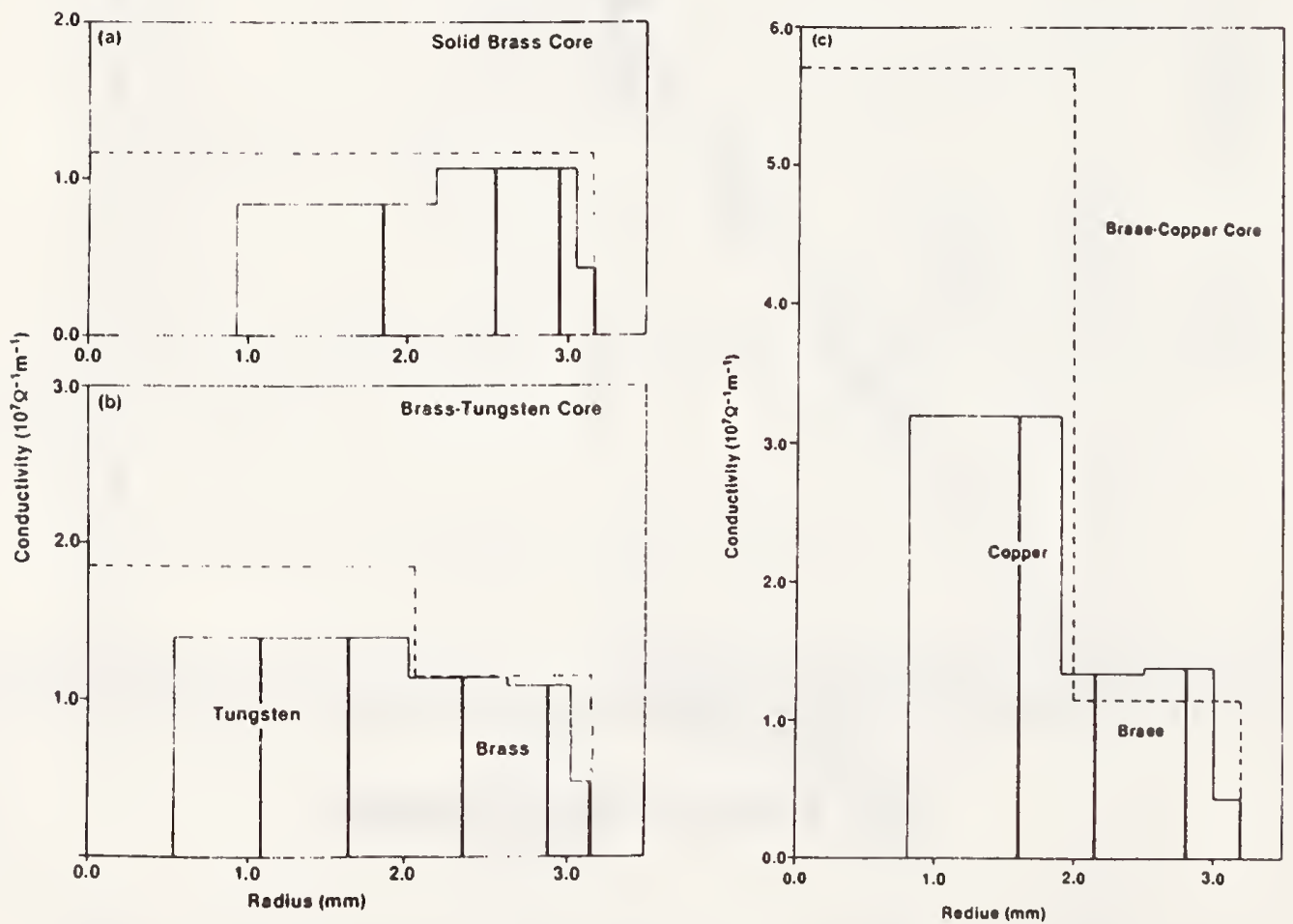

Figure 3. Inversion calculations for the data of figure 4. Solid horizontal lines show computed profile; dashed lines give the known conductivity. Heavy vertical lines represent conductive shells. 


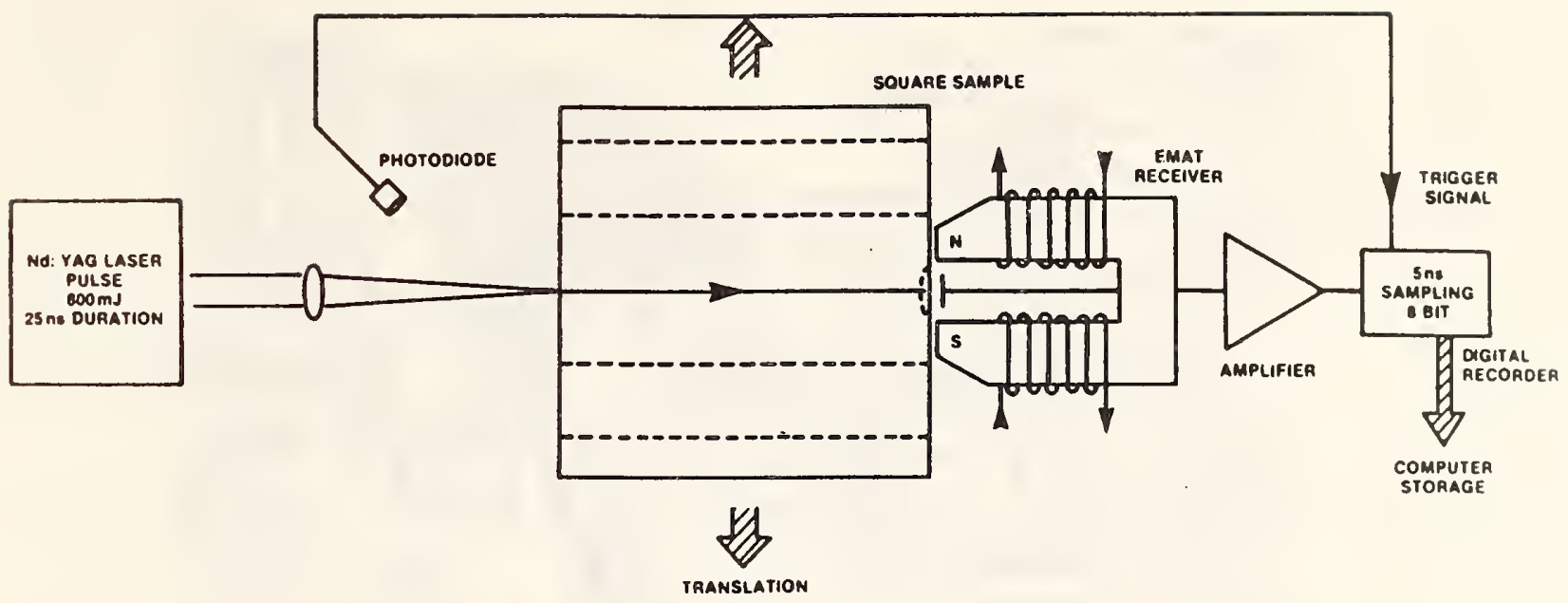

Figure 4. Schematic diagram of apparatus for measuring TOF values in square steel billet.

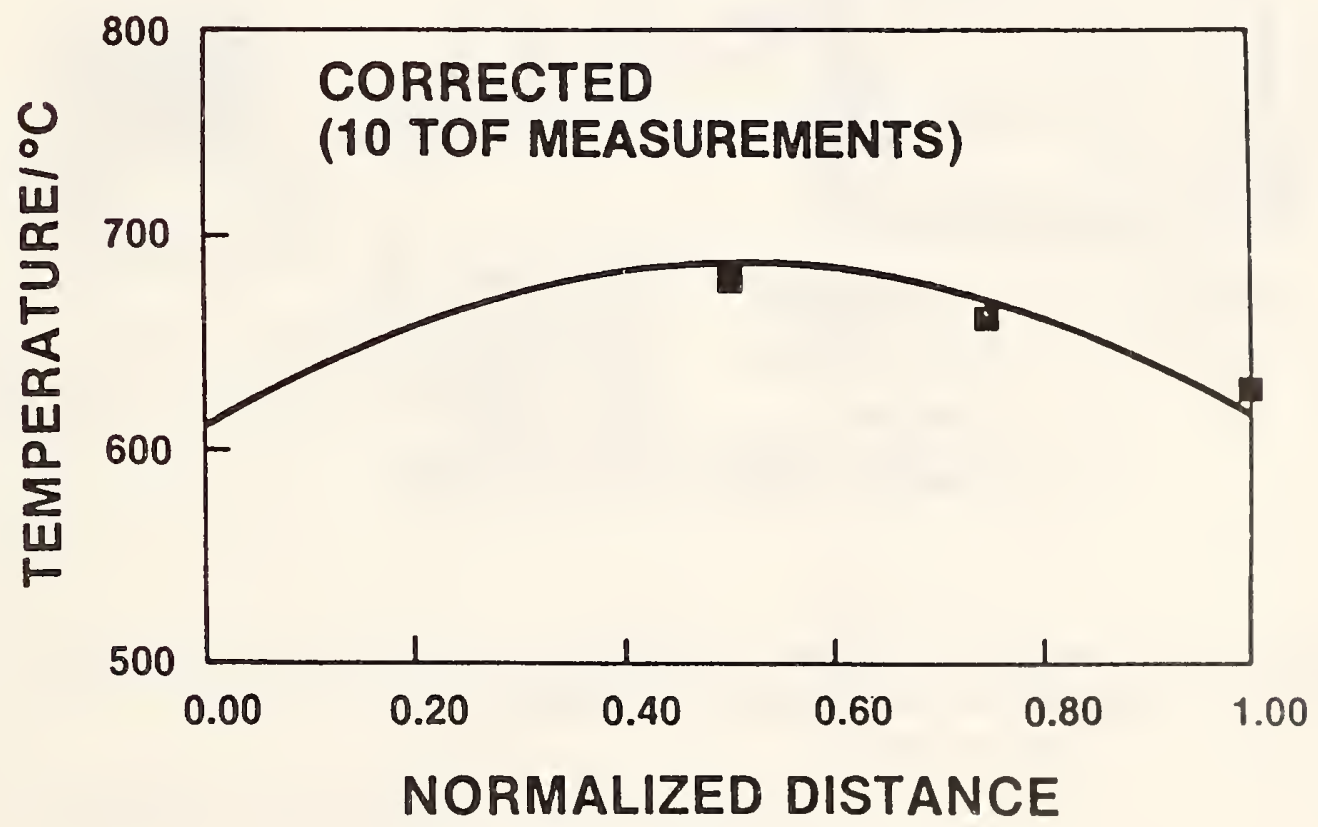

Figure 5. Reconstructed temperature profile for square steel billet corrected for temperature drift. 


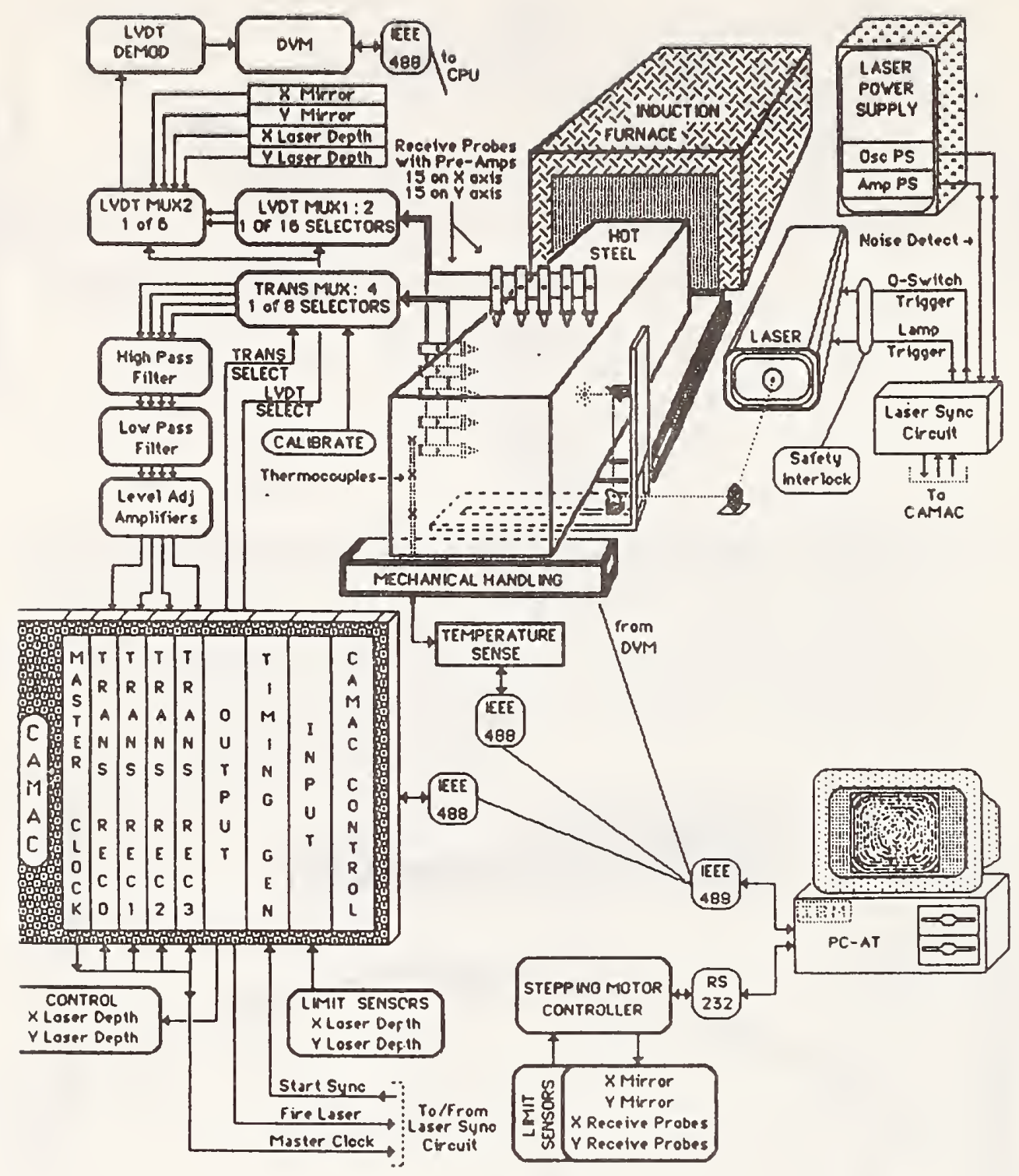

Figure 6. Schematic diagram of automated system for measuring internal temperatures in steel. 
Figure 7 .

Change of Young's modulus as a function of time for 2024 aluminum alloy.

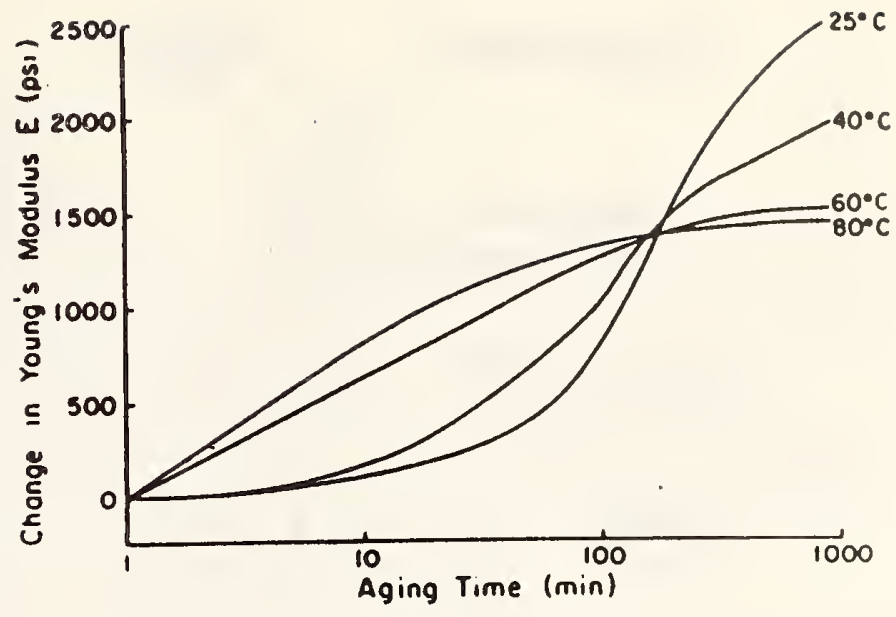

Figure 8.

Change of shear modulus as

a function of time for 2024

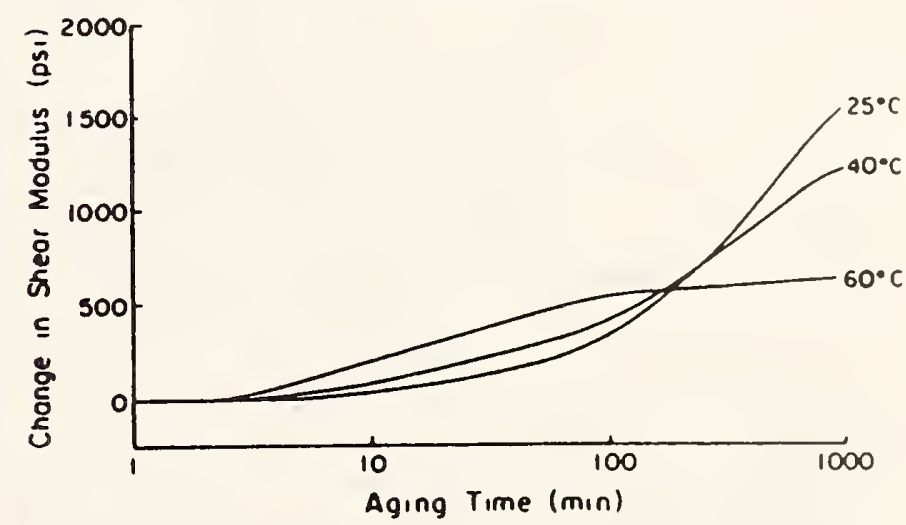

aluminum alloy.

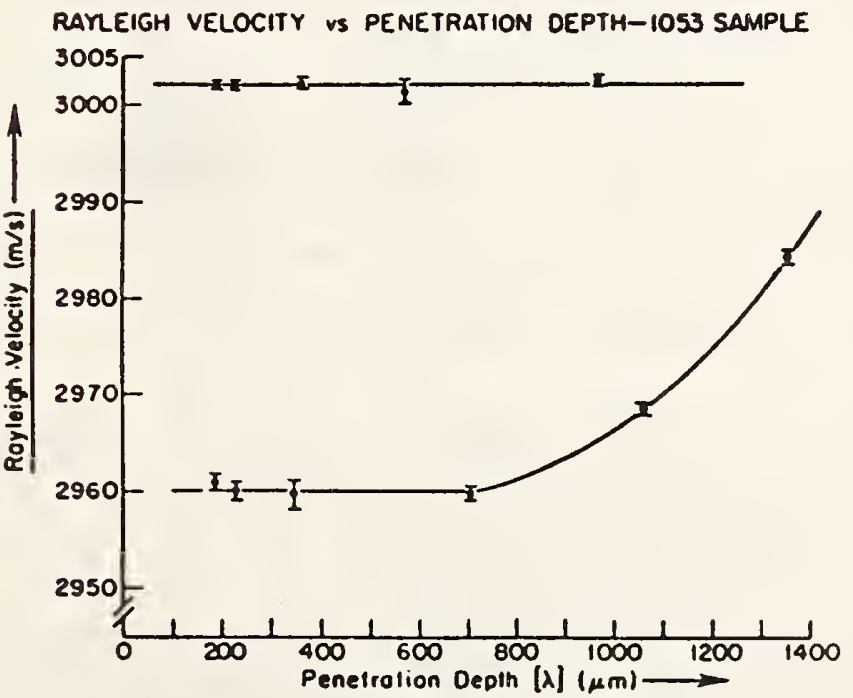

Figure 9.

Rayleigh surface wave velocity as a function of penetration-depth. 


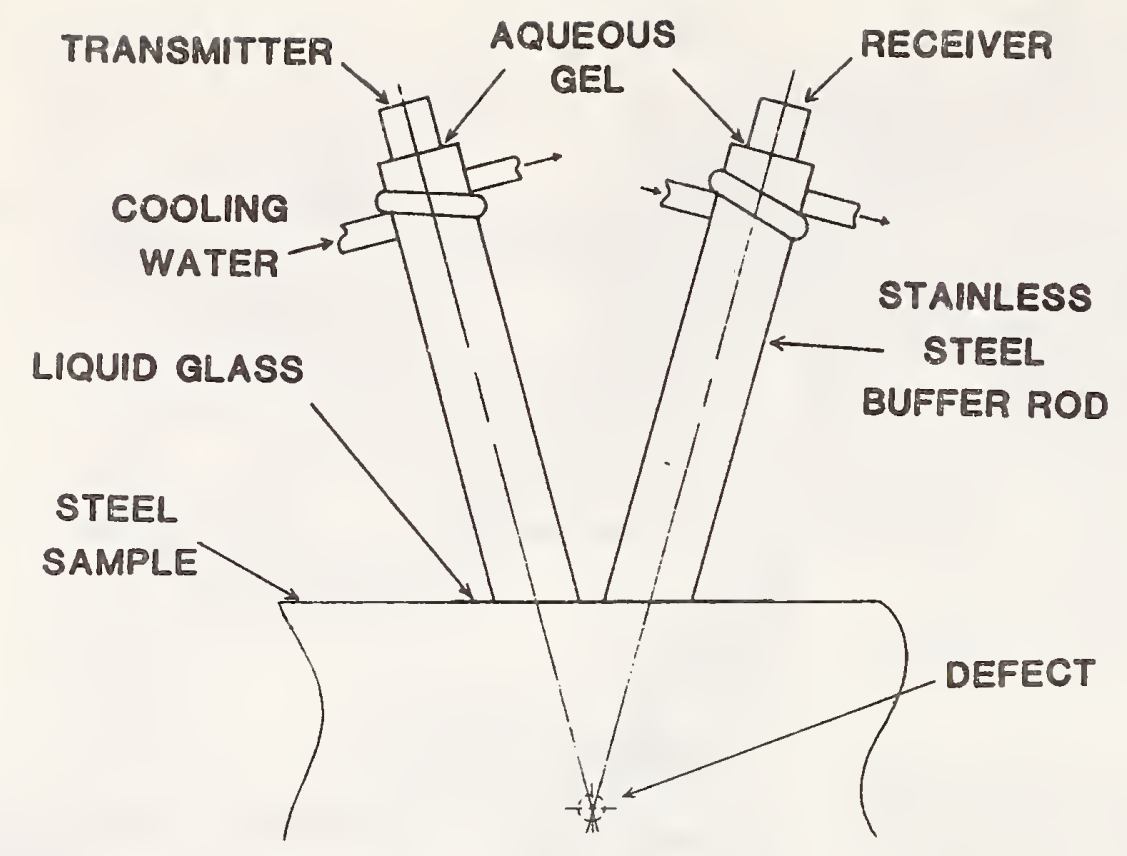

Figure 10. Schematic Diagram of Probe Assembly

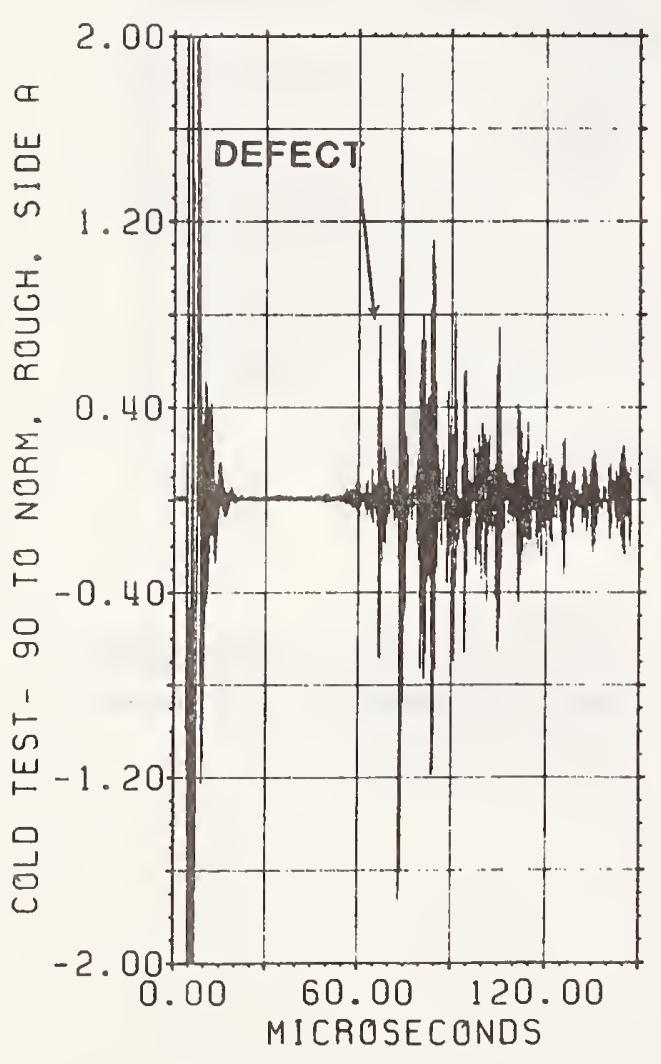

Figure 11. Flaw Signal from Cold Steel

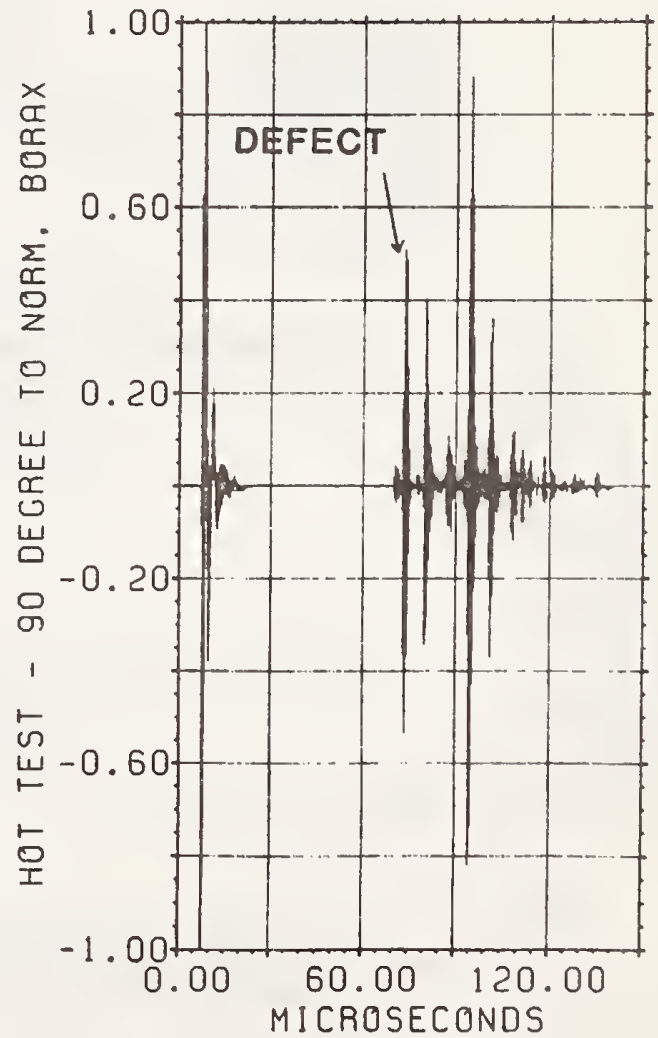

Figure 12. Flaw Signal from Hot Steel 
Magnetic Materials

Subtask 6 of Task 15442

L. H. Bennett

A study of eletrodeposited compositionally modulated alloys (CMA) has been initiated with the Electrodeposition Group, in cooperation with the Naval Research Laboratory. Alloys with 500 alternating layers of $1.4 \mathrm{~nm} \mathrm{Cu}$ and $1.4 \mathrm{~nm} \mathrm{Ni}$ were prepared. This, and similar alloys of $1.6 / 1.6 \mathrm{~nm}$ and $2.0 / 2.0 \mathrm{~nm}$ were measured by ferromagnetic resonance and magnetic susceptibility. These measurements permit the separation of magnetization from anisotropy. The results are consistent with a reasonable amplitude of modulation, and comparable to vapor deposited $\mathrm{Cu}-\mathrm{Ni}$ CMA.

In collaboration with Dr. R. E. Watson of Brookhaven National Laboratory, two different applications of results from a new study of the local topology of atoms in crystals was carried out. The original motivation for the study of local topology was an inspection of Frank-Kasper phases (topologicallyclose-packed, TCP). These TCP phases were defined almost 30 years ago in terms of icosahedral and icosahedral-like local topologies: Wigner-Seitz (1.e., Vorono1) polyhedra are constructed about each atomic site. The TCP phases are defined as having only coordination number $12(0,0,12), \mathrm{CN}=14$ $(0,0,12,2), \mathrm{CN}_{1} 15(0,0,12,3)$ or $\mathrm{CN}=16(0,0,12,4)$ polytopes. Frank and Kasper had difficulty in understanding $\alpha$ Mn which behaved like TCP but appeared to have unallowed CN13. A recomputation of the Wigner-Seltz cell for that site found $\mathrm{CN}=14$, but not $(0,0,12,2)$ and therefore was not TCP. A relation to the magnetic moment distribution in the antiferromagnetic $\alpha \mathrm{Mn}$ was found from the disclination paths. Detailed study of the crystal structures and atomic positions for a number of magnetic metals and alloys with Prof. William B. Pearson of the University of Waterloo, Canada led to the suggestion of a new relation between magnetism and the topology of the local atomic environment. It is proposed that there are paths (disclinations) in the crystal along which essential magnetic exchange coupling occurs, and that these paths play a role analogous to the superexchange paths which are important in explaining the magnetism in transition metals salts. Relations to magnetism have been largely unexplored until now. This procedure is being applied to the technologically important new hard magnetic material $\mathrm{Nd}_{2} \mathrm{Fe}_{14} \mathrm{~B}$, as well as to the magnets $\mathrm{SmCo} 5$ and $\mathrm{Nd}_{2}\left(\mathrm{Fe}_{1-\mathrm{x}} \mathrm{Co}_{\mathrm{x}}\right)_{17}$, all of which bear structural resemblance to the Frank-Kasper phases.

The other application of the study of local topology is to the polymorphism of metallic glasses, discovered earlier (based on MMR, density and EXAFS). It was shown that there are two distinct local structural glass configurations in $\mathrm{Ni}-\mathrm{P}$, whose occurrence depends on the glass processing parameters. Based on the "quasicrystalline" model, the fundamental building block in the glass is taken to be the metalloid and its nearest neighbors which are assumed to have the arrangement characteristic of the crystalline system. Using the Wigner-Seitz construction, it was found that the crystal structures in transition metal rich $\mathrm{Ni}-\mathrm{P}$ and related systems fall into two different topological classes ("triangulated" and "non-triangulated") which may account for the polymorphism in the glasses. 
Bennett, L. H.; Watson, R. E. Patterns in the occurrence of the brittle toplogically close-packed phases: Al in High Temperature Alloys: Theory and Design. J. 0. Stlegler, ed. The Metallurglcal Soclety of AIME;

$103 ; 1984$.

Bennett, L. H.; Long, G. C.; Kuriyama, M॰; Goldman, A. I. Local atomic structure in transition metal/metalloid glasses: $\mathrm{Ni}-\mathrm{P}$ in structure and bonding in noncrystalline solids. G. E. Walrafen, ed. 1985; in press.

Bennett, L. H.; Watson, R. E. Systematics of the alloying behavior of the noble metals in Noble Metal Alloys. T. B. Massalsk1, L. H. Bennett, Y. A. Chang and W. B. Pearson, eds. The Metallurgical Society of AIME; 1984; in press.

Bennett, L. H.; Watson, R. E.; Pearson, W. B. Topology of local atomic environments: implications for magnetism and superconductivity. International Conference on Magnetism; 1985; in press.

Bendersky, L.; Kattamis, T. Z.; Biancaniello, F. S. An analytical TEM study of new intermetallic phases in the Co-Sn system. MRS fall meeting. L. H. Bennett; B. C. Giessen; T. B. Massalski, eds. Boston, MA; 82; 1984.

Bendersky, L. A.; Boettinger, W. J. Cellular microsegregation in rapidly solidifled Ag-15 wt\% Cu alloys. Proc. of Fifth Intl. Conference on Rapidly Quenched Metals. S. Steeb; H. Warlimont, eds. Elsevier Sclence publishers B. $V . ; 887 ; 1985$.

Bendersky, L. A.; Boettinger, W. J. Microstructural varlations in melt spun ribbons. Submitted for publication to EMSA, Loulsville; 1985.

Bendersky, L.; Schaefer, R. J.; Blancaniello, F. S.; Boettinger, W. J.; Kaufman, M. J.; Shechtman, D. Icosahedral AI-Mn and related phases: resemblance in structure. Scripta Met. 19: 909; 1985.

Bendersky, L.; Schaefer, R. J.; Biancaniello, F. S.; Shechtman, D. Rapidly solidified Al-Cr alloys: structure and decomposition behavior. J. Mat. Sci.; 1985; in press.

Berlinsky, Y.; Wadley, H.N.G.; Clough, R. B.; Simmons, J. A.; Rosen, M. Acoustic emission as a nondestructive evaluation technique for characterizing martensitic transformation. Proc. of Review of Progress in Quantitative NDE. D. O. Thompson, ed. Plenum Press, NY; 5; 1985.

Berlinsky, Y.; Rosen, M; Simmons, J. A.; Wadley, H.N.G. Acoustic emission: a technique for characterizing the martensitic transformation in Fe-30wt\%N1. Proc. of Review of Quantitative NDE; 1985; in press.

Bertocci, U. Modelling of crack chemistry in the alpha brass-ammonia system in embrittlement by the localized crack environment. R. P. Gangloff, ed. The Met. Soc. of AIME; 49; 1984. 
Bertocci, U.; Wagman, D. S. Copper: oxidation reduction protentials in aqueous solutions. A. T. Bard, J. Jordan, and R. Parson, eds. M. Dekker, NY; 287; 1985 .

Bertocci, U.; Pugh, E. N. Modelling of potential and concentration profiles in cracks in $\mathrm{Cu}$ alloys. Proc. of the Conference on Corrosion Chemistry Within Pits, Crevices and Cracks; 1984; in press.

Bertocci, U.; Koike, M॰; Leigh, S.; Qiu, F.; Yang, G. A statistical analysis of the fluctuations of the passive current. J. Electrochem. Soc; 1985; in press.

Blau, P. J. Measurements and interpretations of sliding wear damage in metals. J. of Tribology; 1985; in press.

Blau, P. J•; Microindentation hardness testing of coatings. Chapter in Proc. Amer. Vac. Society Symposium on Physics and Chemistry of Protective Coatings; 1985; in press.

Blau, P. J.; Wear testing methods and standardization, ASTM Standardization News; 1985; in press.

Blau, P. J.; 01son, C. D. Some applications of thermal wave microscopy to research on sliding wear break-in behavior of a $\mathrm{Cu}-15 \% \mathrm{Zn}$ alloy in Wear of Materials 1985. K. C. Ludema, ed. ASME, NY; 424; 1985.

Blau, P. J. Tribology terminology, ASTM Standardization News: 13: 15; 1985.

Blau, P. J. Methods and applications of microindentation hardness testing. Chapter in Handbook of Applied Metallography, G. Vander Voort, ed. Van Nostrand Co., NY; 1985; in press.

Blau, P. J.; Shives, T. R. Microindentation hardness testing, ASTM Standardization News; 13: 47; 1985.

Boettinger, W. J. The structure of solid solutions. Metals Handbook; 9 th edition; ASM; 1985.

Boettinger, W. J.; Bendersky, L. A.; Early, J. G. An analysis of the microstructure of Al-8 wt\% Fe rapidly solidified powders. Submitted for publication to Met Trans. A.

Boettinger, W. J.; Coriell, S. R. Microstructure formation in rapidly solidified alloys. Proc. of NATO Advanced Research Workshop on Rapld Solidification Technologies. Submitted for publication; 1985.

Boettinger, W. J.; Shechtman, D.; Kattamis, T. Z.; Schaefer, R. J. The effect of rapid solidification velocity on microstructure and phase solubility extension in $\mathrm{NiAl}-\mathrm{Cr}$ quasibinary eutectic. Proc. of Fifth Int1. Conference on Rapidly Quenched Metals. S. Steeb; H. Warlimont, eds. Elsevier Science Publishers B. V.; 871; 1985. 
Boettinger, W. J.; Perepezko, J. H. Fundamentals of rapid solidification. Proceedings of Symposium on Rapidly Solidified Crystalline Alloys; TMS-AIME; 1985; in press.

Boettinger, W. J.; Burdette, H. E.; Kuriyama, M. White beam synchrotron topography of metals and alloys in Application of X-ray Topographic Methods to Materials Science. S. Weissmann, ed. 283; 1985.

Bomberger, Jr॰, H. B॰; Meyn, D. A.; Fraker, A. C. Environmental effects on titanium and its alloys titanium, Science and Technology. Proc. of Fifth Int1. Conf. on Ti. G. Lutzering, U. Zwicker and W. Bunk, eds. 4: 2435; 1985.

Clough, R. B.; Wadley, H.N.G. Acoustic emission studies of dislocation motion and microfracture in rapid solidification of $\mathrm{Al}$ and $\mathrm{Al}-4.5 \% \mathrm{Cu}$. Proc. of Review of Progress in QNDE 4B, Plenum Press, NY; 661; 1985.

Clough, R. B.; Schaefer, R॰; Wadley, H.N.G. Acoustic emission monitoring of laser drilling in Nondestructive Microstructure Characterization and Process Control, H.N.G. Wadley, ed. ASM; 1985; in press.

Coble, R. L.; Song, H.; Brook, R. J.; Handwerker, C. A.; Dynys, J. M. Sintering of $\mathrm{MgO}$ and $\mathrm{Al}_{2} \mathrm{O}_{3}$. Structure and properties of $\mathrm{MgO}$ and $\mathrm{Al}_{2} \mathrm{O}_{3}$. Advances in Ceramics. W. D. Kingery, ed. 12: 839; 1985.

Corie11, S. R.; McFadden, G. B.; Boisvert, R. F。; Sekerka, R. F. Effect of a forced Couette flow on coupled convective and norphological instabilities during unidirecilonal solidification. J. Cryst. Growth 69: 15; 1984.

Coriell, S. R.; McFadden, G. B.; Sekerka, R. F. Cellular growth during directional solidification. Ann. Rev. Mater. Sci. 15: 119; 1985.

Dobbyn, R. C.; Yoo, K. C. Observation of dislocation images in surface reflection by synchrotron radiation topography in Applications of X-ray Topographic Methods to Materials Science. S. Weissman, ed. Plenum, NY; $241 ; 1985$.

Droney, B. E.; Wadley, H.N.G.; Norton, S. J.; Mauer, F. A. Experiments with ultrasonic sensors to measure internal temperature distribution. Proc. of Review of Progress in Quantitative NDE; 1985; in press.

Early, J. G. Recycling ferrous metals. Kirk-0thmer Concise Encyclopedia of Chemical Technology, Wiley-Interscience; 1985.

Elkind, B.; Rosen, M.; Wadley, H.N.G. Ultrasonic characterization of surface modified layers. Submitted to Met. Trans. A; 1985.

Fang, Q. T.; Glicksman, M. E.; Coriell, S. R.; McFadden, G. B.; Boisvert, R. F. Convective influence on the stability of a cylindrical solid-liquid interface. J. Fluid Mech. 151: 121; 1985. 
Frederikse, H.P.R.; Kahn, A. H.; Dragoo, A. L. Electrical resistivity and microwave transmission of hexagonal boron nitride. J. Amer. Ceram. Soc. $68 ; 1985$.

Gilmore, C. M.; Imam, M. A.; Fraker, A. C.; Yang, S. H.; Van Orden, A. C. The influence of thermal processing on fatigue crack initiation and propogation of Ti-4.5A1-5Mo-1,5Cr. Titanium Science and Technology. Proc. of Fifth Intl. Conf. on Ti, Vol. 4, G. Lutjering, U. Zwicker, and W. W. Bunk, eds. 4: 2091; 1985 .

Gvishi, M.; Bendersky, L.; Rosen, M.; Wadley, H.N.G. Pre-martensitic phenomena in equiatomic Ni-Ti alloy. Phi. Mag•; 1985; in press.

Gvishi, M; Rosen, M; Wadley, H.N.G. Acoustic emission characterization of the martensitic phase transformation in NiTi. Proc. of Review of Progress in QNDE 48; Plenum Press; 651; 1985.

Hahn, H.; Lare, P. J•; Roure, Jr॰, R. H॰; Fraker, A. C.; Ordway, F. Mechanical properties and structure of $\mathrm{Ti}-6 \mathrm{Al}-4 \mathrm{~V}$ with graded porosity coatings applied by plasma spraying for use in orthopedic implants, ASTM Spec. Tech. Pub. 859; 179; 1985.

Handwerker, C. A.; Cahn, J. W.; Yoon, D. N.; Blendell, J. E. The effect of coherency stress on alloy formation: migration of liquid films in Diffusion in Solids: Recent Developments. M. A Dayananda; G. E. Murch, eds. TMS publication. 275; 1985.

Handwerker, C. A.; Cannon, R. M•; Coble, R. L. Final stage sintering of $\mathrm{MgO}$. Structure and properties of $\mathrm{MgO}$ and $\mathrm{Al}_{2} \mathrm{O}_{3}$. Advances in Ceramics. W. D. Kingery, ed. 12: 619; 1985.

Hardy, S. C. The surface tension of liquid silicon. J. Cryst. Growth 69: $456,1984$.

Ives, L. K. An extraction replica method for the study of surface films, ASLE Trans. 28: 87; 1985.

Ives, L. K.; Peterson, M. B. Effect of solid additives on wear by greases containing abrasive particles in Wear of Materials 1985.

K. C. Ludema, ed. ASME, NY; 335; 1985.

Ives, L. K.; Peterson, M. B. Models of solid lubrication mechanisms, in Fundamental of high temperature friction and wear with emphases on solid lubrication for heat engines. Workshop Proc. sponsored by U.S. Army Research Office, Industrial Tribology Institute, Troy, NY; 43; 1985.

Johnson, W. C.; Voorhees, P. W. Equilibrium solute concentrations surrounding elastically interacting precipitates. Met. Trans. 16A: 337; 1985.

Kahn, A. H•; Long, K. R.; Ryckebusch, S•; Testard1, L. R. Determination of electrical conductivity profiles from frequency-sweep eddy current measurement. Proc. of Review of Progress in Quant1tat1ve NDE; 1985; in press. 
Kaufman, M. J.; Fraser, H. L. Microstructural analysis of rapid solidification and undercooling in the Al-Ge alloy systems. Proceedings of the MR Symposium on Rapidly Solidified Metastable Materials. B. H. Kear, B. C. Giessen, eds. 28: 335; 1984.

Kaufman, M. J.; Fraser, H. L. The importance of undercooling in the formation of non-equilibrium structures in the Al-Ge alloy systems. Int. J. Rapid Solidification 1: 27; 1985.

Kaufman, M. J.; Fraser, H. L. Characterization of metastable crystalline phases in the Al-Ge alloy system. Acta Met. 33: 191; 1985.

Kaufman, M. J.; Stanley, J. T॰; Van Aken, D. C.; Field, R. D.; Fraser, H. L. Microstructure of some rapidly solidified Al-base alloys. Rapidly Quenched Metals. S. Steeb, H. Warlimont, eds. 941; 1985.

Kaufman, M. J.; Pugh, E. N. A new approach to improving resistance to transgranular stress corrosion cracking. Proc. of U.S.A.-Japan seminar on Critical Issues in Reducing the Corrosion of Steels. H. Leidheiser, Jr., S. Haruyama, eds. 250; 1985.

Kaufman, M. J. Characterization of stable and metastable phases using analytical electron microscopy. MRS Symposium on Alloy Phase Diagrams L. H. Rennett, B. C. Giessen, T. B. Massalski, eds. 62; 1985.

Kelley, D. R; Johnson, C. E.; Lashmore, D. S. Development of microhardness standards, LabCon West, San Mateo, CA; 1985; in press.

Kuriyama, Mo; Boettinger, W. J. Asymmetric crystal topography with $x$-ray image magnification in Applications of X-ray Topographic Methods to Materials Science. S. Weissmann, ed. Plenum, NY; 23; 1985.

Kuriyama, M.; Long, G. G. Extinction theory in x-ray topography in Applications of X-ray Topographic Methods to Materials Science. S. Weissman, ed. Plenum, NY; 97; 1985.

Kuriyama, M.; Long, G. G.; Bendersky, L. Unit cell structure of rapidly cooled Al-Mn alloys with icosahedral symmetry. Phys Rev. Lett. 55: $849 ; 1985$.

Lashmore, D. L. Plating on aluminum: a review. Plating and Surface Finishing. 72: 36, 1985.

Lashmore, D. L. Electrodeposition of nickel chromium alloys. Proc. of Interfinish '84, Jerusalem, Israel; 1984; in press.

Lashmore, D. S. Pulsed Electrodeposition of nickel-chromium. Proc. Surface Finishing 85, Detroit, MI.; 1985; in press

Lichter, B. D.; Cassagne, T. B.; Flanagan, W. F.; Pugh, E. N. Studies of transgranular stress corrosion cracking in copper gold. Microstructural Science 13: $361 ; 1985$. 
Linzer, M.; Droney, B. E.; Martinez, J. W.; Mauer, F.; Norton, S. J.; Wadley, H.N.G. Progress in development of ultrasonic sensors for monitoring hot steel product. Proc. of the Fifth Process Technology Division Conference; $163 ; 1985$.

Long, G. G.; Revez, A. G.; Kuriyama, M. X-ray absorption study of tantalum oxide films on silicon. J. Non-crystalline Solids 70: 271; 1985.

Low, S. R.; Early, J. G. Drop-weight testing of non-standard specimen geometries. Am. Soc. Testing Materials Spec. Tech. Pub.; 1985; in press.

Mehrabian, R.; Wadley, H.N.G. Sensor needs for materials processing. Proc. of Review of Progress in QNDE 4B; Plenum Press, NY; 839; 1985.

Melmed, A. J.; Twigg, M. E.; Klein, R.; Kaufman, M. J.; Fraser, H. L. The complementary use of atom probe field ion microscopy and analytical transmission electron microscopy for the study of a Ni-base superalloy. J. de Physique, Colloque C9, Supplement au n²12, Tome 45: C9; 1984.

McAlister, A. J.; Murray, J. L. The Al-Ge system. Bulletin of Alloy Phase Diagrams 5(4): $341 ; 1984$.

McAlister, A. J. The Al-Sb system. Bulletin of Alloy Phase Diagrams $5(5): 462 ; 1984$.

McAlister, A. J. The Al-As system. Bulletin of Alloy Phase Diagrams $5(6): 577 ; 1984$.

McAlister, A. J. The Al-Hg system. Bulletin of Alloy Phase Diagrams $6(3): 219 ; 1984$.

McAlister, A. J. The Al-P system. Bulletin of Alloy Phase Diagrams; 1985; in press.

McAlister, A. J. The Al-Pd system. Bulletin of Alloy Phase Diagrams; 1985 ; in press.

McAlister, A. J.; Shull, R. D.; Reno, R. C. Phase equilibrium in the titanium-aluminum system. Titanium ' 84 Science and Technology. North Holland Publishing Co., New York, NY; 1985; in press.

McFadden, G. B.; Coriell, S. R. Nonplanar interface morphologles during unidirectional solidification of a binary alloy. Physica D 12D: 253; 1984.

McFadden, G. B.; Rehm, R. G.; Coriell, S. R.; Chuck, W.; Morr1sh, K. A. Thermosolutal convection during directional solidification. Met. Trans. A 15A: $2125 ; 1984$.

McFadden, G. B.; Coriell, S. R.; Boisvert, R. F.; Glicksman, M. E.; Fang, Q. T. Morphological stability in the presence of fluid flow in the melt. Met. Trans. A 15A: 2117; 1984. 
Mullen, J. L.; Lashmore, D. S. The automation of microhardness measurements. Proc. of the 40 th MFPG Conference. 1985; in press.

Murray, J. L. The Al-Cu system. Inter. Met. Rev. 1985; in press. Murray, J. L. The Bi-Ti system. Bulletin of Alloy Phase Diagrams $5(6): 610 ; 1984$.

Murray, J. L. The Pb-Ti system. Bulletin of Alloy Phase Diagrams $5(6): 613 ; 1984$.

Neyab-Hashemi, A. A.; Clark, J. B.; Swartzendruber, L. J. The Fe-Mg system. Bulletin of Alloy Phase Diagrams 6(3): 235; 1985.

Norton, S. J.; Linzer, M. Reconstructing a spatially-incoherent random source in the near field: exact inversion formulas for circular and spherical arrays. J. Acoust. Soc. Amer. 26(6): 1731; 1984.

Norton, S. J.; Testardi, L. R. Reconstruction of one-dimensional inhomogeneities in elastic modulus and density from measurements of acoustic resonances. Proc. of the 14th International Symposium on Acoustical Imaging. 1985; in press.

Norton, S. J. Iterative reconstruction techniques: convergence as a function of spatial frequency. J. Opt. Soc. Amer. A 2: 6; 1985.

Norton, S. J.; Testardi, L. R. Reconstruction of one-dimensional inhomogeneities in elastic modulus and density using acoustic dimensional resonances. Submitted to J. Acoust. Soc. Amer.

Norton, S. J.; Wadley, H.N.G. Tomographic reconstruction of internal temperature. Proc. of Review of Progress in QNDE 3A; Plenum Press, NY; 309; 1985 .

Okamoton, N.; Massalski, T. B.; Swartzendruber, L. J.; Beck, P. A. The $\mathrm{Au}-\mathrm{Fe}$ system. Bulletin of Alloy Phase Diagrams 5(6): 592; 1984.

Parker, R. L.; Manning, J. R.; Peterson, N. C. Application of pulse-echo ultrasonics to locate the solid/liquid interface during solidification and melting of steel and other metals. J. Appl. Phys. 1985; in press.

Patterson, D. E.; Hujar, R. B.; Escalante, E. Bronze, zinc, aluminum, galvanized steel: corrosion rates as a function of space and time over the United States. Proc. Symposium on Degradation of Materials Due to Acid Rain. Amer. Chem. Soc. 1985; in press.

Paul, E.; Swartzendruber, L. J. The Fe-Nb system. Bulletin of Alloy Phase Diagrams. 1985; in press.

Peterson, M. B.; Bhansali, K. J.; Whitenton, E. P.; Ives, L. K. Galling wear of metals in Wear of Metals 1985. K. C. Ludema, ed. ASME, NY; $293 ; 1985$. 
Pugh, E. N. Progress towards understanding the stress corrosion problem. Corrosion 41: 517 ; 1985 .

Rogers, C. D.; Droney, B. E.; Toth, J. M.; Wadley, H.N.G. Detection of pipe and porosity in hot steel slabs, blooms and billets. Proc. of 26th Mechanical Working and Steel Processing Conf.; 1984; in press.

Rosen, M•; Ives, L. K.; Ridder, S.; Biancaniello, F.; Mehrabian, R. Correlation between ultrasonic and hardness measurements in aged 2024 aluminum alloy. Materials Sci.\& Eng•; 1985; in press.

Ruff, A. W. Analysis of interlaboratory test results of solid particle impingment erosion in Wear of Metals 1985. K. C. Ludema, ed. ASME, NY; 1985; in press.

Ruff, A. W.; Polvani, R. S. Micropenetration testing: Characterizaiton of surface properties of materials involving wear, Surface Technology BAM; Ber1in; 1985.

Shechtman, D.; Schaefer, R. J.; Biancanie110, F. S. Precipitation in rapidly solidified Al-Mn alloys. Met. Trans. 15A: 1987; 1984.

Schaefer, R. J.; Coriell, S. R. Convection-induced distortion of a solid-11quid interface. Met. Trans. 15A: 2109; 1984.

Schaefer, R. J. Principles underlying coatings and surface modification science. Mater. Sci.\& Eng. 70: 1985.

Schaefer, R. J. Ion-beam and laser-induced surface modifications. Mater. Sci.\& Eng. 70: 1985.

Shull, R. D.; McAlister, A. J•; Reno, R. C. Phase equilibria in the titanium-aluminum system. Titanium Science and Technology. G. Lutjering, U. Zwicker, and W. Bank, eds. Pub. by Deutsche Gesellschaft fur Metallkunde, e.v. 1459 ; 1985.

Shu11, R. D.; Kaufman, M. J. Nature of large $\mathrm{Ti}_{4} \mathrm{Cu}_{2} \mathrm{O}$ particles formed during annealing of Cu55Ti45 metallic glass ribbons. Met. Trans. A; 1985; in press.

Simmons, J. A. New method for deconvolution and signature analysis of causal and transient time series--I. Root transforms and causal boundary roots. Submitted to IEEE Trans. ASSP.

Simmons, J. A. New method for deconvolution and signature analysis of causal and transient time series-II. Root projection. Submitted to IEEE Trans. ASSP.

Simmons, J. A. New method for deconvolution and signature analysis of causal and transient time series--III. Deconvolution. Submitted to IEEE Trans. ASSP. 
Singhal, S. P.; Blancaniello, F. S.; Alperin, H. A.; Herman, H. Smallangle neutron scattering study of phase decomposition in the N1-rich side of the N1-Ni3Al miscibility gap. Scripta Met. 19: 133; 1985.

Smith, J. J.; Friant, C. L.; Rosen, M.; Wadley, H.N.G. Nondestructive characterization of rapldly solidified alloys in Nondestructive Microstructure Characterization and Process Control. H.N.G. Wadley, ed. ASM; 1985; in press.

Swartzendruber, L. J.; Shechtman, D.; Bendersky, L.; Cahn, J. W. Nuclear $\gamma$-ray resonance observations in an aluminum-based icosahedral quasicrystal. Physical Review B 33: 1382; 1985.

Swartzendruber, L. J. The Ag-Fe system. BulletIn of Alloy Phase Diagrams 5(6): $560 ; 1984$.

Swartzendruber, L. J. The Fe-Rh system. BulletIn of Alloy Phase Diagrams $5(5): 456 ; 1984$.

Swartzendruber, L. J.; Paul, E. The Fe-Ta (iron-tantalum) system. Bulletin of Alloy Phase Diagrams; 1985; in press.

Swartzendruber, L. J.; Itkin, V. P.; Alcock, C. B. The Fe-N1 system. Bulletin of Alloy Phase Diagrams; 1985; in press.

Swartzendruber, L. J. Thermodynamic assessment of the iron noble-metal equilibrium diagrams. AIME Conference Proc.; New York, NY; 1985;

in press.

Takag1, S; Chow, L. C.; Brown, W. E.; Dobbyn, R. C.; Kuriyama, M. Application of an $x$-ray lmage magnifier to the microradiography of dental specimens. J. Dental Res. 64: 866; 1985.

Testardi, L. R.; Norton, S. J.; Hsleh, T. Determination of Inhomogeneities of elastic modulus and density for one-dimensional structures using acoustic dimensional resonances. J. App1. Phys. 56(10): 2681; 1984 .

Testardi, L. R.; Norton, S. J.; Hsieh, T. Acoustical dimensional resonance tomography: some examples in one-dimensional systems. Submitted to Appl. Phys.

Twigg, M. E.; Melmed, A. J•; Klein, R॰; Kauman, M. J•; Fraser, H. L. A microanalytical study of secondary precipitation in RSR143 using atom probe field ion microscopy and analytical transmission electron microscopy. Proc. of Fifth Int. Conf. on superalloys. M. Ge11, C. S. Kortovich, R. H. Brickne11, W. B. Kent, J. F. Radavich, eds. 631; 1984.

Van Orden, A. C; Ugiansky, G. M.; Rodriquez, M. J.; Escalante, E. Computer assisted corrosion data evaluation and dissemination in Proc. of the Symposium on Computer Aided Acquisition and Analysis of Corrosion Data. M. W. Kendig, U. Bertocci, J. E. Strutt, eds. 181; 1984. 
Voorhees, P. W.; Glicksman, M. E. Thermal measurement of Ostwald ripening kinetics in partially crystallized mixtures. J. Cryst. Growth; 1985; in press.

Voorhees, P. W. The theory of Ostwald ripening. J. Stat. Phys. 38: 231; 1985.

Voorhees, P. W.; Johnson, W. C.; Larala, V. J. Elastic effects during late stage phase transformations. Proc. of the Intl. Seminar on soluteDefect Interaction: Theory and Experiment; 1985; in press.

Wadley, H.N.G.; Norton, S. J.; Mauer, F॰; Droney, B. Ultrasonic measurement of internal temperature distribution. Proceedings of the Royal Society of London; 1985; in press.

Wadley, H.N.G.; Mehrabian, R. Acoustic emission for materials processing: a review. Materials Science and Engineering 65: 245; 1984.

Wadley, H.N.G. Acoustic emission: natures ultrasound. Proceeding of Review of Quantitative NDE; 1985; in press.

Wadley, H.N.G; Norton, S. J.; Mauer, F;. Droney, B. Proceedings of Royal Soc., Series A; 1985; in press.

Watson, R. E.; Bennett, L. H. Optimized predictions for heats or formation of transition-metal alloys II, CALPHAD 8: 307; 1984.

Watson, R. E.; Sternheimer, R. M•; Bennett, L. H. Trends in the electric quadrupole fields at dilute impurity sites in transition metal-transttion metal alloys. Phys. Rev. B 30: 5209; 1984.

Watson, R. E.; Bennett, L. H. The physical modelling of transition metal alloying: the roles that different levels of theory play in High Temperature Alloys: Theory and Design. J. 0. Stiegler, ed. The Metallurgical Society of AIME; $145 ; 1984$.

Watson, R. E.; Bennett, L. H. The quasicrystalline structures of transition metal/metalloid glasses, International Conference on Magnetism; 1985; in press.

Watson, R. E.; Bennett, L. H. The noble metals as incipient transition elements in Noble Metal Alloys. T. B. Massalski, L. H. Bennett, Y. A. Chang, and W. B. Pearson, eds. The Metallurgical Society of AIME; 1984; 1n press

Yoon, D. N.; Cahn, J. W.; Handwerker, C. A.; Blende11, J. E. ; Ba1k, Y. J. Coherency strain induced migration of liquid films through solids; in interface migration and control of microstructure symposium; ASM annual meeting; Detroit; 1984; in press. 
The research programs of the Metallurgy Division are designed and carried out in support of Industrial and scientific needs. Speclalized faclilties within the Division, including metals processing and nondestructive evaluation, attract scientists from both academic and industrial organizations for cooperative research efforts. Interactions with industry, universities, and professional organizations are viewed as an important element of our work with collaborative programs, consulting and general involvement with outside groups being a long standing practice. For example, the Metallurgy Division has been working for more than 70 years with the steel industry to improve the durability and performance of alloys.

In 1985, the Division performed collaborative research with many private organizations through its Industrial Research and Guest Worker programs and other arrangements. Representative examples of such interactions Include:

\section{INDUSTRIAL}

\section{The Aluminum Association}

A new collaborative program with the Aluminum Association directed at the noncontact measurement of internal temperature profiles during high speed aluminum extrusion is being started in the Nondestructive Characterization Group.

\section{American Cyanamid Corporation}

The American Cyanamid Company is sponsoring a Research Associate position at NBS dealing with electrodeposited metal matrix composites.

3. The American Electroplaters Society (AES)

The AES has sponsored for several years a program in the Electrodeposition Group dealing with the electrodeposition of heat and corrosion resistant alloys. A new program will start in FY 86 involving the development of a computer model to predict the composition of binary and higher order alloys under both direct and pulsed current conditions.

4. American Iron and Steel Institute.

During FY 85 a strong collaborative interaction has continued on the development of process control sensors for steel. Under a cooperative research agreement with the AISI, steel industry Research Associates J. Martinez (AISI), B. Droney (Bethlehem Stee1), D. Rogers (U.S. Stee1), J. Cook (Armco), and T. Shelenberger (Inland Steel) have obtained significant new results. 
5. American Society for Metals

The technical activities of the joint NBS/American Society for Metals Data Program for alloy phase diagrams are centered at NBS. The editor and associate editor of the Bulletin of Alloy Phase Diagrams are J. L. Murray and B. Burton. Three category editors of the program are working at NBS: J. L. Murray, L. J. Swartzendruber and A. J. McAlister, for $\mathrm{Ti}-, \mathrm{Al}$-, and $\mathrm{Fe}-$ alloys, respectively.

6. Artech Corp.

Mr. Henry Hahn, President of Artech, has worked with the Wear and Mechan1cal Properties Group (A. C. Fraker) in conducting studies of arc plasma sprayed porous coatings of titanium and Ti-6Al-4V. The strength of the interface, corrosion fatigue behavior and corrosion resistance were determined. Effects of variable parameters in the porous coating application were investigated and best processing methods were determined.

7. Automotive Industry (Chrysler, Ford, General Motors)

The Electrodeposition Group in response to requests from the automotive industry has developed a Step-Test Corrosion standard. Our interaction with these companies has been through visits to NBS by several of their representatives through ASTM and through direct round robin tests of our standards.

8. CEM Corporation

The Electrodeposition Group has cooperated with the CEM Corporation (Lois Jassie) in the development of a microwave thermocouple.

9. COMSAT Laboratories

Several members of the Corrosion Group interacted with scientists from COMSAT Laboratories in a study of the effects of cathodically generated hydrogen on the mechanical behavior of a nickel base alloy, a problem related to the performance of a component of a communication satellite. Slow strain rate tests at NBS under simulated service conditions demonstrated that the alloy can undergo significant embrittlement and indicated the range of expected crack velocities.

10. The Construction Industries Manufactures Association (CIMA) and the Farm and Industrial Equipment Inst1tute (FIMI)

A workshop co-sponsored by Argonne National Laboratories (ANL), CIMA, and FIMI was held at ANL in March 1985 for the purpose of evaluating the federal research areas of greatest interest to the U.S. off-road machinery manufacturers. A serles of panels representing industrial and federal organizations identifled several key technologies including tribology (wear and friction) where 
government research was of interest to industry. P. J. Blau (NBS) described the wear and friction activities in the ISME, and specifically, in the Metallurgy Division. ANL personnel are following up on the workshop to identify possible federal laboratory/industrial joint efforts in the key areas.

11. Deere and Company

A Research Associate Program with Deere and Co. (L. K. Ives, NBS, and P. A. Swanson, Deere and $\mathrm{Co}_{.}$) is concerned with investigating problems connected with the measurement of galling damage and the development of tests to determine the galling behavior of metals. Tests and measurement methods developed at NBS are currently being employed to evaluate alloys used in agricultural and industrial equipment where galling wear is a serious problem.

12. DePuy Mfg. Co., Inc.

Mr. Todd Smith of DePuy has cooperated with A. C. Fraker, NBS, in research designed to study the mechanical and electrochemical effects of applying sintered porous coatings of Co-Cr-Mo to Co-Cr-Mo substrates. Specimens involving extensive preparation and modelled after industrially produced prosthetic devices were provided.

13. C. S. Draper Laboratory, Inc.

Studies are underway involving the microstructural design of beryllium, specifically, the dimensional instability, time dependent shape distortion, and coefficient of thermal expansion. These factors critically determine the navigational precision of inertial guidance instruments that use beryllium alloy components. This is a collaboration among K. Kaplesh and J. McCarthy (Draper) and R. Polvani (Metallurgy Division). Draper has supplied the materials, fabricated the test samples and provided funding. NBS will provide the special measurement capability and interpretation of the data.

14. DuPont Corporation

In cooperation with the DuPont Corp., the Electrodeposition Group has developed a new coating thickness SRM. A group of companies (Biddle Instruments, Magna Flux, Duke Power Company, Pullman Sheet Metal Works, and Frank J. Koch Inc.) have requested two new coating thickness SRM's which have been produced and are now in the FY 85 catalog.

15. FIBA, Inc. and Union Carbide Corporation

A collaborative effort is under way betwen J. H. Smith of NBS and FIBA, Inc. (Mr. P. Horrigan) and Union Carbide ( $\mathrm{Mr}$. R. Tripolet) to evaluate use of acoustic emission techniques for use in the periodic inspection of large steel pressure vessels. NBS is in 
the process of developing specific procedures and test criteria to permit the use of acoustic emission techniques for this application.

16. Howmedica, Inc.

Mr. Larry Gustavison of Howmedica has cooperated with A. C. Fraker of NBS and provided sintered porous coated Co-Cr-Mo research materials and devices for use in metallurgical studies. He also provided the Co-Cr-Mo material used for the Standard Reference Materials 1891.

17. Leco Corp•; Leitz Corp.; Reichart Corp.; Wilson Corp.

A number of industries have been interacting with the Electrodeposition Group in the area of microhardness measurements. These include Leco (F. Toye), Wilson (A. Fee), Reichart (C. Spinella), and Leitz (A. Graf). Each of these companies has been provided with the load-time curve for one or more of their hardness testing instruments. Discussions of hardness testing techniques and problems have been held at NBS with engineers of each of these companies. As a result of these interactions, several of the commercial instruments have been modified.

18. Luxfer USA, Inc. and Detek, Inc.

A collaborative effort between J. H. Smith of NBS and G. Waite of Luxfer and A. Julier of Detek, Inc. has been aimed at developing a reliable method of using eddy current techniques to inspect composite pressure vessels for cracks.

19. National Association of Corrosion Engineers (NACE)

The Corrosion Data Program, a cooperative effort of the National Association of Corrosion Engineers and the National Bureau of Standards will provide materials scientists and engineers with computerized evaluated corrosion data. The pilot project phase has been successfully completed and work has begun on a prototype of the accessible database. The Corrosion Data Workshop, held this past June, brought together over 50 corrosion specialists from industry, government, and universities for an intensive discussion on the present state of and future needs for evaluated corrosion data. The findings of the workshop, which will be published in book form, will be used to help direct the corrosion data program. NACE is seeking funding support from industry to provide start-up and implementation costs for the full scale corrosion data program.

20. Parker Hannifin Corporation

Research on characterizing the weldability of a leaded, resulfurized, rephosphorized carbon steel is being carried out in a cooperative program between Parker Hannifin (W. Hertel), the U.S. Coast Guard 
(H. Hime), and J. G. Early (Metallurgy Division) of NBS. This research is aimed at establishing welding limits for this steel which is not currently allowed in ship components. Welded samples prepared with several joint geometries were provided by Parker Hannifin for characterization at NBS.

\section{Shell 0il Company}

Members of the Corrosion Group took part in several meetings and discussions with representatives of the Shell 0il Company. These interactions, which also involved staff of the Consumer Product Safety Commission and the Department of Transportation, were concerned with the effects of possible ammonia contamination of liquid-propane gas on brass components in the system. Our experience of the electrochemistry and stress corrosion cracking in the brassammonia system proved valuable in attempts to predict possible embrittlement effects and in outlining procedures to combat potential problems.

22. Union Carbide Corp. and Taylor-Warton, Inc.

A collaborative effort is underway between the Wear and Mechanical Properties Group (J. H. Smith) and the Linde Division of Union Carbide (Mr. M. Rana) and Taylor Wharton, Inc. (Mr. K. Miller) to develop criteria for the safe design and fabrication of high strength steel, seamless pressure vessels. Criteria have been developed, based on fracture mechanics principles, to permit the use of new, higher strength steels for the construction of pressure vessels without reducing the level of safety of these vessels.

\section{INDUSTRY/UNIVERSITY}

\section{Metals Processing Laboratory Interactions}

The NBS Metals Processing Laboratory is one of the special facilities available at the National Bureau of Standards to aid researchers from outside NBS in independent or collaborative research and testing of new materials. Such investigators can come to NBS to participate in the preparation of special samples not readily obtainable elsewhere. During the past year, investigators from Martin Marietta, General Electric, Carpenter Technology, Richards Medical, Naval Research Laboratory, Naval Air Development Center, Los Alamos National Laboratory, Massachusetts Institute of Technology, Drexel University, University of Washington, and University of Connecticut have participated in interactions in this program. Collaboration with NBS scientists on metallurgical aspects of the generic technical problems involved is often included in these activities. Particular interest has been shown in rapid solidification technology, where the Metals Processing Laboratory possesses unique capabilities. 


\section{UNIVERSITIES}

1. Carnegie-Mellon University

Professor W. Johnson (Carnegie-Mellon University) and P. Voorhees (Metallurgical Processing Group) have been collaborating on a study of stress effects on alloy coarsening. In high-strength alloys designed for use at high temperatures, control of precipitate size and avoidance of excessive coarsening of the alloy microstructure is important in order to maintain high performance. This joint program in which the expertise of Professor Johnson and his students on elastic interactions in alloys is combined with the expertise of $\mathrm{Dr}$. Voorhees and co-workers at NBS on kinetic effects has resulted in significant progress toward evaluating the effect of stress on coarsening processes.

\section{Johns Hopkins University}

A cooperative program between The Johns Hopkins University and NBS for study of rapid solidification processes has been in progress for the past four years. Typically, in this program rapidly solidified alloys are produced in the NBS Metals Processing Laboratory and then characterized by electron microscopy techniques by scientists from Johns Hopkins (D. Shechtman and L. Bendersky). The results are jointly analyzed by the cooperating NBS and Johns Hopkins scientists to determine the effect of rapid solidification processing on alloy microstructure. This collaboration has recently resulted in a major discovery of a new class of materials, quasicrystals, that do not obey previously accepted crystallographic restrictions concerning periodicity.

3. Johns Hopkins University

Interface characterization of composite materials using ultrasonic techniques has also begun. The fruitful collaboration with The Johns Hopkins University has continued with Professor Moshe Rosen and his graduate students (T. Hsieh, J. Smith, B. Elkind and $\mathrm{K}$. Hershman) interacting strongly with group scientists to make valuable contributions to the task.

4. Johns Hopkins University

A cooperative program has been initiated between $\mathrm{Dr}$. L. H. Bennett (Metallurgy Division), the Johns Hopkins University Applied Physics Laboratory (Dr. K. Moorjani) and the Naval Research Laboratory (Dr. M. Rubinstein) to measure local site symmetry and possible magnetic interactions in the Al-Mn icosahedral phase by nuclear magnetic resonance and with a SQUID magnetometer. 
5. North Carolina State University

This research is a collaborative effort between Dr. H. H. Stadelmaier and Ms. Inge K. Simonsen of N.C. State University and A. C. Fraker (NBS) to determine the identity and conditions of formation of carbides found in Co-Cr-Mo-C alloys. The results should be useful in controlling the amounts and distribution of carbide phases in this material.

6. University of Wisconsin-Madison

Professor J. H. Perepezko (University of Wisconsin) and W. J. Boettinger (NBS Metallurgical Processing Group) have been collaborating on problems related to microstructure formation during rapid solidification. Extensive experience at the University of Wisconsin on the undercooling and nucleation behavior of Iiquid metal droplets has been combined with NBS work on alloy growth kinetics to yield results which present a more comprehensive view of how microstructures develop in rapidly solidified powders and ribbons. This knowledge can be used to tailor microstructures to meet specific alloy property requirements.

TECHNICAL/PROFESSIONAL COMMITTEE LEADERSHIP ACTIVITIES

American Association for Crystal Growth

S. R. Corle11, Executive Committee

American Electroplaters Soclety

Alloy Deposition Handbook

D. S. Lashmore, Editor

American Society of Mechanical Engineers

NDE for Process Control Committee

H. N. G. Wadley, Chairman

Tribology Division, Executive Committee

A. W. Ruff

American Society for Metals

Bulletin of Alloy Phase Diagrams

J. L. Murray, Editor

Washington, DC Chapter

P. J. Blau, Vice Chalrman

J. G. Early, Chairman, Yearbook Committee

American Soclety for Testing and Materials

B7: Light Metals and Alloys; Aluminum Alloy Ingots and Castings

B7.07.09: Conversion Coatings on Aluminum

D. S. Lashmore, Chairman

B8: $\quad$ Electrodeposited Coatings

B8.01: Terminology, Editing Public Relations and Metrication 


$$
\text { WG.05: D. S. Lashmore, Metrication Chatrman }
$$

B8.06: Chemical Conversion Coatings

D. S. Lashmore, Subcommittee Chalrman

B8.10.03: General Test Methods for Microhardness

C. E. Johnson, Liaison to E04

E7: Nondestructive Testing

Jo1nt Task Group on Acoustic Emission; System Calibration

J. A. SImmons, Chairman

E24: Fracture Testing

C. G. Interrante, Member of Executive Committee

E24.05: Terminology for Fracture Testing

C. G. Interrante, Cha1rman

E38: Resource Recovery

J. G. Early, Member-at-Large, and Member of Executive Committee

E38.02: Ferrous Metals Resource Recovery

J. G. Early, Chalrman

F4: Medical and Surgical Materials and Devices

F4/G1: Jo1nt Section on Corrosion of Implants

A. C. Fraker, Co-Chairperson

F7.04: Hydrogen Embrittlement Testing

C. G. Interrante, Chairman, Task Group on Terminology

G18.99: Corrosion of Metals

Standing Comittee on Lialson

E. N. Pugh, Chairman

G2: Erosion and Wear

G2.2: Solld Particle Erosion

A. W. Ruff, Task Group Leader

G2.9: Executive Subcommittee Task Group on Operations

L. K. Ives, Cha1rman

G2.91: Terminology and Definitions

P.J. Blau, Chatrman

ASTM Standing Committee on Terminology

C. G. Interrante, Technical Committee Representative

P. J. Blau, Chalrman, Terminology Coordinating Task Group on Tribology

ASTM Coordinating Group on Terminology for Environmental Efforts

C. G. Interrante, Convener 
Applied Niechanics Review

R. B. Clough, Review Staff

Case Western Reserve University, Materials Research Laboratory, NSF Visiting Committee

E. N. Pugh, Member

Electrochemical Soclety

Editorial Committee

U. Bertocc1, Division Editor

Electrodeposition Division

D. S. Lashmore, Secretary-Treasurer

Federation of Materials Societies

U. Bertocci, S. R. Coriell and G. M. Ugiansky, Trustees

Awards Committee

G. M. Ugiansky, Chairman

Interagency Strategic Materials Stockpile Advisory Group

J. G. Early, NBS Representative

International Institute for the Sclence of Sintering

P. W. Voorhees, Corresponding Member

International Journal of Crystal Growth

R. L. Parker, Associate Editor

International Society of Flectrochemistry

Corrosion Division

U. Bertocc1, Co-Cha1rman

International Standards Organization

TC107: Metallic and Other Non-organic Coatings

D. S. Lashmore, Delegate

1: Terminology

D. S. Lashmore, Delegate

2: Methods of Inspection and Coordination of Test Methods

D. S. Lashmore, Delegate

3: Electrodeposited Coatings and Related Finishes

D. S. Lashmore, Delegate

7: Corrosion Tests

D. S. Lashmore, Delegate

TC156: Corrosion of Metals 
G. M. UgLansky, Delegate

\section{2: Stress Corrosion \\ G. M. Uglansky, Delegate}

TC164: Medical Testing

1. Terminology
C. G. Interrante, Delegate

Maryland Institute of Metals

W. J. Boettinger, Executive Board Member

Materials Sclence and Engineering

L. H. Bennett, Associate Editor

Mechanical Fallures Prevention Group

Committee on Mechanisms of Fallure

J. G. Early, Chalrman

Committee on Fuel Cell Materials Technology in Vehicular

Propulsion

U. Bertocc1, Lialson Representative

National Association of Corrosion Engineers

G. M. Uglansky, Director, ex officio, Board of Directors

Government Affairs Committee

G. M. Ugiansky, Chairman

Office of Energy-Related Inventions, National Bureau of Standards

J. G. Early, Reviewer of Invention Disclosures

Read Research Conferences

Organizing Committee

D. S. Lashmore, Member

Soclety of Automotive Englneers

Committee on Automotive Trim

D. S. Lashmore, Invited Member

Soclety of Automotive Engineers/American Soclety of Testing and Materials Unifled Numbering System for Metals and Alloys

L. H. Bennett, NBS Representative

Society for Blomaterials Standards

A. C. Fraker, Chairperson, Representative

U.S. Civil Service Examiners for Metallurgist

Interagency Board

J. G. Early, Chalrman 
U.S. Department of Transportation

Technical Safety Standards Committee

J.H. Smith, Secretary

Versailles Advanced Materials and Standards

Subcommittee on Wear

A. W. Ruff, U.S. Representative

\section{ASSOCIATED ACTIVITIES}

Members of the Metallurgy Division have been very active during the year in transferring the results of their scientific research to the technical community through a variety of means. Over 60 invited talks were presented at industrial laboratories, technical society symposia, and international conferences. A major corrosion workshop was organized to focus on how the needs of the material industry for corrosion data could be satisfied through the National Association of Corrosion Engineers-National Bureau of Standards Corrosion Data Center. Division scientists wrote or edited five books on topics related to alloy phase diagrams, wear and tribology, and electrodeposition. In the area of providing certified or standard materials for the calebration and standardization needs of U.S. industry, five new Standard Reference Materials for implant materials, coating thickness gages, and corrosion studies were developed by Division researchers and placed on sale by NBS. In the area of electrodeposition technology, microhardness testing, and amorphous alloys patents have been granted or are in preparation. 


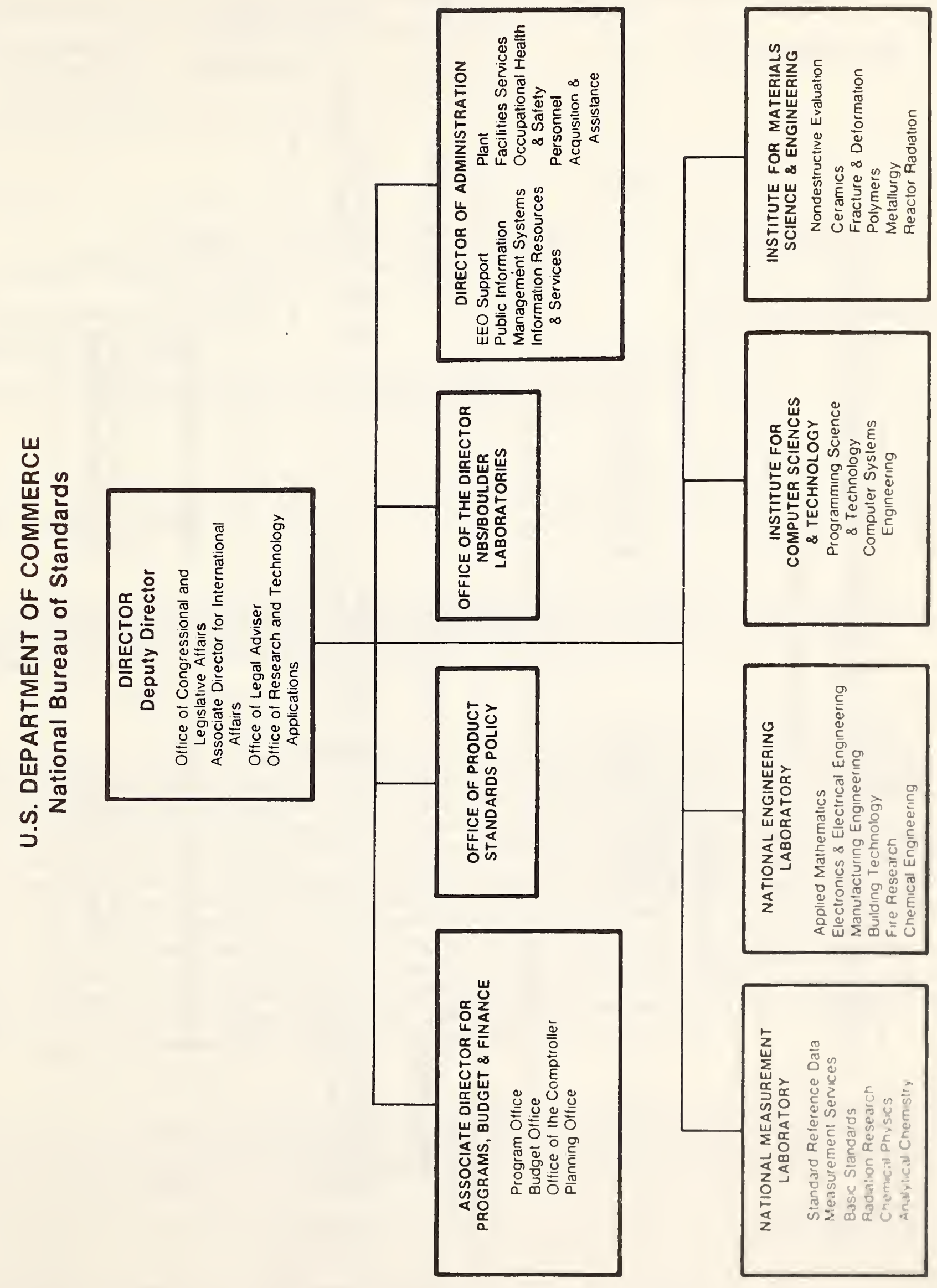




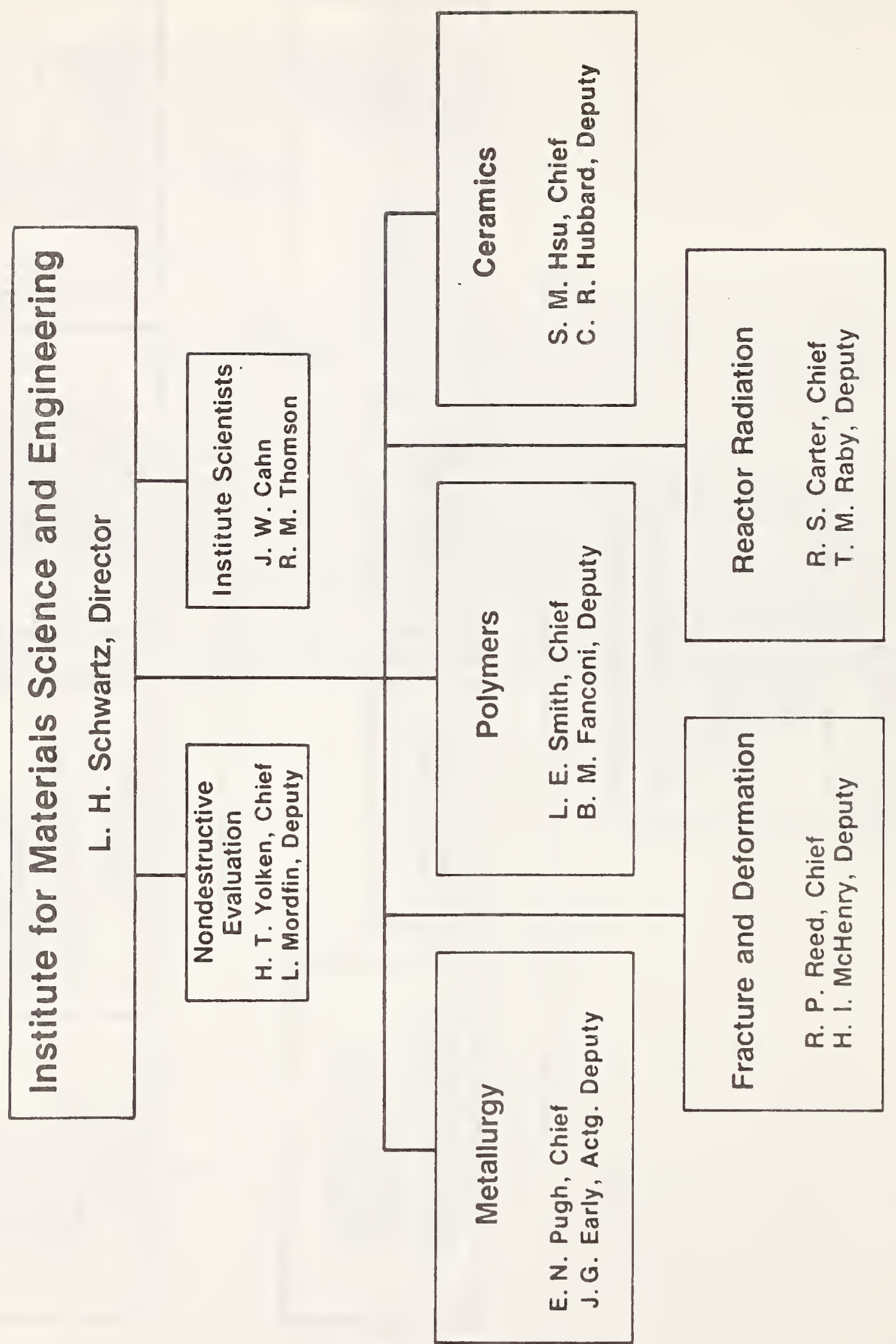




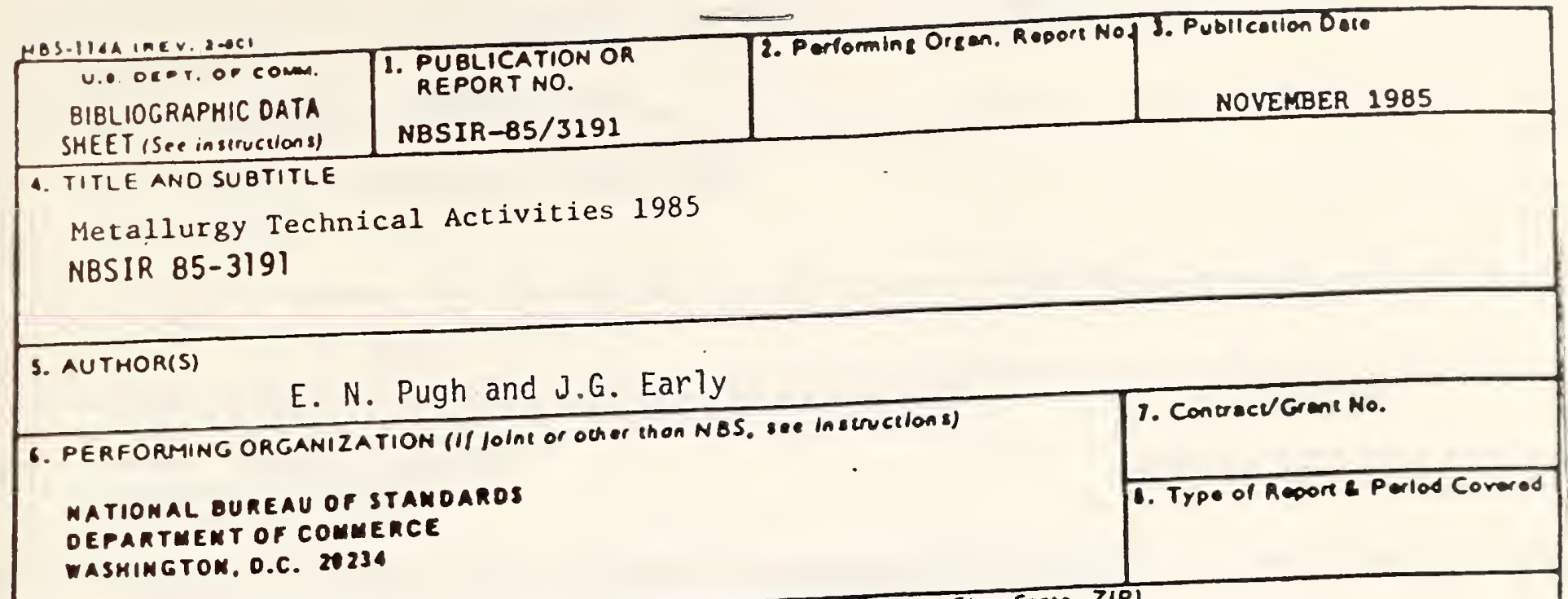

WATION NAME ANO COMPLETE ADDRESS (Streel, Citr. Siote, ZIP)

10. SUPPLEMENTARY NOTES

Document describes a computar pregren; SF-185. FIPS Softwere Summery. Is attedied.

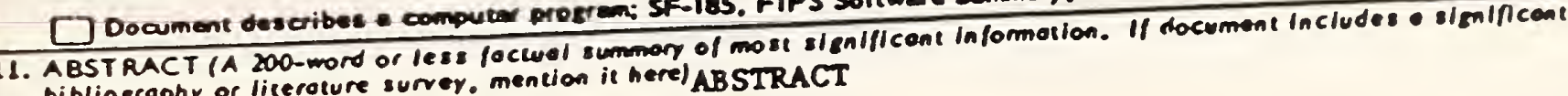
bibliogrophy or liceroture surver. mention it herel ABSTRACT

Thle report sumarises the 1985 activities of the Hetellurgy Division of the National Bureau of Standards. The resears, and on the wethods of their wesurenent. properties relations of eetals an alchrotron radiation research for materiel. Task efforts comprise studies of soch ing, wear and mechanlcal propertiea, chenlcal characterization. wetallurglcal proceselog, etals, electrodeposition, and nondestructive metallurgy, corrosion and protection of mes includes three cooperative data progras characterization. The work heteln describs and industy: the American Soclety for HetalNBS Alloy Phase D1agram Progra, the American Iron and Steel Institute-NBS Steel

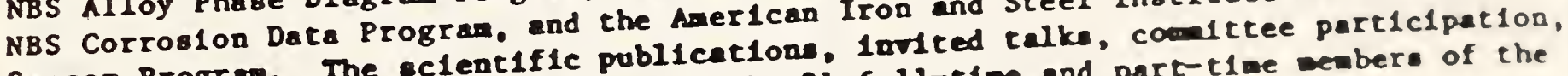
Sensor Program. The sclenteractione of the 91 full-tive and part-tine verber of the

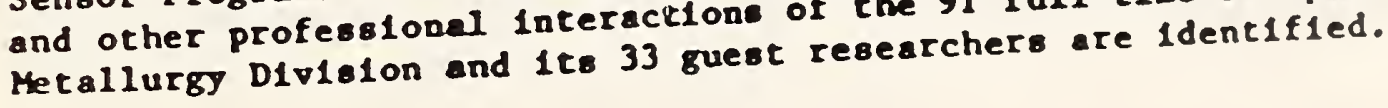
Annual report; industrial interactions: Metallurgy Division; metals: publications: technical activities

13. AVAILABILITH

[X] Unlimited

$\square$ For Olliciel Discribution. Do Nor Relenen w NTIS

[] Order From Superintendent of Documente. U.S. Governmeme Prining Oflice. Weahingion. O.C.

[x] Order From Natlonal Technical Information Serulce (NTIS). Soringlleld. VA 22161

14. NO. OF

PRINTEOPACES

116

1s. Pice

$\$ 16.95$ 

